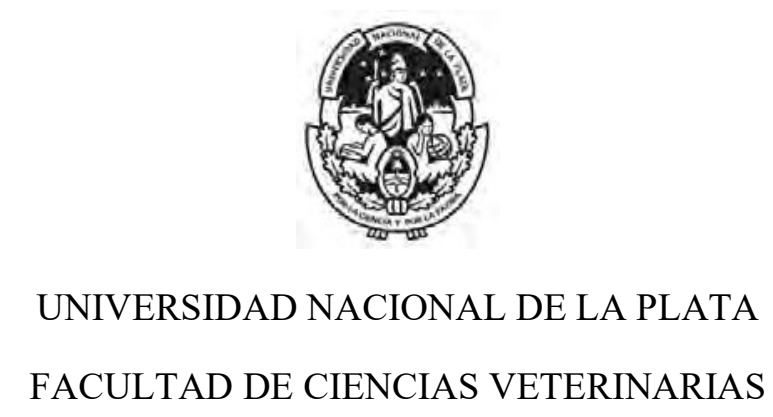

Trabajo de Tesis realizado como requisito para optar al título de Doctora en Ciencias Veterinarias

\title{
Sarcomas óseos en perros: estudio de variables histológicas e inmunohistoquímicas
}

Autora Méd. Vet. Andrea Viviana Pachamé

\section{Directora}

Dra. M.V. Adriana Raquel Massone

\section{Codirector}

Dr. M.V. Eduardo Juan Gimeno

Lugar de trabajo

Cátedra de Patología General. Facultad de Ciencias Veterinarias, Universidad Nacional de La Plata

\section{Miembros del jurado}

Dra. M.V. Mónica E. Diessler

Dra. M.V. Elvira M. Falzoni

Dr. M. Pedro H. González 
Dedicado a mi amor y gran compañero Alfredo

\author{
a mis amados viejos, Susana y Ruben \\ a mis hermanos Adriana y Gabriel \\ a mis sobrinos Morena y Tobías
}

a la memoria de.... mis queridos abuelos incluidos los que me regaló la vida

...a Alicia

...a mi tío Hugo

...a mi querida amiga Eugení

... y en especial a Roni y a Julián

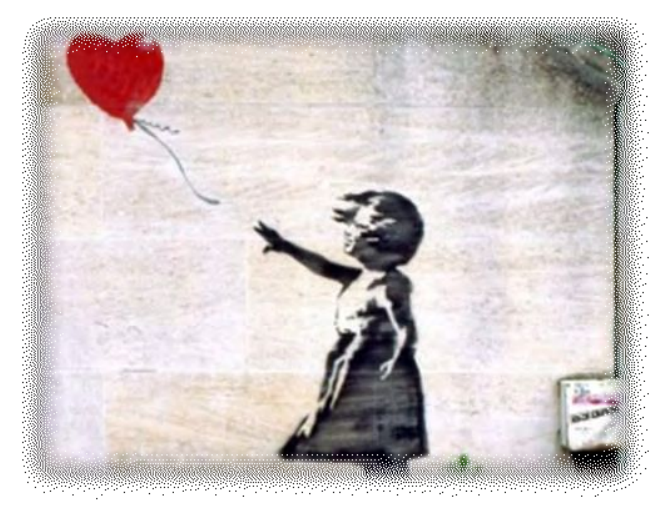


Quiero agradecer todos los momentos vividos a lo largo de este trabajo de tesis, algunos de alegría, entusiasmo, satisfacción y otros de decepción, enojo y tristeza. Momentos que han afianzado mi desarrollo como profesional y como persona. Además, quiero agradecer a cada una de las personas que de alguna manera contribuyeron a que este trabajo fuera posible:

A Alfredo Folino, mi amor, le agradezco el apoyo y el acompañamiento durante esta etapa, sin ello no hubiera sido posible. Por confiar en mí y aguantar mis locuras y, por sobre todas las cosas, por amarme...

A mamá y a papá por confiar en mí e impulsarme desde el primer momento. Por su amor inmenso, su sacrificio y su apoyo que me permitieron la culminación de mi carrera profesional. Por ser mis viejos, los adoro...

A mis hermanos por confiar en mí y por ser dos personas maravillosas que amo profundamente.

A Morena y a Tobías por llenarme el corazón con su alegría y con su amor. Por hacerme descubrir un sentimiento difícil de expresar con palabras, los amo...

A mis perras, Juana y Cata y a mi gata, Misha que, sin darse cuenta, me llenan de amor la vida. Nunca se enterarán, pero es muy importante que estén aquí...

A la Dra. Natalia Castelletti por su incondicional predisposición y compromiso, por compartir conmigo su sabiduría y su amistad. Por abrirme las puertas del Laboratorio Anatomopatológico, Sanatorio Dr. Julio Méndez y por los momentos compartidos junto a la histotecnóloga Gabriela González, que me brindó su ayuda y conocimiento.

Al Dr. Fabián Nishida (Faby) le agradezco enormemente su generosidad, sus inteligentes y atinadas intervenciones, su grandeza y humildad. Por brindarme su cálido afecto y su "buena onda". Por estar siempre presente en esos momentos tan críticos. 
Al Dr. Claudio Barbeito le agradezco infinitamente su buena predisposición para ayudar y enseñar, su generosidad, su empatía. Por brindarme su apoyo, su conocimiento y estar en los momentos más críticos.

Al Dr. Enrique Portiansky le agradezco enormemente su ayuda, sus consejos, su buena predisposición y por siempre tenderme una mano. "Gracias Enri"

A mis directores, Dra. Adriana Massone y Dr. Eduardo Gimeno, les agradezco la aceptación y la confianza sin lo cual hubiese sido imposible realizar este trabajo. Por su ayuda y la libertad con la que me permitieron desarrollar esta tesis.

Al Méd. Vet. Néstor Recchiuti por su profesionalismo, por su grandeza, por su humildad y su generosidad. Por compartir conmigo su sabiduría y su amistad.

A la Dra. Patricia Fernández agradecerle el acompañamiento y la dedicación. Especialmente por brindarme su amistad que valoro profundamente.

Al Dr. Hugo Ortega, le agradezco profundamente su generosidad. Por abrirme las puertas del Instituto de Ciencias Veterinarias del Litoral (ICiVet-Litoral UNL/CONICET) que me permitió la realización de gran parte de este trabajo de tesis.

A la Dra. Valentina Matiller por su apoyo desinteresado desde el primer día que ingresé al ICiVet. Por brindarme el conocimiento, la experiencia y la dedicación necesaria para mi desarrollo. Por su confianza, sus consejos y su amistad.

Al Dr. Julio Idiart por sus consejos, sus aportes y por su generosidad.

A la Licenciada Guadalupe Guidi por su valiosa e importante intervención, por su paciencia, su dedicación, por su contención y calidez. ¡Gracias Guada!

A Soledad Gomar por su afecto, su empuje y apoyo. Por ser una persona muy importante en mi vida.

A la Dra. Viviana De Palma y a los Méd. Vet Juan Osacar y Méd. Vet Sebastián Iveli les agradezco su generosa participación desde el Hospital Escuela de la Facultad de Ciencias Veterinarias de la UNLP. 
Al Méd. Vet. Marcos Beltran y a la Méd. Vet. María Verónica Prío por su aporte desde el Servicio de Radiología del Hospital Escuela de la Facultad de Ciencias Veterinarias de la UNLP.

Al hermoso y gran equipo de docentes y no docentes de la Cátedra de Patología General que me ha acompañado en todo este tiempo y que, de alguna u otra manera colaboraron para que la finalización de este trabajo fuera posible: las/los Méd. Vet. Carolina Wright, Jésica Grandinetti, Juan Falcón, Jésica Granero Agüero, Victoria Torres, Fabiana Paulovich, Lorena Migliorisi, Betiana Álvarez, Silvana Scenna, Agustina Camiña, Andrea Santelices, Patricia Fernández, Enrique Portiansky, Claudio Barbeito y Eduardo Gimeno. A la Licenciada Guadalupe Guidi y a Héctor Enrique y a los que formaron parte de este grupo alguna vez, Pedro Zeinsteger, Pablo Saturno, Marisa López, Fabián Nishida y Susana Sisti.

A mis compañeros y amigos de la Cátedra de Histología y Embriología. En especial a la Dra. Mónica Diessler, Dra. Fiorella Alvarado Pinedo, Dra. Laura Andrini, Dra. Carolina Zanuzzi y Méd. Vet. Rocío Hernández les agradezco su generosa predisposición y compañerismo.

A la Méd. Vet Natalia Caggiano y al Méd Vet. Gonzalo Madariaga les agradezco su ayuda y su buena predisposición.

A la Méd. Vet. Romina Pretti por su apoyo incondicional y por su amistad que valoro profundamente.

A los histotecnólogos Guadalupe Guidi, Lorena Díaz, Carolina Aralda y Rubén Mario, les agradezco por su ayuda en el procesamiento de las muestras de tejidos. A Oscar Cáceres le agradezco su valiosa ayuda en la búsqueda del material.

....y a todas aquellas personas que contribuyeron a que esto se haga posible ...mi gratitud sincera a todos ustedes. 


\section{TRABAJOS PUBLICADOS CON ASPECTOS PARCIALES DEL TRABAJO DE TESIS (publicados o en prensa)}

\section{TRABAJOS PUBLICADOS EN REVISTAS CIENTIFICAS}

1) Pachamé A.V., Beltrán M.J., Recchiuti N.E., Portiansky E.L., Massone A.R., Gimeno EJ. 2017. Lesions of hypertrophic osteopathy in the forelimbs of a dog associated with pulmonary metastasis from a periosteal osteosarcoma. Brazilian Journal of Veterinary Pathology. 10: 61-64. DOI: 10.24070/bjvp.1983-0246.v10i2p61-64

\section{RESUMENES PUBLICADOS EN REVISTAS CIENTIFICAS}

1) Pachamé, A.V., 2014. Sarcomas óseos en caninos: relación de variables histológicas e inmunohistoquímicas con el pronóstico. Analecta Veterinaria 34(1-2): 73 .

2) Pachamé A.V., Gimeno E.J., Massone A.R. 2015. Sarcomas Óseos en Caninos: Estudio Retrospectivo 2003-2013. Revista Ciencias Morfológicas. 17 (2):46.

3) Pachamé A.V., Castelletti N.G., Nishida F., Portiansky E.L., Gimeno E.J., Massone A.R. 2019. Aplicación de un sistema estandarizado de gradación tumoral a sarcomas óseos caninos. Revista de Medicina Veterinaria. (Buenos Aires). 100(2):70. 


\section{RESUMENES PUBLICADOS EN ACTAS DE CONGRESOS}

4) Pachamé A.V., Gimeno E.J., Madariaga G., Recchiuti N.E., Massone A.R. 2012. Osteosarcoma perióstico en el esqueleto apendicular en un canino. VIII Reunión Argentina de Patología Veterinaria y 6to.Seminario de la Fundación "Charles Louis Davis" en Argentina, Facultad de Ciencias Agropecuarias, Universidad Católica de Córdoba, Córdoba, Argentina. 2224 de mayo de 2012.

5) Pachamé A.V., Madariaga G.J., Caggiano N.C., Massone A.R., Gimeno E.J. 2014. Neoplasias mesenquimáticas malignas de piel y subcutis en caninos: reagrupamiento en función del diagnóstico histopatológico y del comportamiento biológico. IX Reunión Argentina de Patología Veterinaria y 8vo. Seminario de la Fundación "Charles Louis Davis" en Argentina. Facultad de Ciencias Veterinarias. Universidad Nacional del Centro de la Provincia de Buenos Aires. Tandil. Buenos Aires. Argentina. 29-31 de octubre de 2014.

6) Pachamé A.V. 2014. Sarcomas óseos en caninos: relación de variables histológicas e inmunohistoquímicas con el pronóstico. Jornada de Ciencia y Técnica 2014, Facultad de Ciencias Veterinarias, Universidad Nacional de La Plata. Buenos Aires. Argentina. 28 de noviembre de 2014.

7) Pachamé A.V., Gimeno E.J., Massone A.R. 2015. Sarcomas Óseos en Caninos: Estudio Retrospectivo 2003-2013. Libro de resúmenes del XVII Congreso de Ciencias Morfológicas y 14 Jornadas de Educación. Sociedad de Ciencias Morfológicas de La Plata. CONICET - Centro Científico y 
Tecnológico- CCT La Plata. Buenos Aires, Argentina. 10-11 de septiembre de 2015.

8) Pachamé A.V., Beltrán M.J., Recchiuti N.E., Massone A.R., Gimeno E.J. 2016. Osteopatía hipertrófica pulmonar asociada a un osteosarcoma perióstico en un canino. X Reunión Argentina de Patología Veterinaria y $10^{\circ}$ Seminario de la Fundación "Charles Louis Davis" en Argentina. Facultad de Ciencias Veterinarias, Universidad Nacional de Litoral. Esperanza, Santa Fé, Argentina. 24-26 de agosto de 2016.

9) Pachamé A.V., Castelletti N.G., Nishida F., Portiansky E.L., Gimeno E.J., Massone A.R. 2018. Aplicación de un sistema estandarizado de gradación tumoral a sarcomas óseos caninos. XI Reunión Argentina de Patología Veterinaria 2018 y $12^{\circ}$ Seminario de la Fundación "Charles Louis Davis" en Argentina. Facultad de Ciencias Veterinarias, Universidad Nacional de La Plata. Buenos Aires. Argentina. 8-10 de agosto de 2018. 
Dejamos de temer a lo que se ha aprendido a entender MARIE CURIE 


\section{Índice}

\section{Resumen}

Abstract

XVI

I. Introducción

I.1. El cáncer, sarcomas óseos en animales

I.2. Consideraciones generales acerca de los sarcomas óseos en perros: aspectos epidemiológicos, comportamiento biológico, características histológicas, criterios de clasificación

I.3. Inmunohistoquímica aplicada al pronóstico

I.3.1. Proliferación y PCNA

I.3.2. Angiogénesis y cáncer. Rol del factor de crecimiento del endotelio vascular y la proteína morfogénica ósea en los sarcomas óseos

I.3.3. Rol de la ciclooxigenasa 2 en la carcinogénesis y el dolor asociado con los sarcomas óseos

I.4. Hipótesis

I.5. Objetivos

I.5.1. Objetivo general

I.5.2. Objetivos específicos

II. Materiales y Métodos

II.1. Criterios de selección de los casos

II.2. Estudio histológico 
II.3. Estudio de la gradación tumoral 45

II.4. Estudio inmunohistoquímico 46

II.5. Análisis cualitativos y cuantitativos de la inmunomarcación 49

$\begin{array}{lr}\text { II.6. Análisis estadístico } & 50\end{array}$

III. Resultados

III.1. Aspectos de la reseña. Estudio histológico. 51

$\begin{array}{ll}\text { III.2. Estudio de la de gradación tumoral } & 69\end{array}$

III.3. Estudio de la localización anatómica con respecto a los tres grados tumorales

$\begin{array}{ll}\text { III.4. Estudios inmunohistoquímicos cualitativos y cuantitativos } & 77\end{array}$

$\begin{array}{ll}\text { III.4.1. PCNA } & 77\end{array}$

$\begin{array}{ll}\text { III.4.2. VEGF-A } & 79\end{array}$

$\begin{array}{ll}\text { III.4.3. VEGFR-1 } & 81\end{array}$

$\begin{array}{ll}\text { III.4.4. BMP-9 } & 83\end{array}$

$\begin{array}{lr}\text { III.4.5. COX-2 } & 85\end{array}$

III.5. Estudio de la localización anatómica con respecto a la inmunomarcación PCNA, VEGF-A, VEGFR-1, BMP-9 y COX-2 89

III.5.1. Localización anatómica y PCNA $\quad 89$

III.5.2. Localización anatómica y VEGF-A $\quad 89$

III.5.3. Localización anatómica y VEGFR-1 90

III.5.4. Localización anatómica y BMP-9 91 
III.5.5. Localización anatómica y COX-2

III.6. Estudio de la gradación tumoral con respecto a la inmunomarcación PCNA,

VEGF-A, VEGFR-1, BMP-9 y COX-2

III.6.1. Grado tumoral y PCNA

III.6.2. Gradación tumoral y VEGF-A

III.6.3. Gradación tumoral y VEGFR-1

III.6.4. Gradación tumoral y BMP-9

III.6.5. Gradación tumoral y COX-2

IV.1. Pacientes: su selección y seguimiento

IV.2. Constatación de la muerte relacionada con la neoplasia

IV.3. Información obtenida de cada uno de los pacientes (casos)

Bibliografía

Anexos

Anexo I

Anexo II 


\section{Abreviaturas}

Los términos en plural que se consignen mediante abreviaturas y símbolos llevarán una "s" final (en este apartado se definen en singular). Aquellos que corresponden a términos en idiomas distintos del español se consignan en cursiva.

aFGF y bFGF: ( del inglés acidic and basic fibroblastic growth factor) Factor de crecimiento fibroblástico ácido y básico

Ang-1/ Ang -2: (del inglés angiopoietin-1/angiopoietin-2) Angiopoyetina-1 y Angiopoyetina-2

BMP: (del inglés Bone Morphogenetic Protein) Proteína morfogénica ósea

BMPR: (del inglés Bone Morphogenetic Protein receptor) Receptor de la proteína morfogénica ósea

BrdU: bromodeoxiuridina

CAP: College of American Pathologists

COX-2: (del inglés cyclooxygenase-2) Ciclooxigenasa-2

FAS: fosfatasa alcalina sérica

FGF: (del inglés Fibroblast Growth Factor) Factor de crecimiento de fibroblastos GT: gradación tumoral

HGF: (del inglés Hepatocyte Growth Factor) factor de crecimiento de hepatocitos IHQ: inmunohistoquímica

MAPK: (del inglés Mitogen Activated Protein Kinase) Proteína quinasa activada por mitógeno

MDR-1: (del inglés Multi Drug Resistance gene-1) Gen de resistencia a múltiples drogas 
MEC: matriz extracelular

MET: (del inglés Mesenchymal Epithelial Transition factor) Transición epiteliomesenquimática

MMP: metaloproteasa

mTOR: (del inglés mammalian target of rapamycin ) Blanco de rapamicina en mamíferos

OSA: osteosarcoma

PCNA: (del inglés Proliferating Cell Nuclear Antigen) Antígeno nuclear de proliferación celular

PGP: (del inglés P-Glycoprotein) Glicoproteína-P

PI3K: (del inglés Phosphatidylinositol 3-Kinase) Fosfatidilinositol 3-cinasa

RTK: receptor tirosina quinasa

SO: sarcoma óseo

TGF $\boldsymbol{\alpha}$ y TGF $\boldsymbol{\beta}$ : (del inglés Transforming Growth Factor $\alpha y \beta$ ) Factor de crecimiento transformante $\alpha$ y $\beta$

VEGF: (del inglés Vascular Endothelial Growth Factor) Factor de crecimiento del endotelio vascular

VEGFR: (del inglés Vascular Endothelial Growth Factor Receptor) Receptor del factor de crecimiento del endotelio vascular 


\section{Sarcomas óseos en perros: estudio de variables histológicas e inmunohistoquímicas}

Palabras claves: gradación tumoral; estudio inmunohistoquímico; estadificación; blancos moleculares; sarcomas óseos en perros; osteosarcoma en perros.

\section{Resumen}

Los sarcomas óseos son neoplasias frecuentes en los perros y los gatos. El osteosarcoma y el condrosarcoma son los subtipos de mayor incidencia en los perros y los humanos. El diagnóstico definitivo se fundamenta en la evaluación clínica, el diagnóstico radiológico e histológico. El estudio de diferentes aspectos inherentes al hospedador, así como también, de las moléculas implicadas en la patogenia de los sarcomas óseos contribuye a la compresión del comportamiento biológico, y a la elaboración de protocolos y estrategias terapéuticas adecuadas. En el presente trabajo de tesis se propuso identificar los subtipos de sarcomas óseos encontrados en perros, evaluar aspectos de la reseña y el sitio anatómico, aplicar un sistema de gradación tumoral y establecer una relación con los estudios inmunohistoquímicos. Para ello se trabajó con muestras que se correspondían con sarcomas óseos en perros. El osteosarcoma fue el subtipo más frecuente. La localización apendicular fue la más habitual y los machos de razas grandes y gigantes fueron los más afectados. La edad promedio fue de 8 años y hubo una fuerte asociación entre el subtipo histológico y la edad. Los sarcomas óseos, 
particularmente el osteosarcoma, presentaron la mayor gradación tumoral con una fuerte asociación entre el subtipo histológico y la gradación. Asimismo, los sarcomas óseos apendiculares y de gradación III evidenciaron mayor expresión del antígeno nuclear de proliferación celular, el receptor 1 del factor de crecimiento del endotelio vascular y la ciclooxigenasa-2. La expresión del factor de crecimiento del endotelio vascular respecto de los subtipos de sarcomas óseos tuvo significación estadística, además, la proteína morfogénica ósea se expresó principalmente en osteosarcomas y condrosarcomas. Estos hallazgos demuestran que la gradación tumoral y la expresión de moléculas de señalización podrían asociarse a un comportamiento muy agresivo y un peor pronóstico en los sarcomas óseos en perros. Esta información proporciona un marco de interés para la construcción futura de perfiles tumorales que podrían predecir el comportamiento tumoral particular para cada paciente afectado y en el desarrollo de novedosos enfoques terapéuticos. 


\title{
Bone sarcomas in dogs: study of histological and immunohistochemical variables
}

Keywords: tumor grading; immunohistochemical study; staging; molecular targets; bone sarcomas in dogs; osteosarcoma in dogs.

\begin{abstract}
Bone sarcomas are common malignancies in dogs and cats. Osteosarcoma and chondrosarcoma are the subtypes with the highest incidence in dogs and humans. The definitive diagnosis is based on clinical evaluation, radiological and histological diagnosis. The study of different aspects inherent to the host, as well as, the molecules involved in the pathogenesis of bone sarcomas contributes to a better the understanding of biological behaviour and to the development of appropriate protocols and therapeutic strategies. The present thesis work aimed to identify the subtypes of bone sarcomas found in dogs, to evaluate aspects of the clinical review and the anatomical site, to apply a grading system and to establish a relationship through immunohistochemical studies. For this purpose, samples that corresponded to bone sarcomas in dogs were used. Osteosarcoma that of the most common subtype appearance. The appendicular location was the most frequent and males of large and giant breeds were most affected. The average age of presence of this tumor was 8 years and there was a strong association between histological subtype and age. Bone sarcomas, particularly osteosarcoma, had the largest tumor
\end{abstract}


gradation with a solid association between histologic subtype and gradation. In addition, appendicular and grade III bone sarcomas showed increased expression of proliferating cell nuclear antigen, vascular endothelial growth factor receptor 1 and cyclooxygenase 2 . Besides, the expression of vascular endothelial growth factor respect to bone sarcoma subtypes was statistically significant, and bone morphogenetic protein 9 was expressed mainly in osteosarcoma and chondrosarcoma. These findings demonstrate that tumor grading and expression of signaling molecules may be closely associated with a very aggressive behaviour and poor prognosis in bone sarcomas in dogs. This information provides a background for the building of tumor profiles that could be able to predict tumor behaviours for individual patients and allow the development of innovative therapeutic approaches in the future. 


\section{Introducción}

\section{I.1. El cáncer, sarcomas óseos en animales}

Se utiliza el término cáncer para referirse a un conjunto de enfermedades íntimamente relacionadas que comparten mecanismos celulares y moleculares similares, entre los que se incluyen autosuficiencia con respecto a las señales de crecimiento, insensibilidad a las señales inhibidoras del crecimiento, capacidad antiapoptótica, potencial proliferativo ilimitado, angiogénesis sostenida, capacidad infiltrativa y diseminación metastásica. Es una de las principales causas de muerte en los animales de compañía y su prevalencia* continúa en aumento (Brønden y col., 2007; Butler y col., 2013). Diferentes estudios demuestran que la mortalidad por cáncer varía entre el 15 a $30 \%$ en perros y, en gatos es del $26 \%$ (Brønden y col., 2007; Butler y col., 2013). La frecuencia y naturaleza de las neoplasias varía entre las distintas especies animales, razas y ubicación geográfica y, además, difieren mucho de acuerdo con el órgano o el tejido donde se originan (Ildefonso Cruz, 1997; Alonso, 2006; Butler y col., 2013; Maniscalco, 2015). En este sentido, el estudio de las diferencias entre las razas de perros es de utilidad para investigar los factores hereditarios en el desarrollo de las neoplasias (Craig, 2001). Dentro de

* Prevalencia: número total de enfermos sobre el número total de la población en riesgo en un momento dado 
las razas de perros, el golden retriever y el bóxer presentan mayor mortalidad por cáncer, seguidas por el pastor alemán y el rottweiler (Craig, 2001). Asimismo, diversos factores predisponentes, así como mutaciones genéticas o cambios epigenéticos que modifican ciertos factores de crecimiento y sus receptores, orquestan la carcinogénesis y la supervivencia del tumor, a menudo haciendo que un único enfoque terapéutico sea insuficiente para un tratamiento eficaz (Maniscalco, 2015). En este sentido, gracias a muchos años de investigación se han logrado importantes avances en oncología veterinaria que han permitido progresar en el diagnóstico, pronóstico y tratamiento de las diferentes neoplasias (Withrow y col., 2013).

Los estudios epidemiológicos en perros y gatos están restringidos debido a una serie de factores; la limitación de censar a los animales de compañía impide la medición directa de los porcentajes de morbilidad y mortalidad, sumado a que normalmente se desconoce la población de origen de los casos y a que muchos propietarios optan por la eutanasia de sus mascotas, debido al costo elevado de los tratamientos o por tratarse de animales gerontes (Butler y col., 2013). En diferentes países del mundo se han publicado numerosas encuestas realizadas a los propietarios de animales de compañía, las cuales han proporcionado una estimación aproximada de la prevalencia de las diferentes enfermedades y las causas (Butler y col., 2013). En el estudio de Bronson (1982) se realizó la necropsia de 2002 perros y el cáncer representó el $20 \%$ de las muertes, con una edad estimada de 5 años, sin embargo, superó el $40 \%$ en perros a partir de los 10 años de edad, lo que confirma que el cáncer es la principal causa de muerte entre los perros gerontes. Uno de los primeros registros de cáncer para animales de compañía fue el Registro de Neoplasias de 
Animales de California vigente en la actualidad (Dorn y col., 1968). En este estudio, fue realizado un registro de la tasa de incidencia de cáncer en el condado de Alameda, entre 1960 y 1966 donde se describe cada 1000 animales la siguiente distribución en perros y gatos respectivamente: aparición de cáncer en todos los sitios 381,2 y 115,8 ; glándula mamaria 198,8 y 25,4 ; piel, 90,4 y 34,7 ; tejido conectivo 35,8 y 17; sistema digestivo 25,2 y 11,2; sistema respiratorio 8,5 y 5 y tejido óseo 7,9 y 4,9 (Dorn y col., 1968). Específicamente en relación con las neoplasias óseas, en una encuesta más reciente realizada en Suecia se analizaron 400000 perros, en ella la tasa de incidencia de tumores óseos fue de 5,5 casos por cada 10000 perros en riesgo (Egenvall y col., 2007). De acuerdo con los registros que se llevaron a cabo en Lima, Perú, publicados por Aco Alburqueque (2016), la frecuencia de distribución de las neoplasias óseas fue de 1,57\% sobre un total de 1214 perros analizados. Los tumores óseos primarios son observados con frecuencia en perros y gatos siendo de rara presentación en otros animales domésticos (Slayter y col., 1994). Baba y Câtoi (2007) indicaron que el osteosarcoma (OSA) representó entre el 5 y $6 \%$ del total de las neoplasias que afectaron a los perros. No obstante, existen avances en el estudio de la biología molecular que han contribuido a una mejor comprensión de la patogénesis del osteosarcoma tanto canino como humano que, además han conducido a la identificación de moléculas (Selvarajah y Kirpensteijn, 2010). 


\section{I.2. Consideraciones generales acerca de los sarcomas óseos en perros: aspectos epidemiológicos, comportamiento biológico, características histológicas, criterios de clasificación}

Los sarcomas óseos (SO) primarios en los perros, en particular el OSA, son de presentación más frecuente respecto de las neoplasias óseas benignas (Thompson y Dittmer, 2017). El desarrollo de tumores secundarios en los huesos, especialmente las metástasis óseas derivadas de carcinomas son muy comunes en pacientes humanos, pero infrecuentes en animales (Thompson y Dittmer, 2017). Dentro de los principales SOs en animales, el OSA es el subtipo de presentación más común en perros y gatos, con una incidencia del $85 \%$ y $70 \%$ respectivamente (Brodey y Riser, 1969; Ehrhart y col., 2013; Craig y col., 2016). En los perros, del mismo modo que en los humanos, el OSA y el condrosarcoma son los subtipos histológicos más comunes y representan el $80 \%$ y el $10 \%$ respectivamente; el fibrosarcoma, el hemangiosarcoma y el tumor de células gigantes, representan el $7 \%$ de los SOs. Los tumores linfoides, mieloides y el liposarcoma de la médula ósea son tumores de presentación infrecuente ( $3 \%$ ) en el esqueleto de perros y gatos (Craig y col., 2016; Czerniak y Dorfman, 2016).

La clasificación de los tumores óseos en animales domésticos es similar a la utilizada para humanos, sin embargo, existen ciertas diferencias que impide la extrapolación directa (Craig y col., 2016). El sistema de clasificación que se muestra en la figura 1 se trata de una modificación del fascículo "Clasificación histológica de los tumores óseos y tumores articulares de los animales domésticos" de la última nómina propuesta por la Organización Mundial de la Salud (OMS) (Slayter y col., 1994). 
Los huesos son órganos compuestos por diferentes tipos de tejidos de origen mesenquimático, como: tejido óseo, tejido adiposo, tejido cartilaginoso y tejido conectivo ordinario, además de vasos sanguíneos y nervios. De este modo, los SOs pueden provenir de los precursores mesenquimáticos de cualquiera de los tejidos mencionados. Estas neoplasias pueden variar desde sarcomas mesenquimáticos indiferenciados a sarcomas que imitan uno de los tipos bien diferenciados de tejido conectivo especializado, el tejido óseo o el tejido cartilaginoso (Thompson y Dittmer, 2017).

De acuerdo con el comportamiento biológico y características celulares, los tumores óseos se agrupan en benignos y malignos (Slayter y col., 1994) (Fig. 1). Asimismo, son clasificados respecto de: 1) el tipo de matriz extracelular (MEC) producida por las células neoplásicas y, para el caso de los SOs, 2) la localización del tumor en el hueso, en: a) periférico, si se origina en el periostio; o b) central, si surge a partir de la metáfisis o cavidad medular.

Los patrones histológicos de los SOs son variables y, en aquellos que presentan características celulares mixtas se considera el potencial maligno del tipo celular predominante para nombrarlos (Slayter y col., 1994, Ehrhart y col., 2013; Craig y col., 2016). 


\section{Clasificación histológica de los tumores óseos}

\begin{tabular}{|l|}
\hline Tumores benignos \\
\hline Osteoma \\
\hline Fibroma osificante \\
Mixoma de la mandibula \\
Osteocondroma \\
Osteocondromatosis felina \\
Condroma \\
Hemangioma
\end{tabular}

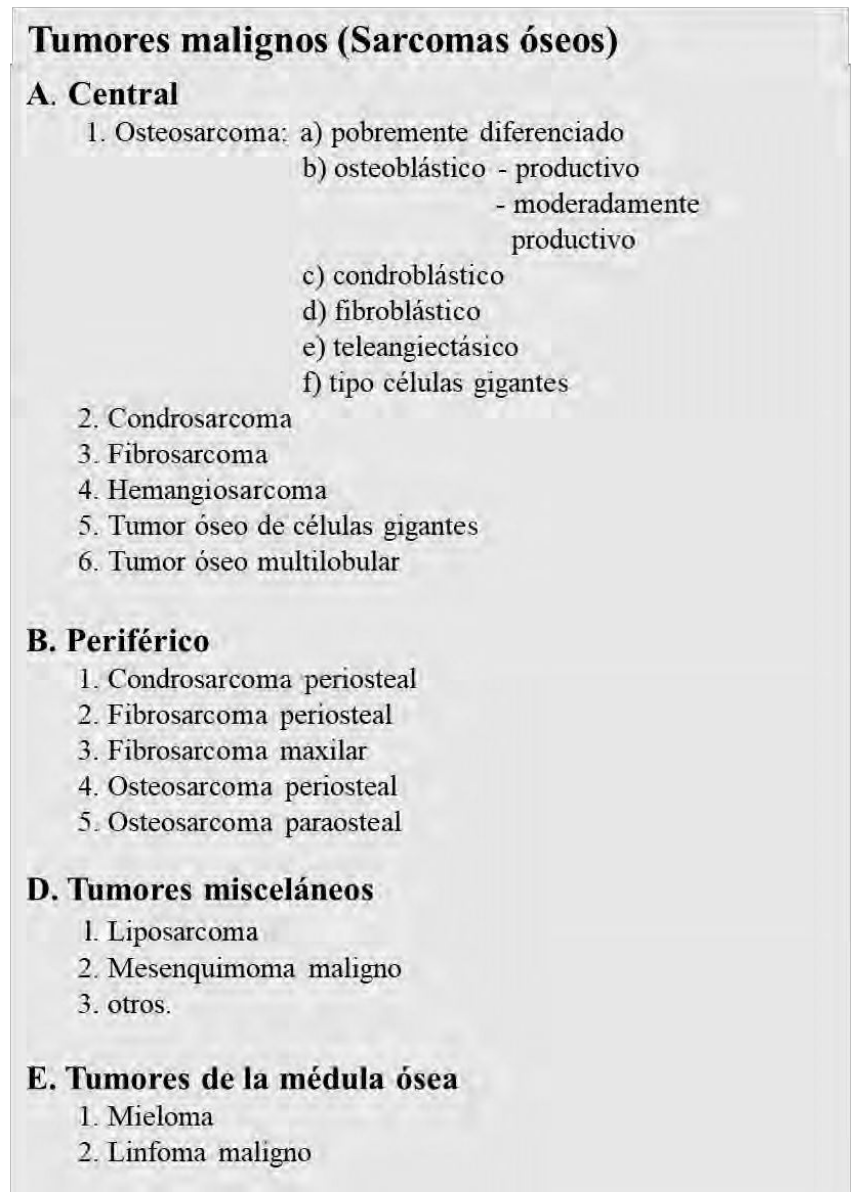

Figura 1. Clasificación histológica de los tumores óseos. Basada en la clasificación histológica de los tumores óseos y articulares de los animales domésticos de la Organización Mundial de la Salud, Slayter (1994). Figura modificada de Craig y col., (2016)

Dentro del grupo de SOs de origen central se encuentra el OSA, una neoplasia mesenquimática primaria que se origina a partir de las células óseas primitivas; estas células producen una cantidad variable de MEC denominada osteoide. El OSA es un tumor que se presenta, con frecuencia, en perros de razas grandes y gigantes y la edad promedio de aparición es de 7 años. Las razas de mayor riesgo son: San 
Bernardo, gran danés, setter irlandés, dóberman, rottweiler, pastor alemán y golden retriever. Asimismo, los factores predisponentes más importantes son el peso y el tamaño del animal (Ehrhart y col., 2013; Craig y col., 2016). No obstante, en muchos países del mundo, incluyendo Argentina, se está incrementando la tenencia de perros de razas pequeñas respecto de las razas grandes y gigantes lo cual implica una menor presentación de SOs, especialmente de OSA. La presentación en los machos suele ser ligeramente más frecuente que en las hembras con una relación de 1,1 a 1,5:1, con algunas excepciones. Los machos y las hembras enteras parecen tener un mayor riesgo, con excepción del rottweiler (Ehrhart y col., 2013). El OSA central se origina en la región metafisaria de los huesos con un comportamiento fuertemente maligno (Slayter y col., 1994; Thompson y Dittmer, 2017). En este sentido, presenta un efecto localmente agresivo que puede inducir osteólisis o estimular la producción de tejido óseo, o bien, ambos procesos de manera simultánea. Sin embargo, en raras ocasiones afecta las articulaciones. Es un tumor que aparece más frecuentemente en el esqueleto apendicular con respecto al esqueleto axial*, con una proporción de 4:1 (Heyman y col., 1992; Baba y Câtoi, 2007; McNeill y col., 2007; Ehrhart y col., 2013; Craig y col., 2016). El OSA es frecuente en el miembro torácico, especialmente, en la zona distal del radio y proximal del húmero. Sin embargo, la presentación en el miembro pelviano se ha asociado con un pronóstico pobre (Misdorp y Hart, 1979; Heyman y col., 1992; Ehrhart y col., 2013). En este sitio, ocurre usualmente en el extremo distal del fémur y el extremo proximal y distal de la tibia, el extremo proximal del fémur es el sitio

\footnotetext{
* Esqueleto axial: esqueleto que comprende la columna vertebral, las costillas, el esternón y el cráneo. Esqueleto apendicular: esqueleto que incluye a los miembros torácicos, pelvianos, la cintura pectoral y la pélvica.
} 
menos común (Ehrhart y col., 2013; Craig y col., 2016). Por otra parte, Heyman y col., (1992) realizaron un estudio en 116 perros con OSA de localización axial y hallaron la siguiente distribución: $27 \%$ en la mandíbula, $22 \%$ en el maxilar superior, $15 \%$ en la columna, $12 \%$ en el cráneo, $10 \%$ en las costillas, $9 \%$ en la cavidad nasal o senos paranasales y $5 \%$ en la pelvis. Asimismo, el OSA presenta un origen periférico y se describen dos tipos, el OSA periosteal con un comportamiento biológico similar al OSA central y el OSA parosteal o yuxtacortical, con un crecimiento más lento, mayor diferenciación celular y un pronóstico más favorable con respecto al OSA central (Slayter y col.,1994; Craig y col., 2016). No obstante, el origen periférico es menos frecuente (Slayter y col.,1994; Ehrhart y col., 2013; Craig y col., 2016; Thompson y Dittmer, 2017).

Por otra parte, las metástasis generalmente aparecen en el curso temprano de la enfermedad; la vía hematógena es la más frecuente y el pulmón es el sitio de preferencia (Czerniak y Dorfman, 2016; Thompson y Dittmer, 2017 ). Otros sitios donde ocurren metástasis son los linfonodos regionales, otros huesos y zonas de tejido blando (Hillers y col., 2005, Ehrhart y col., 2013; Craig y col., 2016; Thompson y Dittmer, 2017). Si bien menos del $15 \%$ de los perros presenta metástasis pulmonar en los estudios radiológicos al momento de presentarse a la consulta, el $90 \%$ de los casos mueren en menos de un año debido a la diseminación metastásica, si el único tratamiento fue la amputación (Brodey y col., 1969; Spodnick y col., 1992; Ehrhart y col., 2013). En este sentido, de acuerdo con lo expresado por $\mathrm{Xu}$ y col., (2013), la angiogénesis es un factor importante para el desarrollo y la progresión tumoral. Las metaloproteasas de matriz (MMP), enzimas encargadas de degradar la MEC, son en parte, las responsables de la diseminación 
local del tumor propiciando la metástasis (Loukopoulos y col., 2003a). Loukopoulos y col., (2003a) hallaron altas concentraciones de MMP-2 y MMP-9 en líneas celulares de OSA central. Además, el OSA, aunque presenta una alta variabilidad de patrones, casi siempre produce matriz osteoide. Esta característica es considerada clave para el diagnóstico histológico y permite diferenciarlo de otros SOs (Slayter y col., 1994; Ehrhart y col., 2013; Craig y col., 2016; Thompson y Dittmer, 2017). Los osteoblastos neoplásicos sintetizan matriz osteoide que se dispone de manera irregular y en la que quedan atrapadas un número variable de células neoplásicas (Thompson y Dittmer, 2017). No obstante, Grundmann y col., (1995) consideraron que la presencia de matriz osteoide presentó una importancia limitada para el diagnóstico ya que, la estructura proteica del osteoide tumoral mostró características similares a la que constituye el osteoide reactivo. Asimismo, Slayter y col., (1994) indicaron que el microambiente del OSA podría actuar como un posible inductor de la diferenciación mesenquimática. El OSA se clasifica en diferentes subtipos histológicos de acuerdo con el origen, las características celulares y la variación y el predominio de MEC de la siguiente manera: pobremente diferenciado, osteoblástico, condroblástico, fibroblástico, teleangiectásico, tipo células gigantes, periosteal y paraosteal (Slayter y col., 1994).

El condrosarcoma es un tumor óseo primario maligno de presentación menos frecuente con respecto al OSA. Su origen es variable, central o periférico, el primero es el más común. Dentro de los animales domésticos afecta principalmente a las ovejas, aunque también se presenta en los perros (Slayter y col., 1994). Este tumor es más frecuente en perros de razas medianas y grandes tales como bóxer, pastor alemán, golden retriever y en mestizos, con un peso corporal entre 20 y $40 \mathrm{~kg}$ (Craig 
y col., 2016; Thompson y Dittmer, 2017). Es habitual en perros de mediana edad y gerontes, con una edad media de presentación que varía entre 5,9 a 8,7 años. Las hembras presentan mayor incidencia que los machos (Craig y col., 2016; Thompson y Dittmer, 2017). En los perros, como en los humanos, aparece con mayor frecuencia en el esqueleto axial, principalmente en costillas y huesos de la cavidad nasal. No obstante, también aparece en el esqueleto apendicular, aunque con menor frecuencia (Craig y col., 2016; Thompson y Dittmer, 2017). Comparado con el OSA, es un tumor de crecimiento lento, de curso clínico más prolongado, sin embargo, la frecuencia de metástasis por vía hematógena es mayor (Craig y col., 2016). El pulmón es el sitio más habitual de metástasis, si bien éstas también pueden presentarse en los riñones, el hígado, el corazón y el esqueleto (Craig y col., 2016; Thompson y Dittmer, 2017). El condrosarcoma presenta aspectos variados en las imágenes radiológicas, sin embargo, la apariencia conocida como en copos de nieve o palomitas de maíz es una característica radiológica distintiva (Slayter y col., 1994). No obstante, deben considerarse conjuntamente los hallazgos clínicos, radiológicos e histológicos para el diagnóstico diferencial con el OSA (Thompson y Dittmer, 2017). En la imagen histológica el condrosarcoma central presenta múltiples lóbulos de células neoplásicas que producen cantidades variables de matriz condroide o matriz fibrilar, pero nunca osteoide (Slayter y col., 1994; Thompson y Dittmer, 2017).

Por otra parte, el fibrosarcoma, el hemangiosarcoma, el tumor de células gigantes y el tumor multilobular son SOs primarios pocos frecuentes, con características particulares que se describen a continuación. 
El fibrosarcoma óseo central es una neoplasia originado en los elementos del estroma localizados dentro de la cavidad medular y produce un patrón de células fusiforme típico del fibrosarcoma de tejido blando con una variada cantidad de colágeno. Sin embargo, las células neoplásicas nunca producen matriz condroide u osteoide. Este tumor induce una osteólisis lenta y es de presentación poco frecuente. No obstante, se presenta con más frecuencia en perros machos maduros de razas grandes y medianas (Slayter y col., 1994; Craig y col., 2016; Thompson y Dittmer, 2017).

El hemangiosarcoma óseo central es una neoplasia que se origina a partir del endotelio vascular en el interior del tejido óseo, de manera similar a la que surge de tejidos blandos. La incidencia varía entre 2 y $3 \%$, dentro de los tumores óseos primarios. En este sentido, es un tumor poco frecuente en animales domésticos. Los perros de razas medianas y grandes son los más afectados y la edad media de aparición es de 6 años. El hemangiosarcoma óseo aparece, con más frecuencia, en el esqueleto apendicular que en el axial; es un tumor agresivo que causa lisis ósea y, a menudo, predispone a fracturas patológicas. El diagnóstico diferencial primario es con el OSA teleangiectásico (Slayter y col., 1994; Craig y col., 2016; Thompson y Dittmer, 2017).

El tumor de células gigantes óseo central tiene su origen a partir de las células del estroma de la médula ósea primitiva y sus células comparten muchas propiedades con los osteoclastos. Existe poca información acerca del comportamiento biológico de este tumor debido a la escasa casuística en animales. Se presenta en los seres humanos y en los animales y exhibe, con frecuencia, un comportamiento benigno. Los animales domésticos principalmente afectados son el perro, el caballo y el gato 
(Craig y col., 2016; Thompson y Dittmer, 2017). Es un tumor vascularizado, con una población abundante de células neoplásicas mononucleares y multinucleadas, con núcleos muy similares entre sí. Dichas células no sintetizan matriz osteoide. El diagnóstico diferencial primario es con el OSA de células gigantes.

El tumor óseo multilobular central es un tumor con un comportamiento potencialmente maligno, de crecimiento lento, pero localmente infiltrativo. Se desarrolla con frecuencia en los huesos del cráneo y con menor frecuencia en las costillas. Se presenta principalmente en el perro, aunque también se ha encontrado en el gato y el caballo. Es un tumor característico en las razas de perros medianas y grandes y la edad promedio de aparición es de 8 años con un rango entre 4 a 17 años (Craig y col., 2016; Thompson y Dittmer, 2017). El aspecto macroscópico multilobulado es una característica distintiva. En el examen microscópico se hallan islotes de tejido cartilaginoso y tejido óseo con una variada diferenciación celular, separados por septos de células ahusadas.

Dentro del grupo de origen periférico, se incluyen aquellos SOs que pueden originarse a partir del periostio, tales como: osteosarcoma periosteal y paraosteal, condrosarcoma periosteal, fibrosarcoma periosteal y fibrosarcoma maxilar. Se consideran un grupo separado ya que presentan un crecimiento lento y un comportamiento menos agresivo comparado con los SOs de origen central. El diagnóstico de estos tumores constituye un verdadero desafío y puede ser erróneo si sólo se considera el estudio histopatológico. Por lo tanto, es necesario incluir el estudio radiológico y los datos de la historia clínica para realizar un diagnóstico certero. 
La etiología del cáncer óseo aún es desconocida; sin embargo, se han identificado factores que contribuyen y juegan un rol importante en la patogénesis tanto en los humanos como en los animales (Ehrhart y col., 2013; Czerniak y Dorfman, 2016). Estos factores pueden ser inherentes al hospedador tales como el peso, el tamaño y el sexo u otros que incluyen las radiaciones ionizantes, sustancias químicas, irritación crónica debido a implantes metálicos durante la reparación de una fractura, infartos del tejido óseo y ciertas enfermedades del sistema esquelético (Wolke y Nielsen, 1966; Brodey y Riser, 1969; Ehrhart y col., 2013; Craig y col., 2016). Diferentes autores mencionaron que el origen de estos tumores podría presentar una base hereditaria, debido a la alta prevalencia dentro de las razas grandes y gigantes y por la alta incidencia en algunas familias relacionadas (Brodey y Riser, 1969; Misdorp y Hart, 1979; Ehrhart y col., 2013). Además, se ha vinculado la aparición de OSA con aquellos huesos que reciben una gran sobrecarga de peso al final del cierre metafisario. Por consiguiente, los perros más pesados presentan mayor riesgo a sufrir injurias en la zona epifisaria que podrían ser un estímulo iniciador para el desarrollo del cáncer, a partir de la inducción de señales mitogénicas que predisponen a la aparición de un linaje celular mutante (Ehrhart y col., 2013). Conjuntamente, diferentes alteraciones en las vías de señalización de ciertos factores de crecimiento, citocinas y hormonas han sido relacionadas con la patogenia del OSA (Modiano y col., 2013). Asimismo, este tumor presenta una gran complejidad genética y una gran cantidad de mutaciones con respecto a otros sarcomas, lo que dificulta el estudio del perfil molecular (Gorlick y Khanna, 2010; Xie y col., 2017). Diferentes autores demostraron que los perros con OSA presentaron una sobreexpresión del gen p53 mutado, que indicaría una relación 
causal potencial (Loukopoulos y col., 2003b; Cullen y Breen, 2017). Entre los signos y hallazgos clínicos asociados con la progresión de los SOs se mencionaron: dolor, hipercalcemia, anemia, mayor susceptibilidad a infecciones, fracturas espontáneas y disminución de la movilidad, entre otros. En consecuencia, este cuadro compromete el estado funcional, la calidad de vida y la supervivencia de los pacientes (Jimenez Andrade y col., 2010). Los perros que presentan OSA apendicular manifiestan claudicación debido al dolor asociado con las microfracturas o a lesión del periostio y con frecuencia tumefacción de la zona donde se encuentra el tumor (Ehrhart y col., 2013). En cambio, los signos asociados con el OSA del esqueleto axial varían de acuerdo con el sitio de localización e incluyen: tumefacción, disfagia, exoftalmos, entre otros (Ehrhart y col., 2013). Estos pacientes presentan una sensibilidad somatosensorial generalizada que se caracteriza por una sensibilización periférica y central exacerbada producto de un sistema inhibidor deficiente. Además, el dolor es tan intenso que suelen ser refractarios al tratamiento analgésico paliativo (Monteiro y col., 2018).

El OSA en los humanos y los perros comparte muchas características entre las que se incluyen: anormalidades genéticas, alta incidencia de morbilidad y mortalidad, localización, características histológicas y respuesta a diferentes modalidades de tratamiento (Gorlick y Khanna, 2010; Schmidt y col., 2013). En este sentido, el OSA que afecta a los perros se ha utilizado como modelo para la comprensión de esta enfermedad en humanos, así como también para diversos estudios entre los cuales se encuentran nuevos enfoques terapéuticos, estudios sobre genes relacionados con el pronóstico, y estudios relacionados con los mecanismos moleculares implicados en la patogenia y progresión del OSA (Gorlick y Khanna, 
2010). De esta manera, los oncólogos veterinarios utilizan actualmente criterios de clasificación y citológicos de malignidad aplicados para los OSAs humanos (Loukopoulos y col., 2004; Selvarajah y col., 2009; Thompson y Dittmer, 2017).

El diagnóstico preciso de los tumores óseos requiere de una adecuada evaluación clínica, diagnóstico radiológico e histológico, sin esta información los hallazgos aislados en las muestras de biopsias pueden ser mal interpretados (Ehrhart y col., 2013; Craig y col., 2016; Czerniak y Dorfman, 2016; Thompson y Dittmer, 2017). En medicina humana esta triangulación se conoce como diagnóstico triangular de Jaffe, y permite evaluar a los tumores óseos como entidades individuales (Czerniak y Dorfman, 2016). No obstante, con el advenimiento de las técnicas moleculares esta tríada se ha ampliado y actualmente incluye, además, los datos moleculares (Fig. 2).

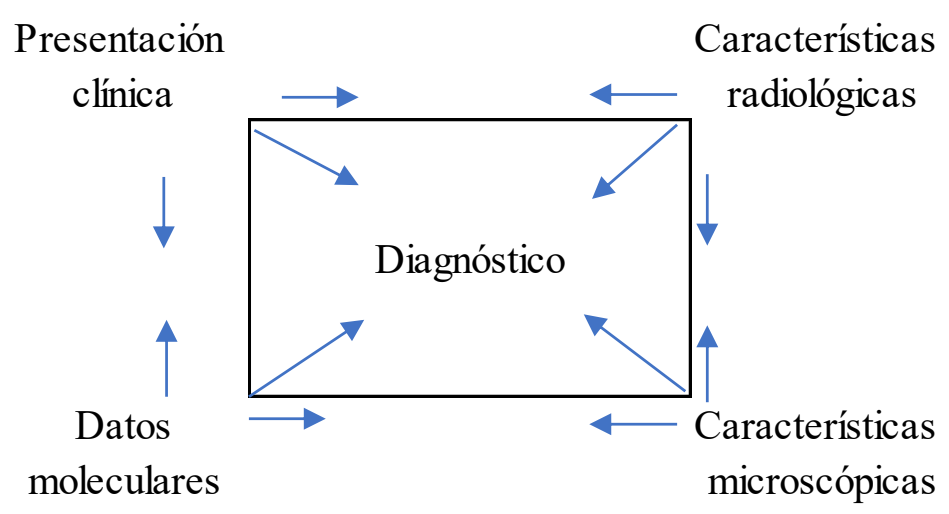

Figura 2. Enfoque analítico para el diagnóstico de sarcomas óseos en humanos en el que se incluye cuatro grupos diferentes de datos (clínicos, radiológicos, microscópicos y moleculares) para establecer un diagnóstico. Modificado de Czerniak y Dorfman, 2016.

Técnicas como inmunohistoquímica (IHQ), citometría de flujo, reacción en cadena a la polimerasa y microscopía electrónica, pueden, en ciertos casos, contribuir con 
la identificación correcta de los subtipos histológicos de los SOs (Ehrhart y col., 2013; Thompson y Dittmer, 2017). No obstante, a pesar de los recientes y numerosos avances en el área de la patología, incluidas las técnicas moleculares, la evaluación de los tejidos con la microscopía óptica sigue siendo uno de los parámetros de elección para arribar al diagnóstico. La identificación temprana junto con una correcta clasificación es de suma importancia para proporcionar un pronóstico al paciente. En medicina veterinaria no hay avances significativos al respecto, en comparación con lo que sucede en medicina humana (Ehrhart y col., 2013). Sin embargo, algunos adelantos sobre el estudio de la patogenia han permitido extender el tiempo de sobrevida en los perros. En este sentido, Schmidt y col., (2013) mencionaron que la sobrevida de los perros con OSA no superó los 5 meses si la amputación fue el único tratamiento realizado. En medicina veterinaria el sistema de clasificación actual de los SOs se establece principalmente considerando un criterio histológico y el tipo de matriz que producen las células óseas tumorales, coincidentemente con la clasificación propuesta por la Organización Mundial de la Salud (Slayter y col., 1994). Un sistema similar es aplicado en medicina humana para clasificar a los SOs, particularmente el OSA, incluso es utilizado como un indicador pronóstico para aquellos pacientes que padecen este tipo de cáncer (Kirpensteijn y col., 2002; Czerniak y Dorfman, 2016; Thompson y Dittmer, 2017).

Por otra parte, establecer un sistema de estadificación* ha comenzado a tomar relevancia en los animales debido a que el comportamiento biológico de ciertos

\footnotetext{
* En medicina, estadificación es la acción y efecto de estadificar, es decir, determinar la extensión y gravedad de una enfermedad, en especial el cáncer
} 
tumores se estima en relación con el mismo (Loukopoulos y Robinson, 2007; Ehrhart y col., 2013). En medicina humana se utilizan dos sistemas de estadificación, que evalúan diferentes parámetros, en pacientes que padecen este tipo de tumor (Czerniak y Dorfman, 2016). El primero es el sistema TNM, cuyas siglas hacen referencia a tumor, nódulo linfático y metástasis, respectivamente. Dicho sistema fue diseñado por el American Joint Committee on Cancer. El segundo es el sistema de Enneking, el mismo se aplica tanto a los tumores óseos como para los tumores de tejido blando (Enneking, 1986). Este sistema se basa en la evaluación de dos parámetros básicos: agresividad biológica y extensión local de la enfermedad (Enneking, 1986; Czerniak y Dorfman, 2016). La estadificación histológica de los SOs en humanos se basó históricamente en el sistema de Broders, el cual evalúa la celularidad, la atipía nuclear y el grado de anaplasia. Asimismo, se enfatiza la importancia de estadificar un paciente con cáncer para poder emitir un pronóstico e iniciar el tratamiento adecuado para ese paciente en particular (Rubin y col., 2010; Czerniak y Dorfman, 2016). Hasta el momento, no existe un sistema universalmente aceptado para los SOs en humanos y animales (Petersen y Wardelmann, 2016; Thompson y Dittmer, 2017). El sistema utilizado en humanos para evaluar sarcomas de partes blandas, denominado French Grading and the National Cancer Institute Grading, nunca fue validado para los SOs (Petersen y Wardelmann, 2016).

Por otra parte, la séptima edición del manual de estadificación del American Joint Committee on Cancer propone un sistema de cuatro grados para la estadificación de los OSAs humanos, donde los grados (G) 1 y 2 son considerados de bajo grado y, G3 y G4 de alto grado. Este sistema sólo considera la diferenciación celular, 
siendo G1, altamente diferenciado; G2 medianamente diferenciado; G3 poco diferenciado y G4 indiferenciado. Al mismo tiempo, el College of American Pathologists (CAP) propone un sistema de estadificación, utilizado actualmente, en el cual el grado de malignidad se estima de acuerdo con una subtipificación histológica propia (Rubin y col., 2010; Petersen y Wardelmann, 2016) (Tabla 1; Anexo I).

Por otra parte, actualmente en medicina veterinaria se utiliza un sistema de gradación tumoral (GT) que proporciona una excelente valoración sobre la agresividad biológica de ciertos tumores (Peña y col., 2013; Sabattini y col., 2015). Es probable que en el futuro el comportamiento de la totalidad de los tumores se relacione con la GT (Kirpensteijn y col., 2002; Ehrhart y col., 2013). De hecho, diversos estudios destacaron la importancia de aplicar un sistema de gradación para los tumores óseos en humanos y en perros, como un factor significativo predictivo de pronóstico, asociado con el tiempo de sobrevida y el intervalo libre de enfermedad (Grundmann y col., 1995; Inwards y Unni, 1995; Kirpensteijn y col., 2002; Loukopoulos y Robinson, 2007; Czerniak y Dorfman, 2016). En este sentido, en medicina veterinaria fueron estudiados dos sistemas de GT, particularmente sobre el OSA. Estos fueron adaptados de sistemas de clasificación preexistentes, sin embargo, ambos evalúan parámetros básicos utilizados en medicina humana (Kirpensteijn y col., 2002; Loukopoulos y Robinson, 2007; Czerniak y Dorfman, 2016). 
Tabla 1. Estadificación de los osteosarcomas según el College of American Pathologists (modificado de Rubin y col., 2010)

\begin{tabular}{|l|l|}
\hline $\begin{array}{l}\text { Grado 1 } \\
\text { (bajo grado) }\end{array}$ & OSA central de bajo grado/ OSA parosteal/ adamantimoma \\
\hline Grado 2 & OSA periosteal \\
\hline $\begin{array}{l}\text { Grado 3 } \\
\text { alto grado) }\end{array}$ & $\begin{array}{l}\text { Sarcoma de Edwing/ tumor primitivo del neuroectodermo/ } \\
\text { OSA convencional/ OSA teleangiectático/ condrosarcoma } \\
\text { mesenquimático/ OSA de células pequeñas/ OSA secundario/ } \\
\text { OSA superficial de grado alto/ condrosarcoma } \\
\text { indiferenciado/ cordoma indiferenciado/ tumor maligno de } \\
\text { células gigantes }\end{array}$ \\
\hline Grado variable & $\begin{array}{l}\text { condrosarcoma convencional (G1-3) / sarcomas de tejido } \\
\text { blando (leiomiosarcoma, liposarcoma, sarcoma pleomorfo } \\
\text { indiferenciado) }\end{array}$ \\
\hline
\end{tabular}

El estudio de la GT en animales contempla la evaluación de los siguientes parámetros: grado de diferenciación, índice mitótico (número de mitosis por 10 campos utilizando un objetivo con magnificación 40x), grado de pleomorfismo celular o nuclear, grado de necrosis, invasividad, reacción del estroma, tamaño y número de núcleos, celularidad general y respuesta linfoide. El índice mitótico, el grado de necrosis y el grado de pleomorfismo son considerados parámetros de importancia para determinar el comportamiento biológico del tumor (Loukopoulos y Robinson 2007). Además, son las únicas características objetivas y cuantificables que se pueden establecer mediante el conteo manual, morfometría computarizada o cuantificación química (Loukopoulos y Robinson 2007; Ehrhart y col., 2013). Kirpensteijn y col., (2002) y Loukopoulos y col., (2007) evaluaron en diferentes 
grupos de perros con OSA tres parámetros importantes de la GT (pleomorfismo, índice mitótico y grado de necrosis) y destacaron la importancia de este sistema como un factor predictivo de pronóstico. En este sentido, los hallazgos de sus estudios demostraron que aquellos OSAs que manifestaron metástasis tuvieron una GT significativamente más alta, grado III (GIII), con respecto a los que no habían metastatizado (Kirpensteijn y col., 2002 y Loukopoulos y col., 2007). Asimismo, establecieron una relación entre la GT y la localización anatómica de los OSAs, aquellos con localización apendicular tuvieron la mayor GT (GIII), particularmente un índice mitótico significativamente más alto con respecto a aquellos con una localización axial (Loukopoulos y Robinson, 2007).

Los marcadores predictivos son moléculas útiles para seleccionar pacientes con alta probabilidad de responder exitosamente a un tratamiento determinado. Dentro de los biomarcadores tumorales, los marcadores de pronóstico se consideran predictores de comportamiento futuro de la enfermedad en humanos (Senra y Quintela, 1999). La búsqueda de mejores marcadores se centra en los mecanismos moleculares que subyacen al comportamiento del tumor tales como la progresión del ciclo celular alterado, la proliferación, la apoptosis y la angiogénesis (Mukaratirwa, 2005). De acuerdo con su función, los marcadores se reúnen en seis grupos: 1) de proliferación; 2) de apoptosis; 3) moléculas de la MEC; 4) moléculas de adhesión celular, 5) de angiogénesis y 6) reguladores del ciclo celular (Mukaratirwa, 2005). Se considera que estos marcadores pueden ser producidos por el propio tumor o por el tejido circundante como respuesta a la lesión tumoral (Campuzano Maya, 2010; Lazcano Hermida y col., 2016). Ellos, pueden ser estudiados a partir de diferentes muestras tales como: a) el tejido tumoral y b) 
fluidos o células aisladas. Además, estos biomarcadores pueden contribuir con la segregación de pacientes en grupos y, de esta manera, podrán identificarse pacientes cuyo pronóstico no requiere de la terapia adyuvante luego de la cirugía y pacientes cuyo pronóstico requieran terapia adyuvante agresiva (Mukaratirwa, 2005; Diessler, 2009).

Los SOs presentan un comportamiento muy agresivo que se relaciona con un pobre pronóstico. Sin embargo, desde hace algunos años diversos estudios han incluido otras variables que podrían relacionarse con el pronóstico entre las que se incluyen: a) la localización anatómica, b) el tamaño y la GT, c) la concentración de fosfatasa alcalina sérica (FAS), d) el gen de resistencia a múltiples drogas MDR1 o glicoproteína-P (PGP) y e) marcadores de proliferación. A continuación se describen:

a) El comportamiento biológico del tumor se relaciona con la localización anatómica, en el esqueleto apendicular o esqueleto axial. En este sentido, Loukopoulos y Robinson, (2007) demostraron que la localización anatómica estuvo relacionada con el pronóstico. El OSA apendicular presenta un comportamiento más agresivo que el OSA de localización axial. Esto se evidencia a partir de una mayor incidencia de metástasis, una GT elevada (GIII), particularmente con un elevado índice mitótico, y un tiempo de sobrevida mucho menor. En contraste, el OSA con localización axial, presenta una GT baja y un comportamiento menos agresivo (Kirpensteijn y col., 2002; Loukopoulos y Robinson, 2007; Schott y col., 2018). 
b) En medicina humana el tamaño tumoral se relaciona con el pronóstico, de este modo, los pacientes que presentan SOs de gran tamaño poseen un pronóstico negativo. Por otra parte, en medicina humana y veterinaria la GTIII fue relacionada con un pobre pronóstico (Kirpensteijn y col., 2002; Loukopoulos y Robinson, 2007; Czerniak y Dorfman, 2016).

c) Los perros con OSA apendicular presentan una elevada concentración de FAS sérica que se ha asociado con un pobre pronóstico (Ehrhart y col., 2013).

d) La resistencia a los medicamentos a través de la medición del gen MDR-1 o de la PGP se asoció con un peor pronóstico en aquellos pacientes humanos que padecían OSA y condrosarcoma de alto grado (GIII) (Hernández Cortés y col., 2000; Selvarajah y Kirpensteijn, 2010). En medicina veterinaria los estudios más recientes al respecto fueron realizados sobre linfoma, tumores de mama y melanoma en perros (Sokołowska y col., 2015; Fino y col., 2016; Finotello y col., 2016; Levi y col., 2016).

e) La actividad proliferativa de las neoplasias se estima contando la cantidad de mitosis o mediante la inmunomarcación de sustancias como: el antígeno Ki67, el antígeno nuclear de proliferación celular (PCNA) y la bromodeoxiuridina incorporada (BrdU) y el posterior recuento de células. También se han utilizado otros métodos como el análisis de ploidía de ADN o la tinción con AgNOR para cuantificar nucléolos (Okada y col., 2003; Ohta y col., 2004; Mukaratirwa, 2005; Loukopoulos y Robinson, 2007; Ehrhart y col., 2013). 


\section{I.3. Inmunohistoquímica aplicada al pronóstico}

Selvarajah y Kirpensteijn, (2010) mencionaron para el OSA en perros la existencia de biomarcadores predictivos de pronóstico, entre ellos: p53; factores angiogénicos como el factor de crecimiento del endotelial vascular (VEGF); factor de transición epitelial mesenquimático (MET) conocido también como el receptor del factor de crecimiento de hepatocitos (HGF); ciclooxigenasa-2 (COX-2); erzina; MMPs; PGP y MDR-1 (Gorlick y Khanna, 2010; Selvarajah y Kirpensteijn, 2010). Asimismo, la tasa de proliferación de células tumorales es el principal determinante de la agresividad de un tumor $\mathrm{y}$, por lo tanto, un importante factor pronóstico (Mukaratirwa, 2005). Sin embargo, se conoce muy poco sobre la actividad proliferativa de las neoplasias en perros a diferencia de lo que ocurre en seres humanos (Ohta y col., 2004). Los marcadores de proliferación están presentes en determinadas fases del ciclo celular y la actividad proliferativa de una neoplasia se ha estimado mediante el inmunomarcación de sustancias tales como: antígeno Ki67, PCNA y BrdU, entre otros (Ohta y col., 2004).

\section{I.3.1. Proliferación y PCNA}

El PCNA es una proteína accesoria de la ADN polimerasa $\delta$ y está relacionada con la síntesis de ADN y la proliferación celular (Castellano y col., 1996). La proteína se detecta en la fase tardía de G1 dentro del ciclo celular, inmediatamente antes del comienzo de la fase $\mathrm{S}$, donde se encuentra en su máxima expresión, declinando durante G2 y M. PCNA está presente en todos los tejidos con células en proliferación. De modo que se utiliza con frecuencia para la identificación, 
mediante el estudio inmunohistoquímico de células en proliferación ya que presenta una fuerte asociación con regiones donde está ocurriendo la síntesis de ADN (Preziosi y col., 1995; Bechtel y col., 1998; Czerniak y Dorfman, 2016). En este sentido, es utilizado, en ciertas neoplasias en animales y humanos como marcador pronóstico (Poblete, 2001; Coronato y col., 2002; Ma y col., 2016; Mestrinho y col., 2017). La medición de PCNA en tumores sólidos, se correlaciona con la actividad mitótica, la fase S del ciclo celular y el grado histológico del tumor (Cullen y Breen, 2017).

I.3.2. Angiogénesis y cáncer. Rol del factor de crecimiento del endotelio vascular y la proteína morfogénica ósea en los sarcomas óseos

La angiogénesis es un mecanismo de múltiples pasos, que incluye la formación de nuevos vasos a partir de redes vasculares preexistentes. Se considera un proceso fisiológico importante para la vascularización de los tejidos en la etapa embrionaria (Saavedra Torres y col., 2017). Durante la etapa postnatal, este proceso se lleva a cabo en la reparación de los tejidos dañados, la formación y el crecimiento de los huesos y el desarrollo de la placenta en la preñez. No obstante, la angiogénesis se presenta, de manera temprana, en el desarrollo de procesos patológicos como el cáncer y desempeña un papel importante en el crecimiento y la diseminación metastásica de las células tumorales. La angiogénesis se lleva a cabo en un microambiente tisular adecuado, en el que debe existir un balance entre los mediadores químicos que la promueven (factores proangiogénicos) y aquellos que la inhiben (factores antiangiogénicos) (René, 2007; Cullen y Breen, 2017; Saavedra 
Torres y col., 2017). Las células tumorales inducen la angiogénesis en un proceso similar al que ocurre en la angiogénesis fisiológica, en este sentido, la hipoxia constituye un factor desencadenante para este proceso (Saavedra Torres y col., 2017). A nivel celular la hipoxia provoca un incremento del factor inducible por la hipoxia, que en el núcleo promueve la transcripción de diversos genes, entre los que se encuentran dos potentes factores angiogénicos, el VEGF y el factor de crecimiento derivado de plaquetas. Además, las células tumorales sintetizan y liberan otros factores de crecimiento angiogénicos, como los factores de crecimiento fibroblástico ácido y básico (aFGF y bFGF) o bien, estimulan a otras células a liberar factores angiogénicos (Xie y col., 2017). Asimismo, existen otras moléculas implicadas en la regulación positiva de la angiogénesis tales como el HGF, la angiogenina, las angiopoyetinas-1 y -2 (Ang-1 y Ang-2), la interleucina 8, las prostaglandinas, los factores de crecimiento transformante alfa y beta (TGF $\alpha$ y TGF $\beta$ ), entre otros. Sin embargo, los factores de crecimiento implicados principalmente en la angiogénesis tumoral son el VEGF, la Ang-2, y el bFGF, aunque en concentraciones más altas que en la angiogénesis fisiológica (Saavedra Torres y col., 2017). Además de las células tumorales, existen otros tipos celulares que participan en la angiogénesis tales como: células derivadas de la médula ósea, macrófagos, neutrófilos, mastocitos y precursores mieloides que infiltran los márgenes del tumor y contribuyen a la formación de nuevos vasos (Cullen y Breen, 2017).

Durante el proceso de angiogénesis la MEC es degradada por MMPs que son liberadas y activadas por las células neoplásicas. Además, propician el crecimiento tumoral y estimulan la liberación del VEGF y otros factores de crecimiento 
angiogénicos. Por consiguiente, estos factores de crecimiento estimulan la migración de las células endoteliales a partir de los vasos sanguíneos más cercanos como también, la expresión de proteínas necesarias para la neovascularización. De esta manera, se regenera la MEC para dar sostén y nutrir a los nuevos vasos que propiciarán la metástasis y el potencial maligno del tumor (Saavedra Torres y col., 2017). En este sentido, las MMPs son los principales mediadores responsables de las alteraciones que ocurren en el microambiente tumoral a lo largo de la progresión del cáncer (Van Damme y col., 2004; Saavedra Torres y col., 2017). Durante el crecimiento y la progresión tumoral estas proteasas desempeñan un rol fundamental, promueven la degradación del tejido conectivo y los componentes de la membrana basal, además de activar factores de crecimiento, receptores de superficie para moléculas de adhesión y ciertas citocinas (Bourboulia y Stetler Stevenson, 2010). La interacción con los componentes de la MEC permite que las células tumorales se tornen menos adherentes entre sí y, por lo tanto, expresen mayor potencial para migrar y producir metástasis (Noël y col., 2008).

El VEGF, también conocido como factor de permeabilidad vascular, es un factor angiogénico importante en el proceso de angiogénesis. La familia de VEGF comprende ocho miembros de proteínas homodiméricas: VEGF-A, VEGF-B, VEGF-C, VEGF-D, VEGF-E y los factores de crecimiento placentario 1 y 2 . De esta familia, el más estudiado es el VEGF-A, que es referido simplemente como VEGF (Rosales Torres y Guzmán Sánchez, 2011). Ejercen sus funciones mediante la interacción con tres receptores tirosina quinasa: VEGFR-1 (receptor 1 de VEGF, tirosina quinasa de tipo fms, Flt-1), VEGFR-2 (receptor 2 de VEGF con dominio quinasa activo, Flk-1/KDR) y VEGFR-3 (Flt-4) y dos receptores no tirosina quinasa 
neuropilina 1 y neuropilina 2. La estimulación de la vía de señalización a partir del VEGFR-1 y VEGFR-2 promueve la angiogénesis mientras que la mediada por VEGFR-3 conduce a la linfangiogénesis (Fig. 3). Esta interacción propicia la proliferación, supervivencia y migración de las células endoteliales como también la expresión de citocinas y MMPs (Saavedra Torres y col., 2017). En este sentido, el VEGF interviene tanto en procesos fisiológicos como patológicos, que incluyen el desarrollo del embrión, la vasculogénesis, la hematopoyesis temprana, la ovulación, la reparación de heridas, la endometriosis, la degeneración macular neovascular del ojo, las enfermedades inflamatorias crónicas y las neoplasias, entre otros (Meyer y col., 1999; Ng, 2008; Rosales Torres y Guzmán Sánchez, 2011).

En humanos se han identificado cinco isoformas angiogénicas derivadas del gen VEGF; estas isoformas son el resultado del proceso de splicing alternativo mediante el corte y el empalme del ARNm de VEGF. En este sentido, el grupo que incluye las isoformas ácidas de VEGF no se une fácilmente a la heparina, y por lo tanto llegan rápidamente a la célula endotelial. En contraste, las isoformas básicas de VEGF, se unen a la heparina, permaneciendo secuestradas en la MEC (Ferrara y Davis Smyth, 1997; Poon y col., 2001). El VEGF presenta alta afinidad de unión al VEGFR-1 y VEGFR-2 y se reconoce como el principal estimulador de la angiogénesis, mediante la proliferación, migración y supervivencia de las células endoteliales, en condiciones fisiológicas y patológicas (Meyer y col., 1999; Rahimi, 2006; Rosales Torres y Guzmán Sánchez, 2011). Ambos receptores son necesarios para promover el crecimiento de los vasos sanguíneos (Rahimi, 2006; Bavcar y Argyle, 2012; Saavedra Torres y col., 2017). 
Los receptores tirosina quinasa (RTK) son proteínas de superficie que se unen con diferentes ligandos extracelulares, entre los que se incluyen: factores de crecimiento, hormonas y diversas citocinas (Bavcar y Argyle, 2012). Los mecanismos de activación de la mayoría de los RTK han sido bien caracterizados. En este sentido, la transautofosforilación de los RTK y, posteriormente, su capacidad para fosforilar proteínas diana son el sello distintivo de la activación de los RTK (Rahimi, 2006; Alberts y col., 2015a). Además de regular procesos normales en las células, los RTK y las vías de señalización intracelular que ellos activan, son fundamentales en la oncogénesis en diversos tipos de cáncer (Bavcar y Argyle, 2012). En este sentido, dos vías citoplasmáticas están particularmente desreguladas en varios tipos de cáncer en humanos y animales (London, 2013; Alberts y col., 2015b). La primera incluye miembros de la familia $R A S$, las mutaciones en esta vía han sido asociadas con varios cánceres humanos. La segunda vía citoplasmática incluye a la fosfatidil inositol-3 quinasa $(P I 3 K)$ y sus transductores de señal asociados, $A K T$, factor nuclear $\kappa \mathrm{B}$ y el blanco de rapamicina en mamíferos mTOR, entre otros (London, 2013; Alberts y col., 2015b; Sanz Ressel y col., 2019). La desregulación de una variedad de RTK tales como: el receptor 1 de factor de crecimiento similar a insulina, el VEGFR, el receptor 2 del factor de crecimiento epidérmico humano, y el receptor del factor de crecimiento derivado de plaquetas, han sido implicados en la patogenia de los SOs pediátricos (RiveraValentin y col., 2015). Además, existen circuitos de activación autocrinos que se producen cuando la célula tumoral expresa, simultáneamente, el RTK y los factores de crecimiento. En la mayoría de los tumores ambas moléculas se encuentran sobreexpresadas. En este sentido, se han descripto circuitos de activación autocrina 
en los OSAs de perros que presentan paralelamente coexpresión de MET y su ligando, HGF (London, 2013). Por otra parte, se ha demostrado que los receptores VEGFR-1, VEGFR-2 y VEGFR-3 se expresan tanto en células endoteliales como en líneas celulares de sarcomas (Xie y col., 2017).

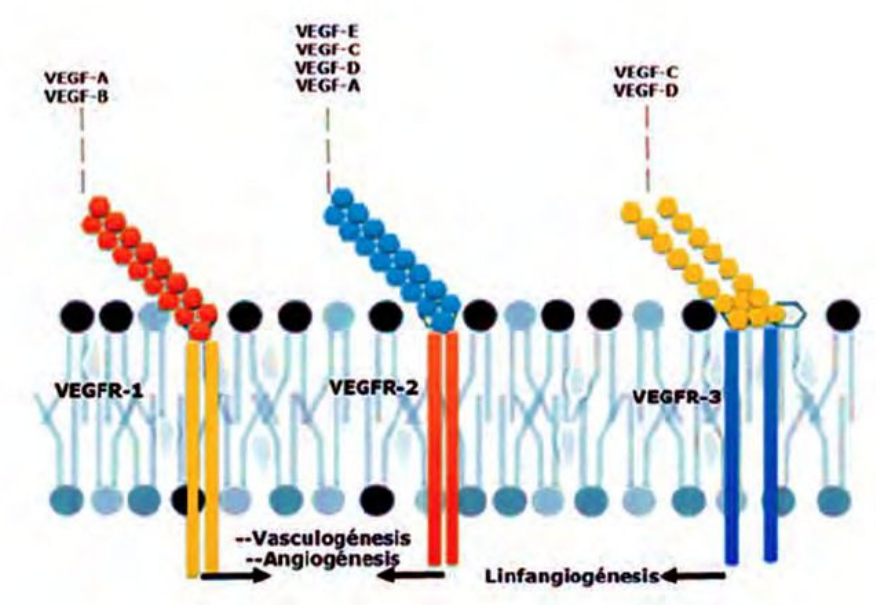

Figura 3. Esquema de compatibilidad de unión entre los factores de crecimiento endotelial vascular y sus receptores. (Extraído de Saavedra Torres y col., 2017)

Al igual que otros receptores de actividad tirosina quinasa, el VEGFR se dimeriza y con la unión al ligando experimenta transautofosforilación, desencadenando una cascada de señalización. Esto induce la fosforilación de diferentes proteínas tales como la proteína quinasa-C, la fosfolipasa C-gamma, $P I 3 K$, sintasa endotelial de óxido nítrico y $m T O R$, que regulan los mecanismos involucrados en la angiogénesis (Martínez Ezquerro y Herrera, 2006). Se considera que los efectos angiogénicos que presenta la familia de VEGF están mediados principalmente a través de la interacción con el VEGFR-2 por lo que esta vía ha sido priorizada para el desarrollo de terapias antiangiogénicas (Meyer y col., 1999; Rahimi, 2006; Dejana y col., 2008; Rosales Torres y Guzmán Sánchez, 2011). Si bien el VEGFR-1 tiene una 
afinidad 10 veces mayor por el VEGF, su activación presenta menos impacto como disparador de moléculas de señalización intermediarias con respecto a lo que sucede con el VEGFR-2 (Waltenberger y col., 1994; Li y col., 2004; Falcon y col., 2016). Se considera que el VEGFR-1 es un RTK con una función quinasa deficiente, su capacidad para fosforilar otros sustratos es despreciable debido a que está pobremente fosforilado en tirosina (Rahimi, 2006). Sin embargo, Rahimi, (2006) indicó que el VEGFR-1 tuvo un rol importante pero mucho más complejo en la modulación positiva y negativa de la angiogénesis. La capacidad del VEGFR-1 para modular la angiogénesis presenta tres mecanismos complejos detallados en la figura 4.

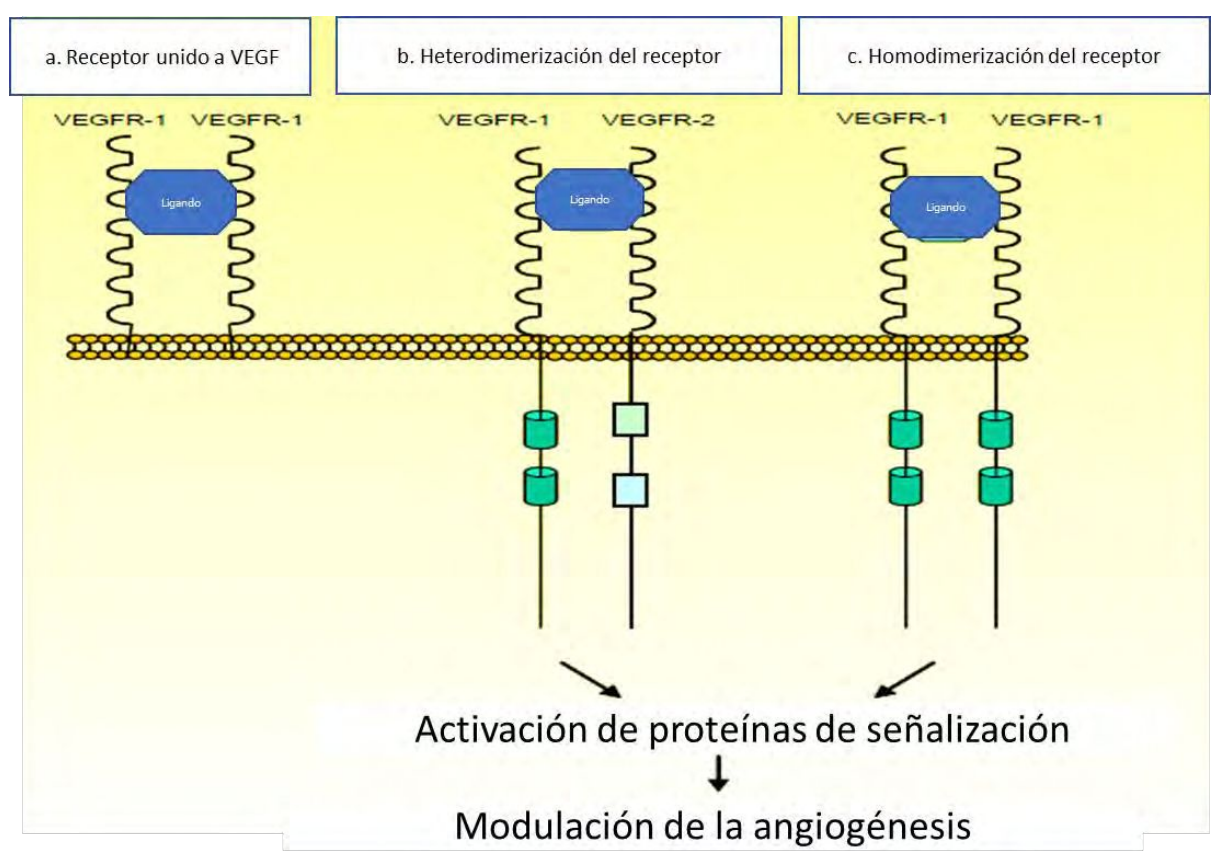

Figure 4. Representación esquemática de la participación del VEGFR-1 en la angiogénesis. a) El VEGF queda atrapado en el VEGFR-1, este mecanismo evita que el VEGF se una al VEGFR-2. b) El VEGFR-1 regula la angiogénesis a través de la heterodimerización del VEGFR-2 o VEGFR-3. c) El tercer mecanismo del VEGFR-1 es a través de la homodimerización del receptor. Este tipo de activación del VEGFR-1 conduce a la activación de proteínas de señalización que podrían regular la angiogénesis de manera positiva o negativa. (Modificado de Rahimi, 2006) 
Cuando el VEGF se une al dominio extracelular del VEGFR-1, activa la vía de señalización de la proteína quinasa activada por mitógeno $(M A P K)$. En el núcleo e Cuando VEGF se une al dominio extracelular del VEGFR-1, activa la vía de señalización de la proteína quinasa activada por mitógeno (MAP). En el núcleo esta enzima fosforila serinas y treoninas en varias proteínas implicadas en la regulación de genes, alterando su capacidad para controlar la transcripción y produciendo cambios en el patrón de la expresión génica (Alberts y col., 2015). De esta manera, se produce la expresión de MMPs, interleucinas y ciertos factores de crecimiento que son exportados a la MEC (Saavedra Torres y col., 2017). En las células precursoras endoteliales, el VEGF controla la síntesis y las vías de señalización necesarias para promover la angiogénesis tumoral. Este factor de crecimiento inhibe la apoptosis celular cuyo objetivo es evitar interrumpir el mecanismo angiogénico (Saavedra Torres y col., 2017). Las MMPs cumplen un rol complejo en la angiogénesis, promueven la migración de las células endoteliales y estimulan la liberación del VEGF y otros factores proangiogénicos, como el FGF-2 y el TGF $\beta$, desde la MEC (Sounni y col., 2011). En modelos animales han demostrado que las MMPs regulan el proceso de formación y maduración de nuevos vasos sanguíneos, a través del control que ejercen sobre los factores de crecimiento y citocinas que suscitan el reclutamiento de pericitos (Patterson y Sang, 1997). El VEGF es considerado un biomarcador de valor pronóstico en OSAs humanos (DuBois y Demetri, 2007; Xie y col., 2017). Dado que la angiogénesis es un acontecimiento esencial para el crecimiento, invasión y metástasis tumoral y, considerando que el VEGF es un regulador clave en el proceso de angiogénesis, fue propuesto en seres humanos como un blanco terapéutico para el OSA ya sea inhibiendo la unión del 
VEGF-A al VEGFR-2 o bloqueando el sitio de unión del VEGFR-2 (Xie y col., 2017). Mac Gabhann y col., (2010) destacaron la importancia de los receptores como blanco terapéutico no así la del factor de crecimiento.

Por otra parte, la proteína morfogénica ósea (BMP) es un factor de crecimiento que pertenece a la superfamilia del TGF $\beta$. Las BMP fueron originalmente aisladas del tejido óseo como proteínas que inducen, in vivo, la formación de tejido óseo y cartílago en sitios ectópicos por fuera del esqueleto (Urist 1965). Se demostró que la matriz ósea desmineralizada estimula la formación de tejido óseo cuando se implanta ectópicamente en el músculo o debajo de la piel debido a la existencia de BMP (Grgurevic y col., 2017). La vía de señalización de BMP es una de las vías clave responsable de la inducción de la diferenciación osteogénica y la regulación de la formación ósea (Granjeiro y col., 2005; Nguyen y col., 2014). Las BMPs se consideran morfógenos potentes y tienen un rol central en el desarrollo temprano, participan en: la determinación del patrón dorsal-ventral, la organogénesis y la diferenciación celular. Se ha demostrado que estas proteínas regulan un amplio espectro de actividades biológicas que incluyen roles en: proliferación, diferenciación, migración, quimiotaxis y muerte en diferentes tipos celulares. Exhiben actividad sobre varios órganos y tejidos: en el tejido óseo y el tejido cartilaginoso, regulan el crecimiento y la diferenciación de condroblastos y osteoblastos in vitro (Miyazono y col., 2010; Herrera y col., 2014; Gomez Puerto y col., 2019). En la actualidad, se consideran reguladores claves de la homeostasis del tejido adulto (Herrera y col., 2014). Además, intervienen en procesos patológicos como el cáncer, donde pueden promover o inhibir la proliferación y progresión de las células tumorales según el microambiente celular. Además, 
intervienen en la angiogénesis tumoral (Nguyen y col., 2014; Katagiri y Watabe, 2016; Ye and Jiang 2016). (Fig. 5)

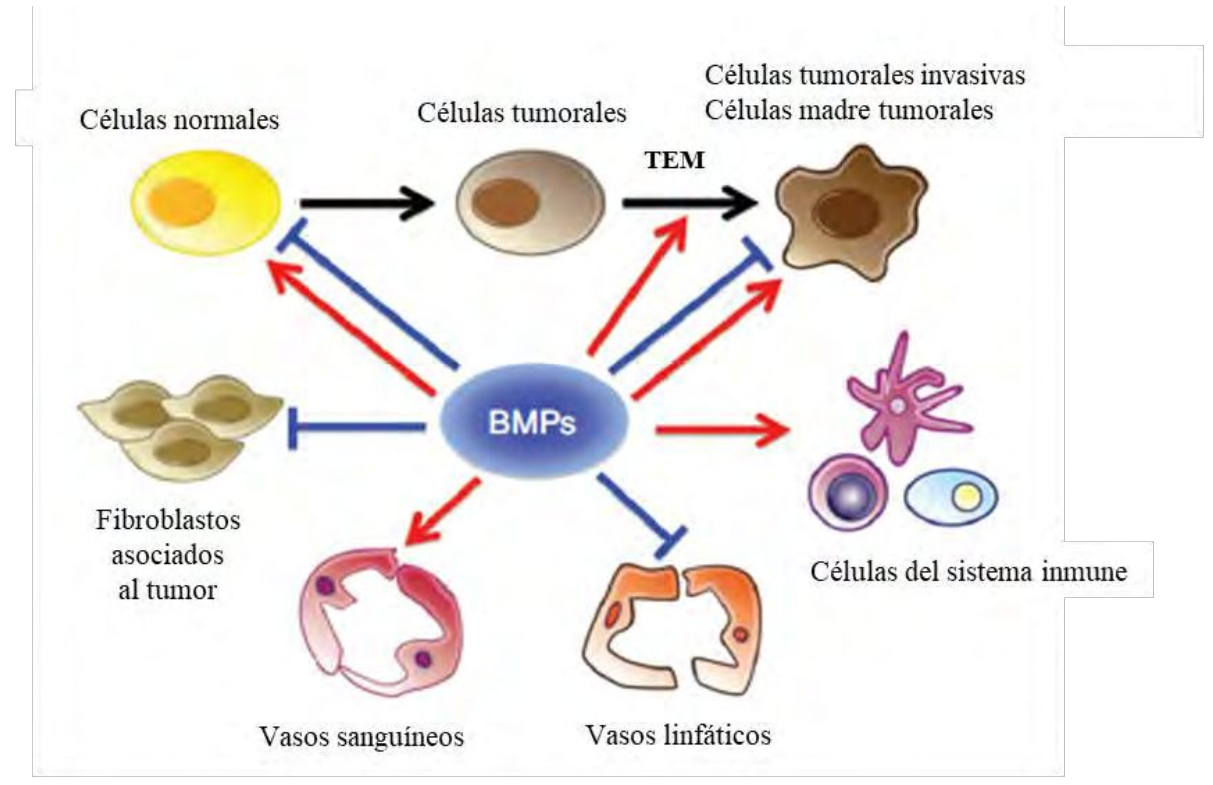

Figura 5. Roles de las proteínas morfogénicas óseas en el cáncer. Se muestran los efectos protumorales (rojo) y antitumorales (azul) de las proteínas morfogénicas óseas sobre diversos componentes que constituyen el microambiente del cáncer. Las proteínas morfogénicas óseas pueden promover o suprimir la proliferación y la progresión de las células cancerosas dependiendo del microambiente celular. TEM, transición epiteliomesenquimático. (Modificado de Katagiri y Watabe, 2016)

La familia de la BMP está constituida por más de diez miembros y, de acuerdo con la homología estructural y funciones han sido clasificadas en diferentes grupos, entre los que se incluyen las BMP-2/-4, las BMP-5/-6/-7/-8, las BMP-9/-10 y las BMP-12/-13/-14 (Ducy y Karsenty, 2000; Bragdon y col., 2011; Herrera y col., 2014; Katagiri y Watabe, 2016). De las cuales, las BMP-2, BMP-4, BMP-7, BMP9 y BMP-13 son las más estudiadas en el proceso de osteogénesis (Yoshikawa y col., 2004; Nguyen y col., 2014). 
Al igual que otros miembros de la superfamilia del TGF $\beta$, las BMPs inducen respuestas celulares específicas a través de su interacción con los receptores transmembrana tipo I y tipo II, que presentan actividad serina / treonina quinasa. Se han identificado tres receptores BMP tipo II (BMPR-II) y cuatro receptores BMP tipo I (BMPR-I), estos últimos también conocidos como quinasas similares a los receptores de activina (Activin like kinase receptor 1 - ALK-1), en adelante, serán referidos de esta manera (Otsuka, 2010; Katagiri y Watabe, 2016; Gomez Puerto y col., 2019). La gran variabilidad de afinidad entre los diferentes ligandos y sus receptores permite explicar las respuestas pleiotrópicas que presentan las BMPs (Otsuka, 2010; Álvarez San Martín, 2018; Gomez Puerto y col., 2019). La señalización celular es principalmente autocrina o paracrina, sin embargo, algunas BMPs, como las BMP-6, BMP-9 y BMP-10 circulan en sangre y pueden actuar por mecanismos endocrinos (Gomez Puerto y col., 2019).

La unión de las BMPs simultáneamente con ambos receptores, ALK-1 y BMPR-II, lleva a una interacción entre los dominios citoplasmáticos de ambos, de esta manera el receptor quinasa tipo II transfosforila el receptor de tipo I, lo que conduce a su activación (Katagiri y Watabe, 2016; Gomez Puerto y col., 2019). Dicho proceso propicia la activación de la vía de señalización dependiente de Smad, que consiste en la fosforilación de proteínas Smad, específicamente Smad-1, Smad-5 y Smad-8, que son factores de transcripción involucrados en la vía de señalización de las BMPs (Miyazono y col., 2010; Ye y Jiang, 2016; Gomez Puerto y col., 2019). Estas Smad se acoplan a Smad-4, y así forman un complejo hetero-oligomérico, Smad1/-5/-8/-4 que es traslocado al interior del núcleo celular. Allí se une a zonas diana en el ADN e inducen la transcripción de genes específicos, de esta manera estimulan 
y modulan la expresión génica (Katagiri y Watabe, 2016; Ye y Jiang, 2016; Gomez Puerto y col., 2019).

La señalización de las BMPs también puede seguir una vía independiente de Smad, especialmente a través de $M A P K$, que incluye la quinasa regulada por señales extracelulares, la quinasa N-terminal c-Jun y p38 (Nguyen y col., 2014) o bien, activando a pequeñas GTPasas como Rho y Rac. Cualquiera sea la vía activada, finalmente, estimulan y modulan en el núcleo la transcripción de genes específicos (Ye y Jiang, 2016; Gomez Puerto y col., 2019) (Fig. 6). La vía de señalización de las BMPs puede ser regulada durante la unión del ligando al receptor o durante la transducción de la señal y la regulación de los genes diana (Ye y Jiang, 2016). Por otra parte, existen otros ligandos que, mediante la unión al dominio extracelular, también pueden formar complejos con los receptores ALK-1 y BMPR-II e inducir su activación. 


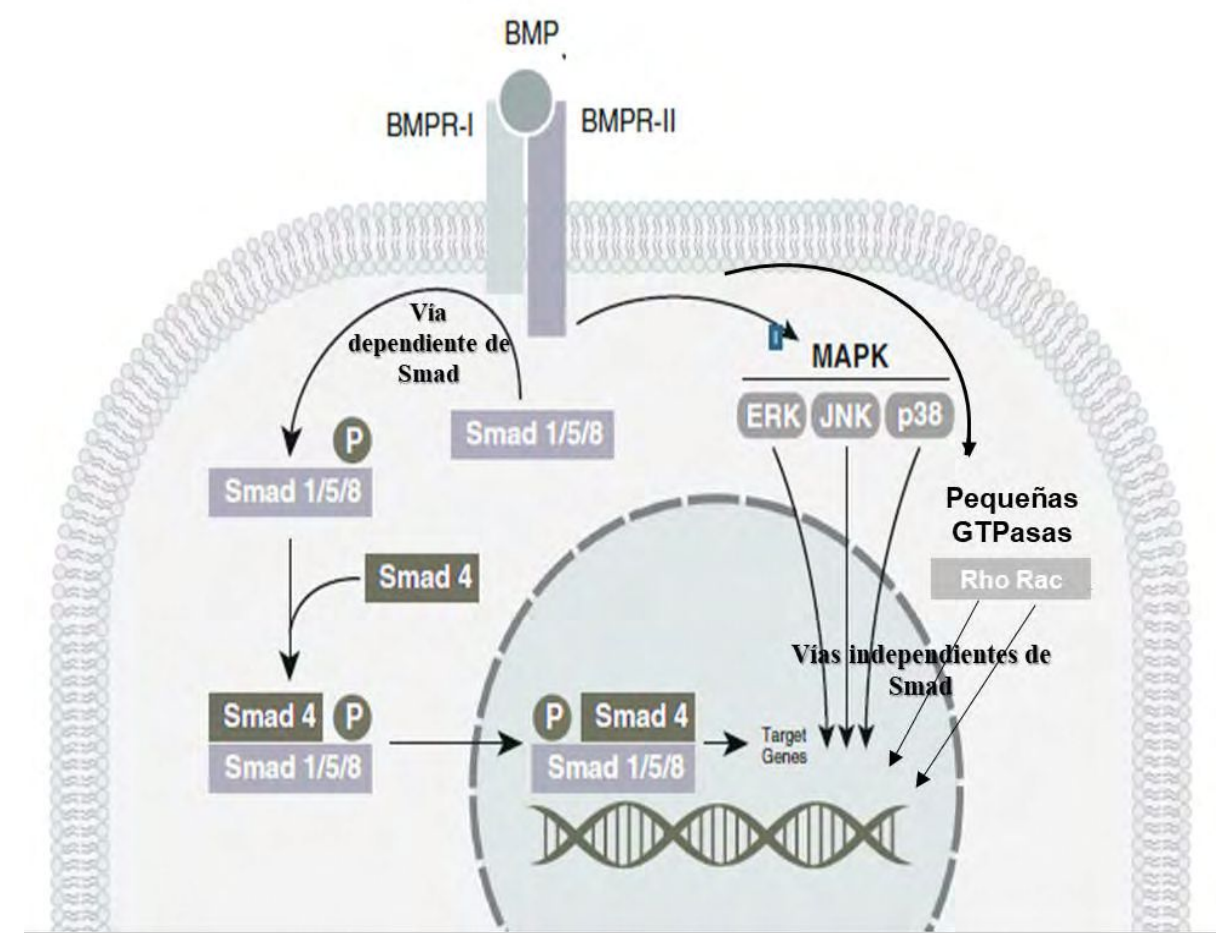

Figura 6. Vía de señalización de la BMP. Vía dependiente de Smad: los ligandos BMP se unen a BMPR-II, lo que conduce al reclutamiento y fosforilación ALK-1 y su posterior activación. A continuación, se activa la vía de señalización de Smad. La señalización de la BMP también puede seguir una vía independiente de Smad, con la activación de $M A P K$ que incluyen la quinasa regulada por señal extracelular, la quinasa N-terminal c-Jun y la $p 38$ o bien activando pequeñas GTPasas como Rho y Rac. (Modificado de Nguyen y col., 2014)

Por otra parte, diversos estudios han sugerido que miembros de la familia de las BMPs fueron involucrados en el desarrollo y mantenimiento del sistema vascular como también en la angiogénesis tumoral (Oh y col., 2000; Cunha y col., 2010; Suzuki y col., 2010; Katagiri y Watabe, 2016; Ye and Jiang 2016; Akatsu y col., 2017). En este sentido, las BMP-9 y BMP-10, son reguladores clave en la biología de la célula endotelial (crecimiento y migración) como también en el proceso de angiogénesis y crecimiento tumoral (David y col., 2007; Hu Lowe y col., 2011; 
Herrera y col., 2014; Katagiri y Watabe, 2016). Al igual que los demas miembros de la familia BMP, el grupo de la BMP-9 y BMP-10 se une a los receptores ALK1 y BMPR-II sin embargo, presentan gran afinidad por el ALK-1 (David y col., 2007; Vecchia y col., 2013; Akatsu y col., 2017). Estos receptores ALK-1 se expresan principalmente en las células endoteliales en proliferación, tanto en condiciones fisiológicas como patológicas. En este último caso, se encuentran ampliamente distribuidos en las células endoteliales de los vasos sanguíneos tumorales (Cunha y col., 2010; Hu Lowe y col., 2011; Xie y col., 2017). De este modo, los hallazgos referidos a la participación de BMP-9 y su principal receptor ALK-1 en la angiogénesis tumoral, recibieron una atención considerable debido a que el uso de inhibidores de la BMP-9 así como las terapias de bloqueo de ALK-1, han mostrado resultados prometedores para el tratamiento de ciertos tipos de cáncer en humanos (Cunha y col., 2010; Mitchell y col., 2010; Bendell y col., 2014; Gupta y col., 2015). No obstante, es probable que la señalización de la BMP-9 tenga efectos opuestos sobre la angiogénesis (Wiley y Jin, 2011). En este sentido, según Wiley y Jin, (2011) la BMP-9 podría provocar diversas respuestas en las células endoteliales, y estimular o inhibir la proliferación dependiendo del contexto celular y la concentración de la BMP-9.

Por otra parte, la activación de ALK-I en las células endoteliales es inducida por acción de otros factores proangiogénicos tales como el VEGF y el b-FGF que son sobreexpresados por las mismas células neoplásicas, las células del estroma y las células mieloides que infiltran el tumor (Hu Lowe y col., 2011). Por lo tanto, la intervención de múltiples factores de crecimiento y sus receptores en la angiogénesis tumoral favorece la resistencia a las terapias oncológicas utilizadas en 
seres humanos puesto que las mismas involucran generalmente a un único blanco terapéutico, así como, anti-VEGF o anti-VEGFR desestimando el rol de otros factores de crecimiento sobre la angiogénesis tumoral (Hu Lowe y col., 2011). Akatsu y col., (2017) demostraron que la BMP-9 y BMP-10 junto al VEGF estimulan la angiogénesis tumoral en seres humanos. Además, destacaron la importancia de realizar nuevas terapias oncológicas involucrando ambos factores (BMP-9/BMP-10 y VEGF) como blancos terapéuticos (targeting dual), con el objetivo de producir un bloqueo más efectivo de la angiogénesis tumoral (Akatsu y col., 2017). En este contexto, es de destacar que no existen estudios previos acerca del rol de estas moléculas sobre la angiogénesis tumoral en los SOs de perros.

Asimismo, las alteraciones en la vía de señalización de las BMP están vinculadas con diferentes cuadros clínicos, que incluyen enfermedades vasculares, esqueléticas y cáncer en humanos (Miyazono y col., 2010; Katagiri y Watabe, 2016). Existe escasa información en relación con el rol de las BMPs en la patogenia de los tumores óseos. Sin embargo, la activación de la vía de señalización de las BMP fue relacionada con un peor pronóstico en pacientes humanos con OSA (Nguyen y col., 2014). Yoshikawa y col., $(1994,1988)$ hallaron que los pacientes humanos con OSA que presentaban activación en la vía de transducción de las BMP mostraron alta incidencia de metástasis, resistencia a la quimioterapia y tuvieron un corto tiempo de sobrevida. 
I.3.3. Rol de la ciclooxigenasa 2 en la carcinogénesis y el dolor asociado con los sarcomas óseos

La ciclooxigenasa $2(\mathrm{COX}-2)$ es una enzima involucrada en una variedad de funciones celulares importantes, que incluyen el crecimiento y la diferenciación celular, la angiogénesis y los mecanismos de tolerancia inmune durante la implantación de blastocistos (Xiong y col., 2003). Además, posee un rol significativo en la carcinogénesis (Fosslien, 2000; Sabino y col., 2002; Castells y col., 2007). Existen dos isoformas de la ciclooxigenasa, la COX-1 y la COX-2, ambas intervienen en la síntesis de prostaglandinas, prostaciclinas y tromboxanos. La primera isoforma contribuye con la síntesis de las prostaglandinas involucradas principalmente con la citoprotección gastrointestinal. La segunda es inducida en sitios de respuesta inflamatoria por diferentes citocinas, tales como el factor de necrosis tumoral alfa, la interleucina $1 \alpha$ y $\beta$, el lipopolisacárido bacteriano y por algunos factores de crecimiento que estimulan la síntesis de la COX-2 (Fosslien, 2000).

Diferentes estudios demostraron que, en ciertas neoplasias humanas, incluidos los sarcomas, las células tumorales sobreexpresan la COX-2, no así la COX-1 (Fosslien, 2000; Masferrer y col., 2000; Davar, 2001; Sabino y col., 2002; Castells y col., 2007). En este sentido, la sobreexpresión de la COX-2 en diferentes neoplasias fue vinculada con el proceso de transformación y progresión neoplásica y, además con la inducción del dolor en el cáncer (Fosslien, 2000; Castells y col., 2007). La expresión de esta isoforma es variable dentro del tejido tumoral y entre diferentes tipos de tumores (Fosslien, 2000). Además, la COX-2 favorece la neovascularización, un hecho fundamental para el crecimiento tumoral (Castells y 
col., 2007). Según Fosslien, (2000) durante este proceso, las nuevas células endoteliales sintetizaron COX-2 dentro del tumor, en cambio los vasos sanguíneos normales expresaron solo la COX-1 (Fosslien, 2000). De acuerdo con el estudio realizado por Castells y col., (2007), el uso de antiinflamatorios no esteroideos (AINEs) que inhiben específicamente la actividad de la COX-2, se asoció con una menor incidencia de neoplasias colorrectales, entre otras.

El dolor asociado con el cáncer óseo se relaciona con la reabsorción ósea (osteólisis) inducida por el propio tumor y con la liberación, a partir de las células inflamatorias o tumorales, de compuestos prostanoides tales como las prostaglandinas quienes promueven y mantienen el dolor provocado por este tipo de cáncer (Payne, 1997; Fosslien, 2000). Además, la osteólisis induce un aumento en el número y tamaño de los osteoclastos activados (Clohisy y col., 1996). Los animales que manifiestan dolor presentan un conjunto estereotipado de cambios neuroquímicos en la médula espinal que parecen reflejar la sensibilidad periférica y central de las vías involucradas en la generación y mantenimiento del dolor (Sabino y col., 2002). Según Sabino y col., (2002), la inhibición crónica de la COX-2 atenuó gran parte de estos cambios neuroquímicos y, por consiguiente, bloqueó el dolor. Además, el bloqueo de esta isoforma condujo a una reducción significativa de la proliferación e hipertrofia de los osteoclastos y a un descenso de la osteólisis (Sabino y col., 2002). De esta manera, los inhibidores selectivos de la COX-2 podrían ser utilizados para el tratamiento del dolor asociado con el cáncer por períodos extensos sin afectar el estado de homeostasis orgánica, dado que presentan un menor efecto perjudicial sobre el sistema gastrointestinal comparado con el uso de AINEs no selectivos (Sabino y col., 2002). Asimismo, los inhibidores selectivos de la COX-2 
disminuyen la proliferación celular y aumentan la apoptosis tanto en las células tumorales como en las células endoteliales, lo que potenciaría su efecto antiangiogénico.

\section{I.4. Hipótesis}

La expresión de moléculas vinculadas con el comportamiento biológico de los SOs en perros se relaciona con la localización anatómica, los subtipos histológicos y la gradación tumoral.

\section{I.5. Objetivos}

\section{I.5.1. Objetivo general}

Identificar los subtipos de SOs en perros, aplicar un sistema de gradación histológica y establecer su relación con los estudios inmunohistoquímicos.

\section{I.5.2. Objetivos específicos}

1) Clasificar los SOs en subtipos histológicos, sobre la base del sistema de clasificación actual de la OMS.

2) Evaluar características tales como el sexo, la edad, la raza y la localización anatómica de los SOs en perros.

3) Aplicar un sistema de gradación histológico sobre los SOs en perros. 
4) Evaluar la expresión de moléculas tales como: PCNA, VEGF, BMP-9 y COX-2 y establecer su relación con la localización anatómica, el subtipo histológico y la GT.

5) Contribuir en la identificación de moléculas que indiquen las propiedades biológicas particulares de la neoplasia, como su capacidad proliferativa y metastásica. 


\section{Materiales y Métodos}

\section{II.1. Criterios de selección de los casos}

Las muestras analizadas en el presente trabajo correspondieron a material obtenido de lesiones de perros e ingresado al Servicio de Anatomía Patológica, Laboratorio de Patología Especial Dr. Bernardo Epstein, Facultad de Ciencias Veterinarias, Universidad Nacional de La Plata, durante el período 2003-2013. Todas las muestras se encontraban incluidas en parafina luego de haber sido fijadas en formol al $10 \%$ tamponado. Las muestras se correspondían con casos diagnosticados oportunamente como SOs. Estas muestras habían sido fijadas con formol al $10 \%$ tamponado y descalcificadas con ácido etilendiaminotetraacético (EDTA) (Anexo II). Se habían procesado mediante técnicas de rutina, y coloreado mediante la técnica de Hematoxilina y Eosina (H-E) para su posterior diagnóstico anatomopatológico.

Se incluyeron sesenta y ocho casos con diagnóstico de sarcomas óseos en perros. Con el propósito de determinar que el material perteneciente a los casos de archivo reunía las condiciones para ser incluido en el trabajo, el diagnóstico anatomopatológico fue reevaluado y ratificado o rectificado según el caso.

Ante la necesidad de determinar la gradación de los SOs, se evaluaron los sesenta y ocho SOs y se descartaron aquellas muestras con escasas áreas tumorales, 
hemorragias masivas y extensas áreas de necrosis. Cincuenta y un casos resultaron adecuados para proseguir con el estudio de la gradación de los SOs.

Por otra parte, se realizó un estudio inmunohistoquímico a los sesenta y ocho SOs iniciales con el anticuerpo antivimentina para evaluar la integridad antigénica. Se seleccionaron cincuenta y seis casos para proseguir con el estudio inmunohistoquímico.

Asimismo, la cantidad de muestras examinadas para el análisis de las variables tales como raza, edad, sexo y localización anatómica fueron inconstante de acuerdo con los datos disponibles en cada caso.

\section{II.2. Estudio histológico}

Para el estudio histológico se realizaron cortes de $5 \mu \mathrm{m}$ de espesor. Para el análisis y clasificación de estos cortes, se consideró la última nómina propuesta por la Organización Mundial de la Salud (Slayter y col., 1994). Durante la observación microscópica se confirmó el diagnóstico anatomopatológico, se evaluaron el tipo de matriz producida por las células atípicas y los principales criterios de malignidad (pleomorfismo, índice mitótico y porcentaje de necrosis tumoral).

\section{II.2.1. Captura de imágenes}

Las imágenes correspondientes a los distintos cortes en estudio fueron capturadas mediante una cámara de video digital (Olympus DP71, Olympus, Japón) montada sobre un microscopio trinocular (Olympus BX50, Tokio, Japón) y conectada con 
una computadora. El programa informático utilizado para el análisis de imágenes digitales fue ImagePro Plus v6.3, Media Cybernetics, EE. UU.). Las imágenes fueron guardadas con formato TIFF, para conservar todos los detalles observados con el microscopio. Todos los datos obtenidos a partir del análisis fueron exportados a una planilla de cálculo (Microsoft ${ }^{\circledR}$ Excel para Office $^{\circledR} 365 \mathrm{MSO}$, versión 1910) para su posterior análisis estadístico.

\section{II.3. Estudio de la gradación tumoral}

En cada uno de los 51 casos analizados se evaluaron los criterios de malignidad utilizados para el sistema de GT propuesto por Loukopoulos y Robinson (2007), que considera tres parámetros histológicos: pleomorfismo nuclear, índice mitótico (cantidad de mitosis por 10 campos utilizando un objetivo con magnificación 40x) y porcentaje de necrosis. Para la determinación de la GT, los parámetros pleomorfismo nuclear y porcentaje de necrosis recibieron un puntaje que iba de 0 a 3, mientras índice mitótico fue de 1 a 4 (Tabla 2). De esta manera, se obtuvo una puntuación tumoral de 1 a 10 para cada SO, valor que luego fue convertido en grados I, II o III (Tabla 3).

Finalmente, estos valores fueron sumados para generar un grado entre I y III. Así, los valores en 1 y 5 se correspondieron con un grado I (GI), de 6 a 7 con un grado II (GII) y de 8 a 10 con un grado III (GIII). 
Tabla 2. Puntuación de los parámetros aplicados a los sarcomas óseos analizados (Modificado de Loukopoulos y Robinson, 2007)

\begin{tabular}{|c|c|c|c|c|c|c|c|c|c|c|c|}
\hline \multicolumn{4}{|c|}{ Pleomorfismo nuclear } & \multicolumn{4}{c|}{ Índice mitótico } & \multicolumn{3}{c|}{ Porcentaje de necrosis } \\
\hline Ausente & $\begin{array}{c}\text { Leve } \\
(<25 \%)\end{array}$ & $\begin{array}{c}\text { Moderado } \\
(15-50 \%)\end{array}$ & $\begin{array}{c}\text { Acentuado } \\
(>50 \%)\end{array}$ & 1 a 10 & 11 a 20 & 21 a 30 & $>30$ & Ausente $<15 \%$ & $15-50 \%$ & $>50 \%$ \\
\hline 0 & 1 & 2 & 3 & 1 & 2 & 3 & 4 & 0 & 1 & 2 & 3 \\
\hline
\end{tabular}

Tabla 3. Sistema de gradación tumoral (puntuación final a partir del pleomorfismo nuclear, índice mitótico y porcentaje de necrosis) (Modificado de Loukopoulos y Robinson, 2007)

\begin{tabular}{|c|c|c|c|}
\hline Puntuación histológica & 1 a 5 & 6 a 7 & 8 a 10 \\
\hline Grados & I & II & III \\
\hline
\end{tabular}

\section{II.4. Estudio inmunohistoquímico}

Los cortes para técnicas de IHQ fueron montados en portaobjetos con cargas positivas (Biotraza ${ }^{\circledR}$ HDAS001, China). Se seleccionaron, asimismo, bloques de órganos normales (riñón e intestino de perro) para ser incluidos como controles positivos de los diferentes anticuerpos. El control negativo del ensayo incluyó muestras procesadas de la misma manera excepto por la omisión del anticuerpo primario que fue reemplazado por una solución salina tamponada con fosfato (PBS: phosphate buffered saline).

Las secciones de cada muestra tumoral se incubaron en estufa a $60{ }^{\circ} \mathrm{C}$ durante 30 min para fundir la parafina. Luego, se sumergieron en gradaciones decrecientes de alcoholes para hidratarlos. Para bloquear la peroxidasa endógena, los portaobjetos se incubaron en $\mathrm{H}_{2} \mathrm{O}_{2}$ al $3 \%$ durante 30 min y se lavaron con agua destilada durante 
$5 \mathrm{~min}$, tres veces. Para la recuperación antigénica (Anexo III), los portaobjetos se colocaron en un recipiente con solución tamponada de citrato $\mathrm{pH}$ 6,0 (Anexo IV), y se realizó recuperación antigénica mediante horno de microondas. Los portaobjetos se dejaron enfriar durante 20 minutos en estufa a $25^{\circ} \mathrm{C}$, se lavaron dos veces con PBS (Anexo IV). Las secciones se incubaron en solución de bloqueo (albúmina sérica bovina y albúmina sérica caprina) a temperatura ambiente. Las secciones se incubaron con el anticuerpo primario en cámara húmeda a $4{ }^{\circ} \mathrm{C}$ durante la noche. Los anticuerpos primarios utilizados para este estudio fueron: anti-PCNA (monoclonal) para detectar núcleos de células en proliferación, anti-VEGFA (monoclonal) y anti-VEGFR-1 (policlonal) para identificar el factor de crecimiento del endotelio vascular A (VEGF-A) y el receptor 1 del mencionado factor (VEGFR-1), respectivamente. Además, se utilizó el anticuerpo primario antiBMP- 9 (policlonal) con el objetivo de identificar la proteína morfogénica ósea-9 (BMP-9). Conjuntamente, el anticuerpo anti-COX-2 (policlonal) fue utilizado para demostrar la presencia de ciclooxigenasa-2. Los detalles de clon, dilución y proveedor de cada anticuerpo se consignan en la tabla 4.

Tabla 4. Anticuerpos específicos empleados para el estudio inmunohistoquímico de los sarcomas óseos en caninos

\begin{tabular}{|c|c|c|c|}
\hline Anticuerpos & Clon/código & Dilución & Proveedor \\
\hline PCNA & PC10 & $1: 3000$ & Dako \\
\hline VEGF-A & 26503 & $1: 25$ & R\&D System \\
\hline VEGFR-1 & ab2350-500 & $1: 100$ & Abcam \\
\hline BMP-9 & sc-130703 & $1: 100$ & Santa Cruz Biotechnology \\
\hline COX-2 & aa584-598 & $1: 200$ & Cayman Chemical \\
\hline
\end{tabular}


Luego del lavado con PBS, las muestras fueron incubadas a $25^{\circ} \mathrm{C}$ durante $30 \mathrm{~min}$ con el anticuerpo secundario correspondiente. Para los anticuerpos primarios anti PCNA y anti-COX-2 se utilizó el EnVision ${ }^{\circledR}$ plus Kit (Dako, Carpinteria, CA, EE. UU.) basado en un polímero de dextrano marcado con peroxidasa de rábano picante (HRP) y conjugado con inmunoglobulinas anti-conejo y anti-ratón (Anexo V). Mediante este método, la enzima peroxidasa asociada al polímero actúa sobre el peróxido de hidrógeno $\left(\mathrm{H}_{2} \mathrm{O}_{2}\right)$, que se agrega junto con el sistema revelador. El producto de esta reacción, a su vez, reacciona con un dador de electrones (cromógeno) que, finalmente, genera la formación de un producto coloreado insoluble y agua. Para aquellos anticuerpos primarios como el anti VEGF-A, anti VEGFR-1 y BMP-9 se realizó la incubación con el anticuerpo secundario universal del Kit HRP CytoScan ${ }^{\circledR}$ Detection System (Sigmal Aldrich, Rocklin, CA, EE. UU.) (Anexo V).

Los portaobjetos se lavaron con PBS y se revelaron con 3',3'diaminobencidina (DAB peroxidase substrate Kit, SK-4100; Vector Laboratories, Burlingame, EE. UU.). La reacción se detuvo con agua corriente. La DAB se utilizó como cromógeno por su capacidad de interaccionar con el producto de esta reacción enzimática y generar un precipitado pardo en los sitios de unión de los anticuerpos con los antígenos de interés. Posteriormente, se realizó una coloración de contraste con hematoxilina de Gill para la coloración de los núcleos. Las regiones marcadas positivamente se evidenciaron con una coloración pardo-dorada oscura, producto de la oxidación de la DAB. Finalmente se deshidrataron en alcoholes de graduación creciente, xilol y se montaron con cubreobjetos. 


\section{II.5. Análisis cualitativos y cuantitativos de la inmunomarcación}

La evaluación cualitativa de los cortes procesados mediante IHQ consistió en la determinación de la presencia o ausencia de marcación y la descripción de su patrón de marcación (citoplasmático o nuclear). De acuerdo con el criterio explicitado previamente, se utilizaron 56 SOs para las pruebas IHQs con los cinco anticuerpos propuestos. En cada caso, se contó la cantidad de células positivas por campo de registro de la muestra tumoral en la imagen digital. El análisis se llevó a cabo en al menos siete imágenes por muestra, capturadas con un objetivo con magnificación 40x (1,0591 $\mathrm{mm}^{2} /$ imagen $)$. Los resultados del análisis cuantitativo de todas las moléculas se expresaron en porcentaje $(\%)=($ células positivas/total de células neoplásicas en el campo)*100. De esta manera, la inmunomarcación fue expresada sobre la base de una puntuación de distribución definida entre los valores 0 y 4 (Tabla 5).

\begin{tabular}{|c|c|}
\hline \multicolumn{2}{|c|}{ Tabla 5. Puntuación de la inmunomarcación de los sarcomas } \\
óseos según el porcentaje de células positivas \\
\hline menos del $10 \%$ & 0 \\
entre el 10 y el $25 \%$ & 1 \\
entre el 25 y el $50 \%$ & 2 \\
entre el 50 y el $75 \%$ & 3 \\
entre el 75 y el $100 \%$ & 4 \\
\hline
\end{tabular}




\section{II.6. Análisis estadístico}

Los resultados obtenidos a partir de la técnica de inmunohistoquímica fueron analizados mediante ANOVA y prueba $\mathrm{t}$ de Student (sujeto al $n$ muestral de cada grupo) con el fin de establecer diferencias en la expresión de las proteínas estudiadas entre los SOs analizados. La comparación múltiple, para establecer las diferencias entre las medias de cada grupo, fue evaluada mediante la prueba posthoc de Tuckey. Por otro lado, se utilizó el análisis mediante tablas de contingencia (test de $\chi^{2}$ ) para registrar y analizar la asociación entre dos o más variables (raza, edad, sexo, localización anatómica, gradación tumoral y la expresión inmunohistoquímica de moléculas tales como PCNA, VEGF, BMP-9 y COX-2).

Aquellos grupos que contenían una cantidad de muestras menor o igual a $2(n \leq 2)$, no fueron considerados para el análisis estadístico.

Finalmente, en aquellos grupos de muestras que no cumplían con la distribución Gaussiana y la homogeneidad de varianzas, se utilizaron las pruebas de KruskalWallis y de Mann-Whitney. El nivel de significación $(\alpha)$ considerado para todos los análisis fue de $\mathrm{P}<0,05$. 


\section{Resultados}

\section{III.1. Aspectos de la reseña. Estudio histológico}

Los subtipos histológicos diagnosticados a partir de la evaluación histológica de los SOs fueron los siguientes: OSA, condrosarcoma, tumor de células gigantes y fibrosarcoma (Figs. 7 a 13, Fig. 14, Fig. 15 y Fig. 16, respectivamente). Dentro del grupo de OSAs se encontraron los siguientes subtipos histológicos: OSA osteoblástico productivo (Fig. 7), OSA tipo células gigantes (Fig. 8), OSA condroblástico (Fig. 9), OSA fibroblástico (Fig. 10), OSA osteoblástico moderadamente productivo (Fig. 11), OSA teleangiectásico (Fig. 12) y el OSA periosteal (Fig. 13). Los OSAs fueron más frecuentes con respecto al total de los SOs analizados, y representó el 87 \% de las neoplasias analizadas (59/68), seguido por el condrosarcoma $9 \%(6 / 68)$. El $4 \%$ restante lo constituyeron dos tumores de células gigantes y un fibrosarcoma (Fig. 17 A). Entre los OSAs, el osteoblástico productivo fue el de presentación más frecuente y representó el $53 \%(31 / 59)$, seguido por el OSA tipo células gigantes $20 \%(12 / 59)$, el OSA condroblástico 15 $\%$ (9/59), el OSA fibroblástico $3 \%$ (2/59), el OSA osteoblástico moderadamente productivo $3 \%(2 / 59)$, el OSA teleangiectásico $3 \%(2 / 59)$ y el OSA perióstico 2 $\%(1 / 59)$ (Fig. 17 B). 

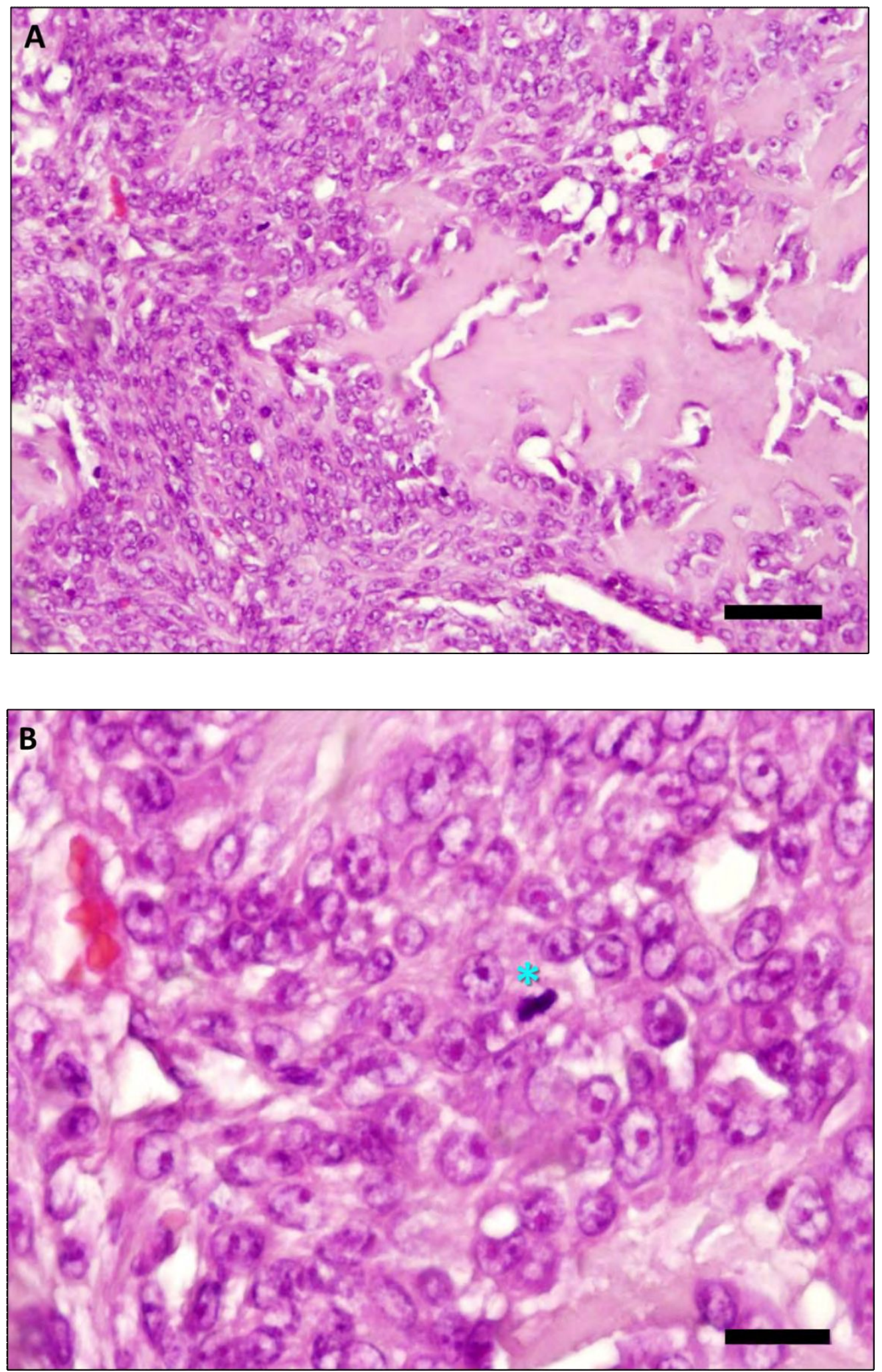

Figura 7. (A) Osteosarcoma osteoblástico productivo. Islas irregulares de matriz osteoide rodeadas por osteoblastos neoplásicos, H-E. (B) Osteosarcoma osteoblástico productivo, mayor detalle celular de la figura 7 A. Células ovaladas con macrocariosis, anisocariosis y nucléolos evidentes con diferente forma y tamaño. Figura mitótica (*), H-E. La barra de escala representa $50 \mu \mathrm{m}$ (A) y $20 \mu \mathrm{m}$ (B). 

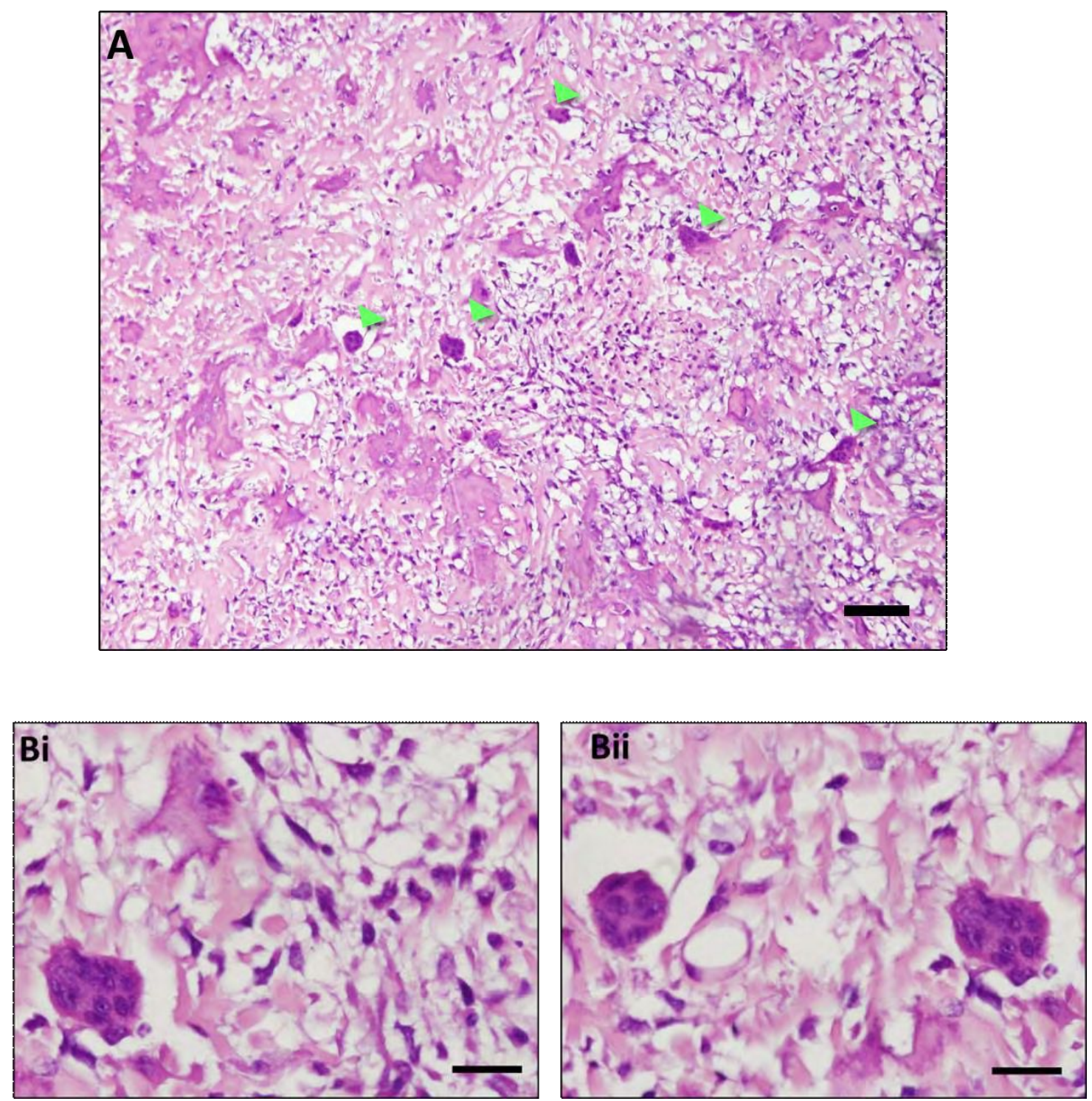

Figura 8. (A) Osteosarcoma tipo células gigantes. Abundantes células gigantes $(\triangle)$ con características de osteoclastos dispersas entre los osteoblastos malignos. Presencia de islas irregulares de matriz osteoide, H-E. (Bi/Bii) Mayor detalle de la figura $8 \mathrm{~A}$, células gigantes con múltiples núcleos con anisocariosis, H-E. La barra de escala representa $50 \mu \mathrm{m}$ (A) y $20 \mu \mathrm{m}$ (Bi y Bii). 

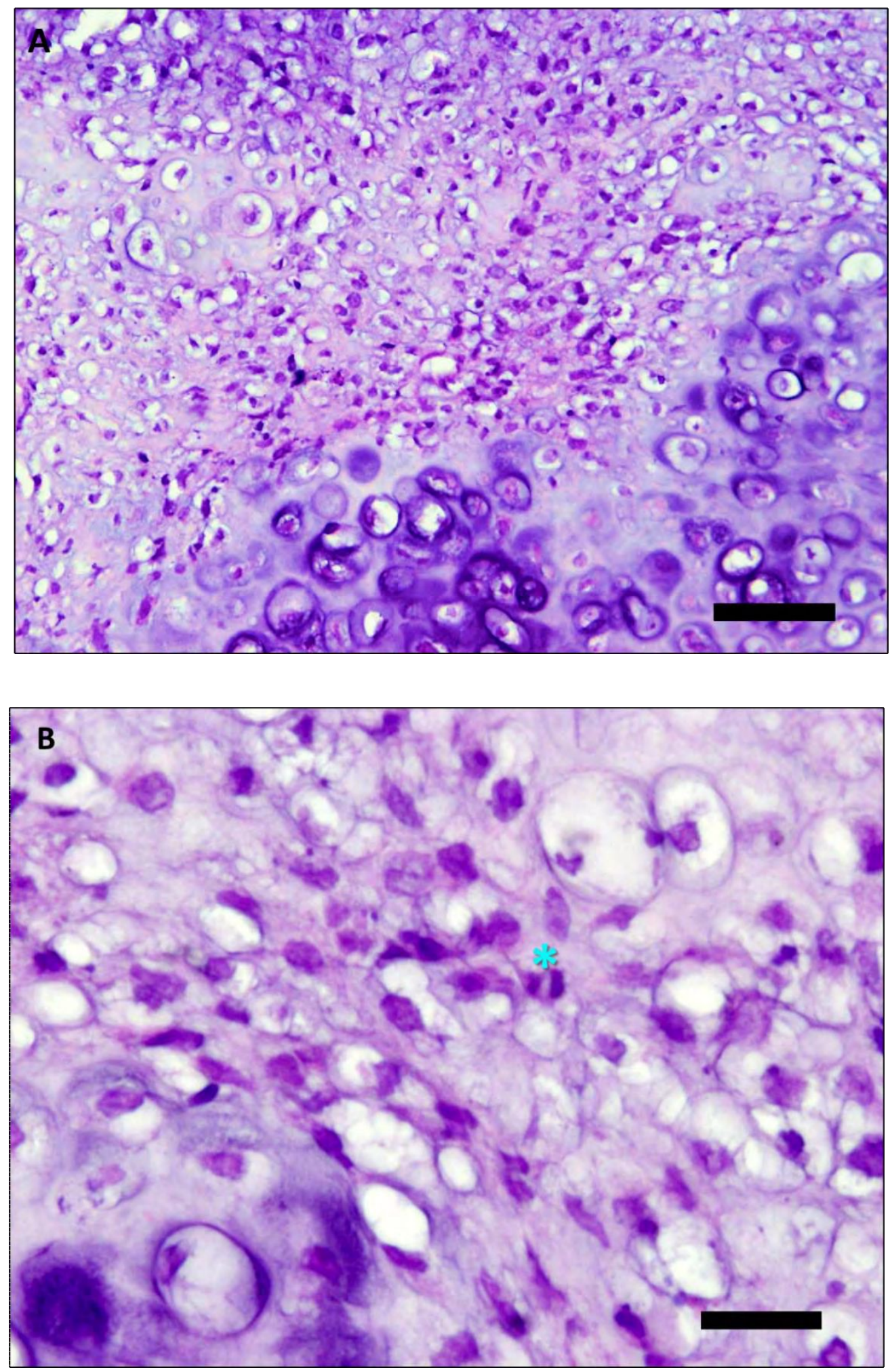

Figura 9. (A) Osteosarcoma condroblástico. Células neoplásicas rodeadas por abundante matriz condroide y escasa matriz osteoide, H-E. (B) Mayor detalle celular de la figura 9 A. Células neoplásicas con macrocariosis y anisocariosis. Figura mitótica $(*), \mathrm{H}-\mathrm{E}$. La barra de escala representa $50 \mu \mathrm{m}(\mathrm{A})$ y $20 \mu \mathrm{m}$ (B). 

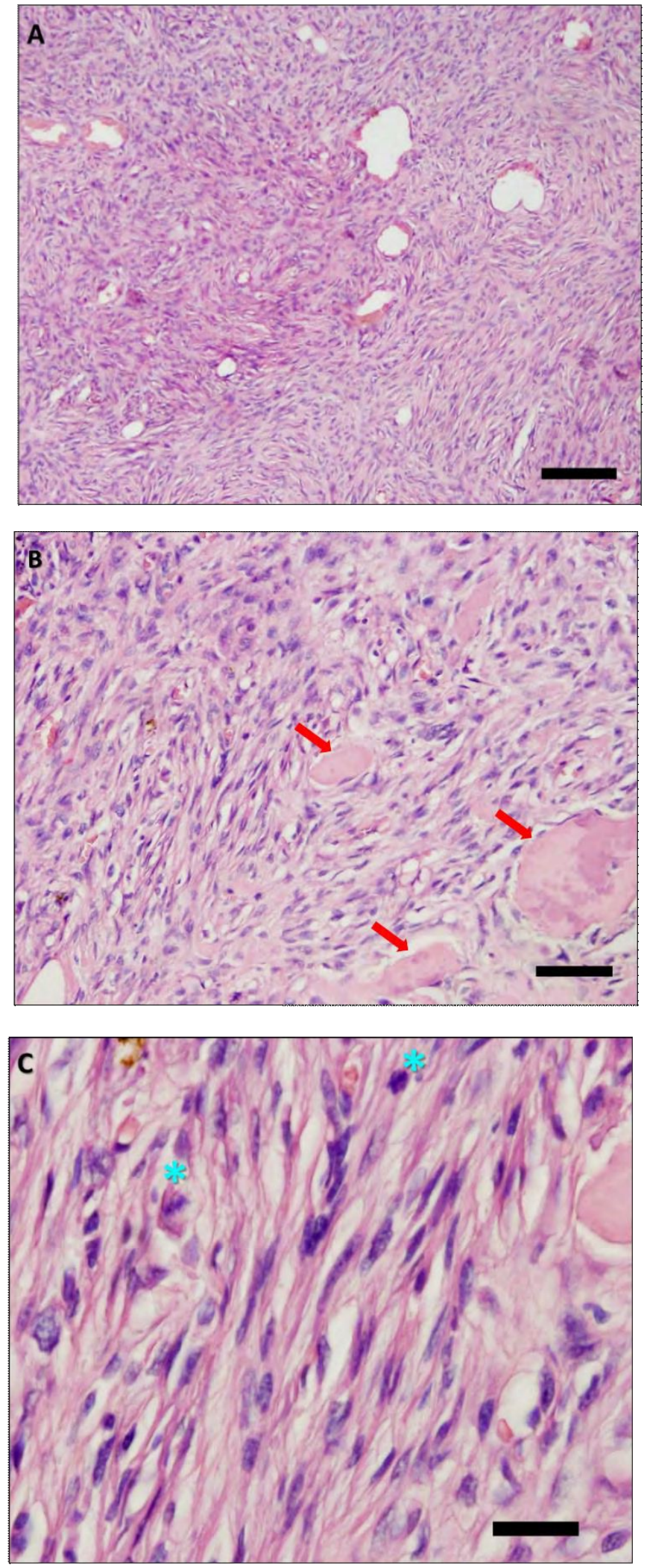

Figura 10. (A) Osteosarcoma fibroblástico. Población de células fusiformes con patrón arremolinado, H-E. (B) Osteosarcoma fibroblástico. Mayor detalle de la figura $10 \mathrm{~A}$, presencia de matriz osteoide $(\longrightarrow$, H-E. (C) Mayor detalle celular de la figura $10 \mathrm{~B}$, marcado pleomorfismo nuclear, núcleos hipercromáticos y figuras mitóticas $\left({ }^{*}\right)$, H-E. La barra de escala representa $100 \mu \mathrm{m}$ (A), $50 \mu \mathrm{m}$ (B) y $20 \mu \mathrm{m}$ (C). 

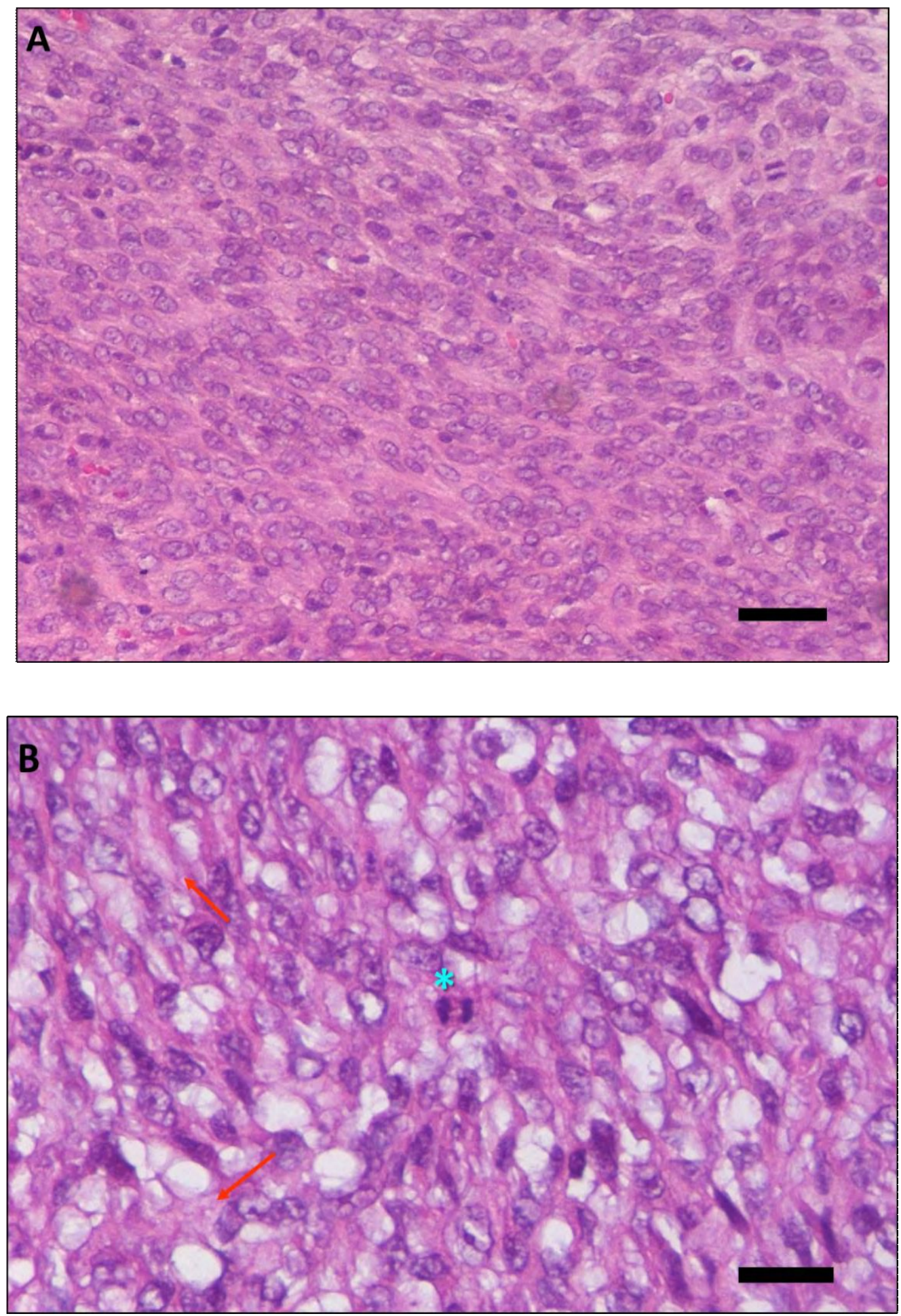

Figura 11. (A) Osteosarcoma osteoblástico moderadamente productivo, rico en células neoplásicas y pobre en matriz osteoide, H-E. (B) Osteosarcoma osteoblástico moderadamente productivo, mayor detalle celular de la figura $11 \mathrm{~A}$. Comprende láminas de osteoblastos neoplásicos ovales a fusiformes con macrocariosis, anisocariosis y nucléolos evidentes. Hebras ocasionales de matriz eosinofílica $(\rightarrow)$, que podrían corresponder a haces de colágeno o matriz osteoide. Figura mitótica $\left({ }^{*}\right)$, H-E. La barra de escala representa $50 \mu \mathrm{m}$ (A) y $20 \mu \mathrm{m}$ (B). 

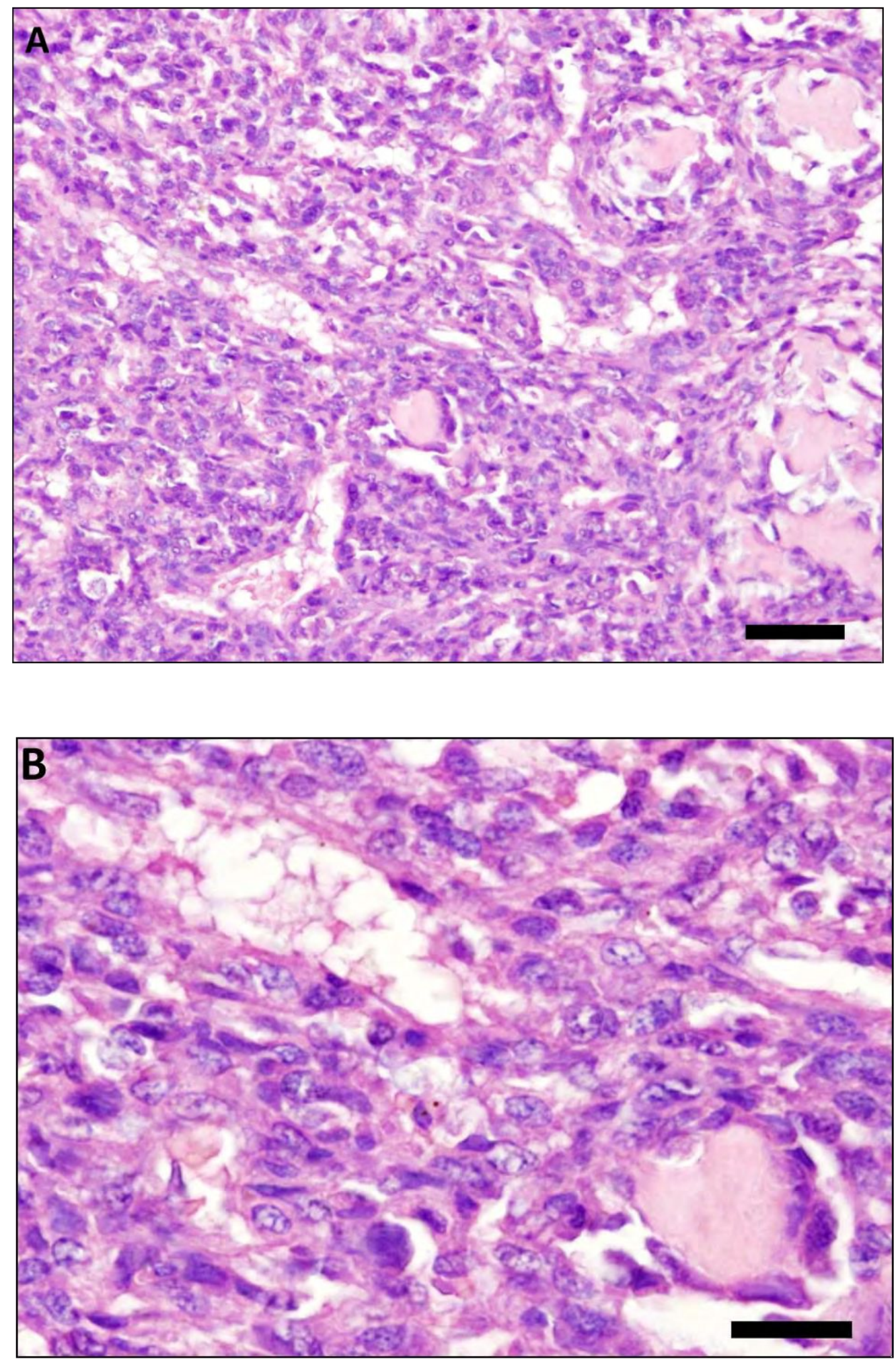

Figura 12. (A) Osteosarcoma teleangiectásico. Presencia de vasos sanguíneos separados por trabéculas compuestas por células neoplásicas y escasas espículas óseas, H-E. (B) Mayor detalle de la figura $12 \mathrm{~A}$, células con atipia nuclear. Múltiples nucléolos evidentes con diferente forma y tamaño, H-E. La barra de escala representa $50 \mu \mathrm{m}$ (A) y $20 \mu \mathrm{m}$ (B). 

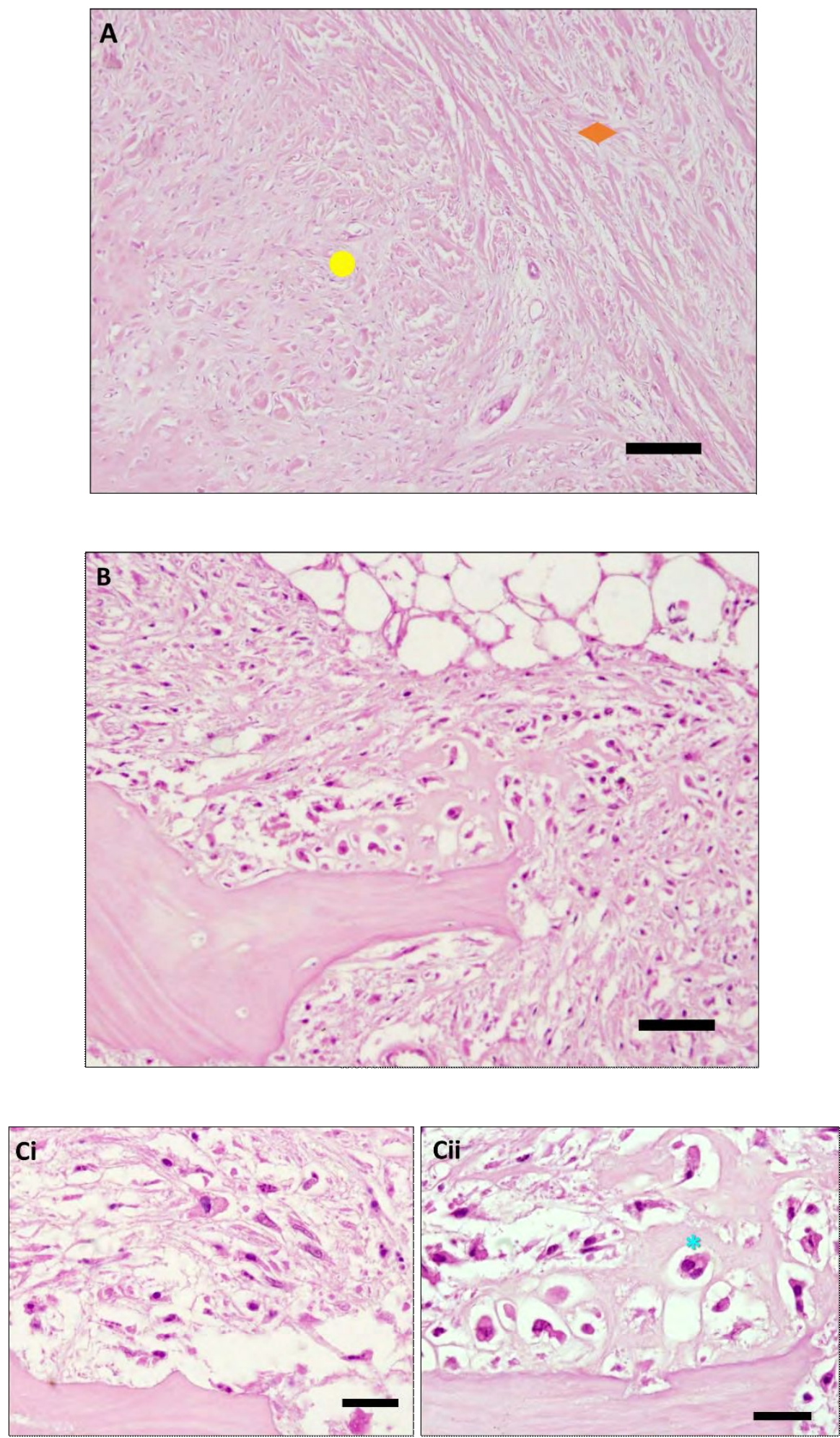

Figura 13. (A) Osteosarcoma periosteal. Periostio $(\Leftrightarrow)$ y tejido neoplásico $($ ), H-E. (B) Osteosarcoma periosteal. Presencia de abundantes células neoplásicas con marcado pleomorfismo, H-E. (Ci/Cii) Mayor detalle de la figura $13 \mathrm{~B}$, células neoplásicas con macrocariosis y anisocariosis. Figura mitótica (*), H-E. La barra de escala representa $100 \mu \mathrm{m}$ (A), $50 \mu \mathrm{m}$ (B) y $20 \mu \mathrm{m}$ (C). 

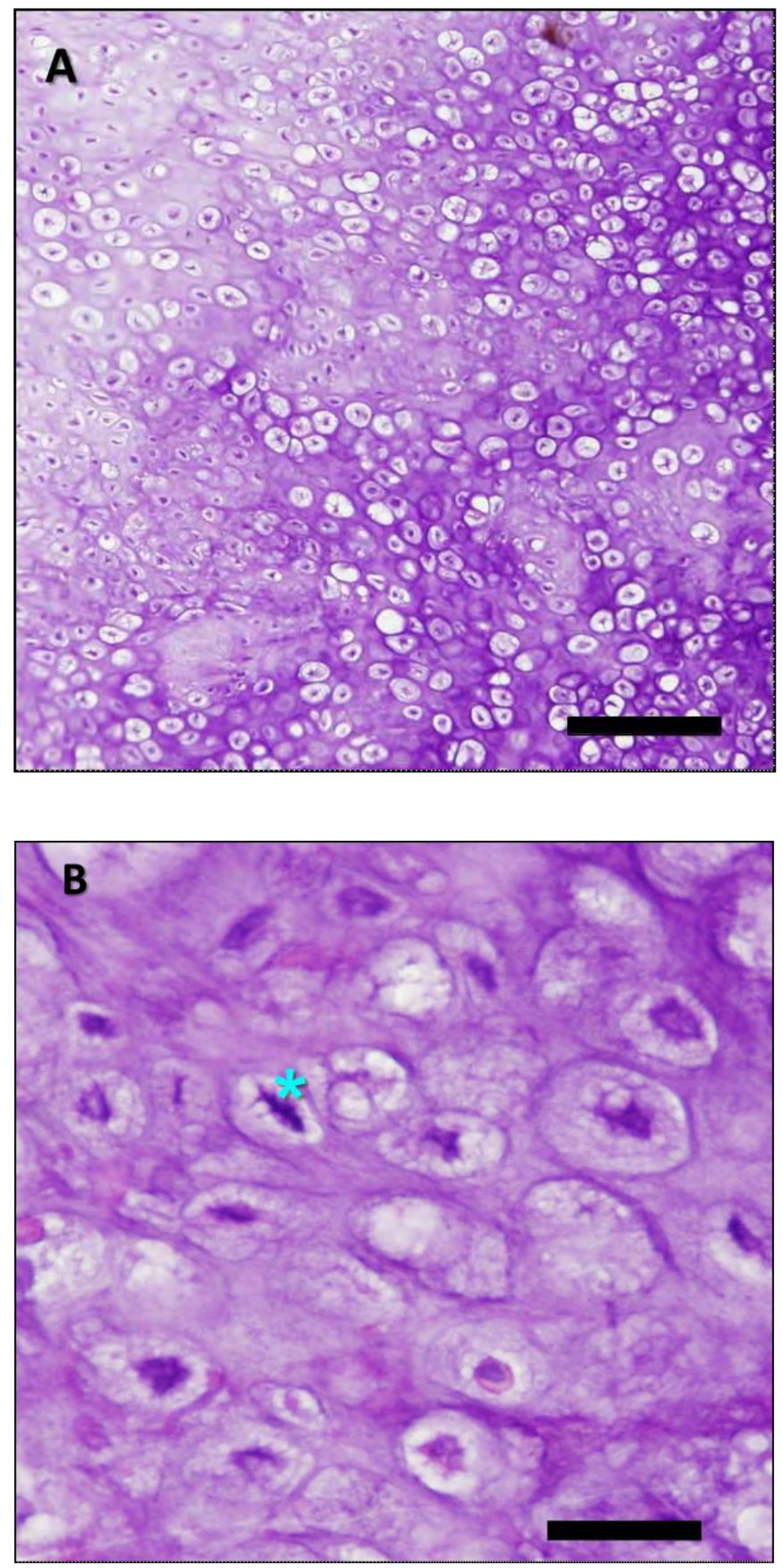

Figura 14. (A) Condrosarcoma. Células neoplásicas con marcado pleomorfismo y núcleos hipercromáticos. Matriz basófila rodeando a estas células, H-E. (B) Mayor detalle de la figura 14 A, se observa basofilia citoplasmática heterogénea, pleomorfismo nuclear, nucléolos prominentes y figura mitótica (*), H-E. La barra de escala representa $50 \mu \mathrm{m}$ (A) y $20 \mu \mathrm{m}$ (B). 

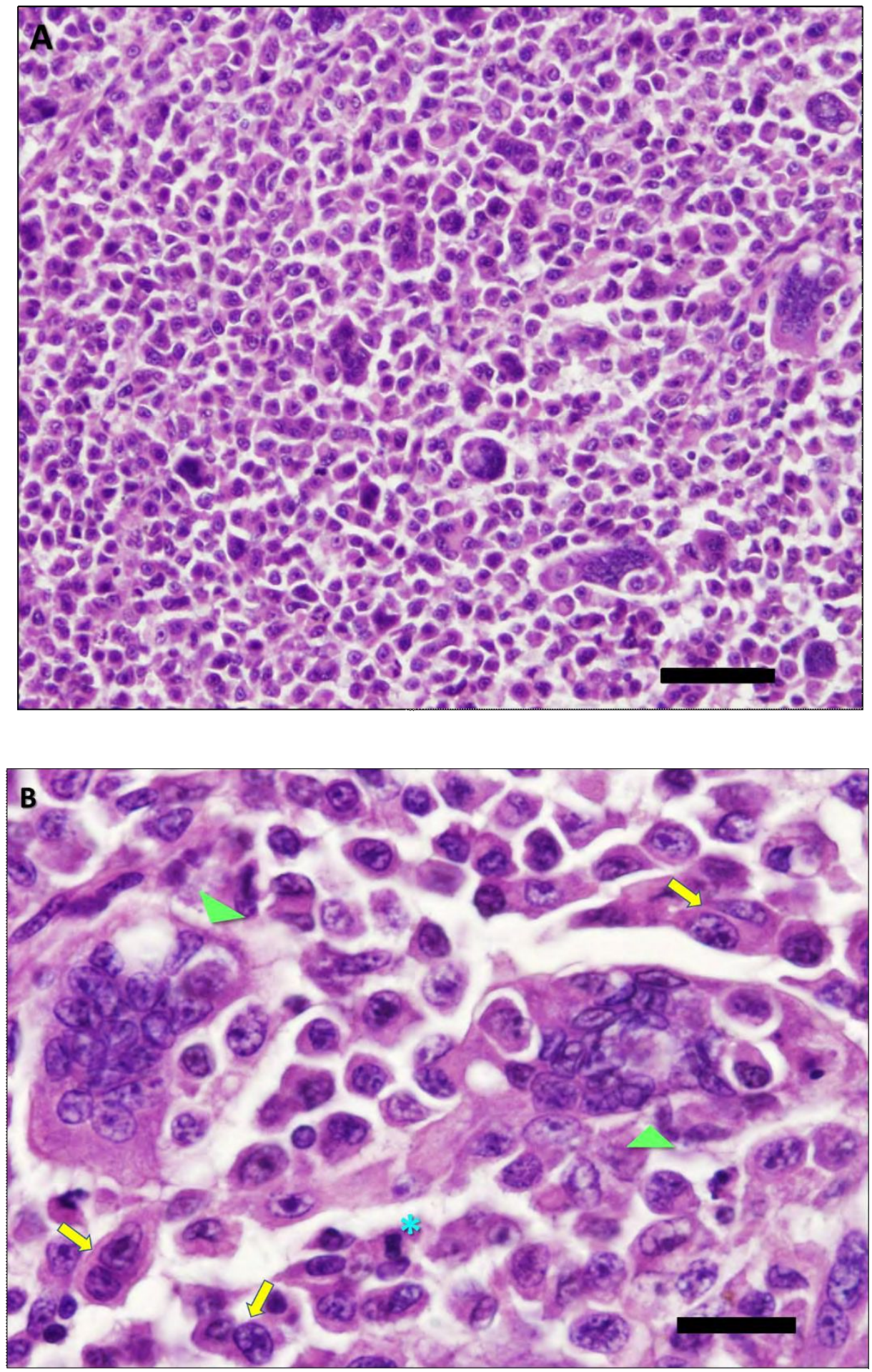

Figura 15. (A) Tumor de células gigantes. Abundante cantidad de células gigantes y células osteoblásticas malignas, H-E. (B) Mayor detalle celular de la figura 15 A: células gigantes con múltiples núcleos y dos o más nucléolos evidentes con diferente forma y tamaño ( Osteoblastos binucleados con anisocariosis $(\Longrightarrow$ ). Presencia de figura mitótica $(*)$, H-E. La barra de escala representa $50 \mu \mathrm{m}(\mathrm{A})$ y $20 \mu \mathrm{m}(\mathrm{B})$. 


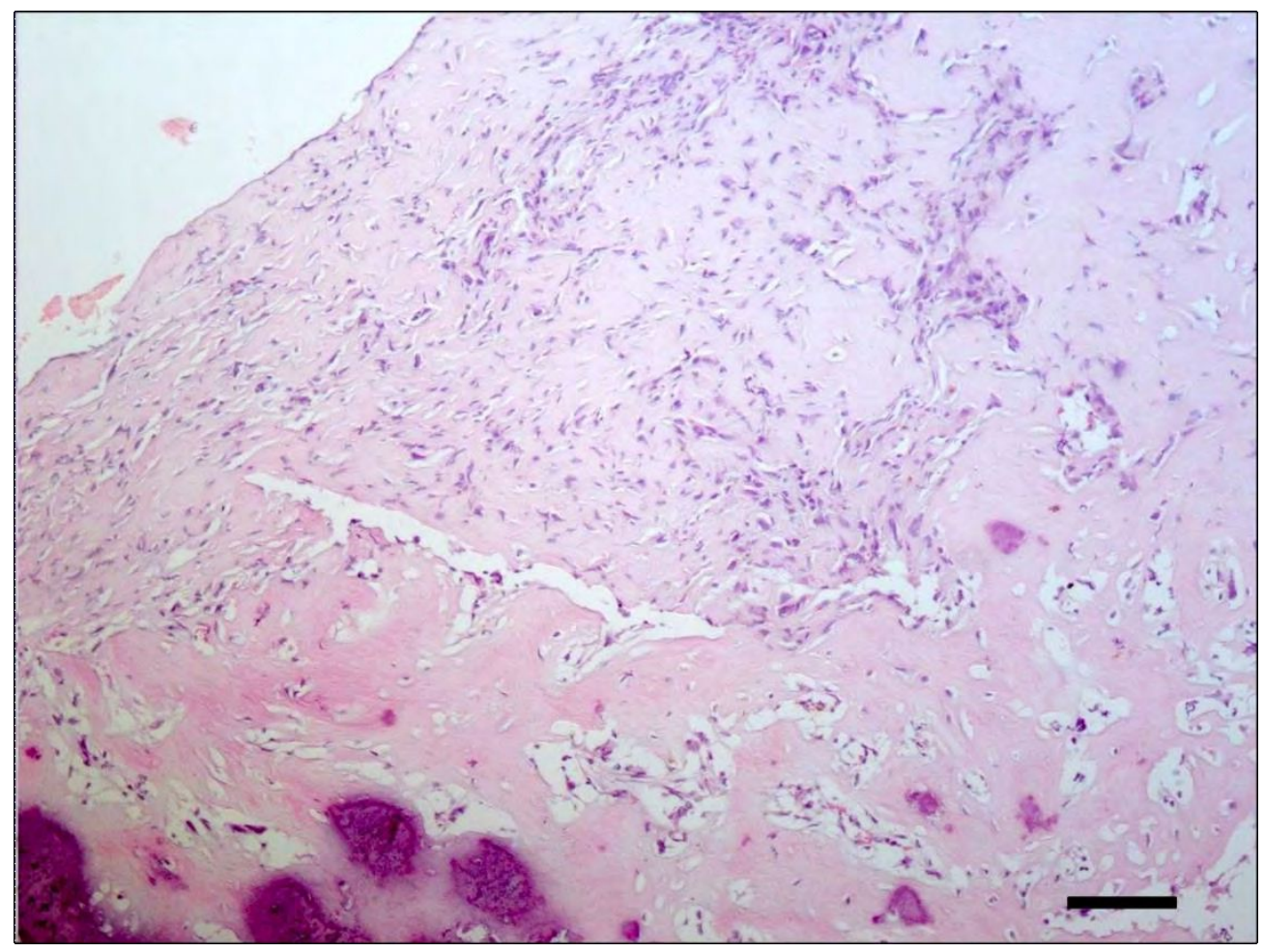

Figura 16. Fibrosarcoma, paquetes entrelazados de tejido conectivo con un patrón característico de células fusiformes y una variada cantidad de colágeno, H-E. La barra de escala representa $100 \mu \mathrm{m}$. 

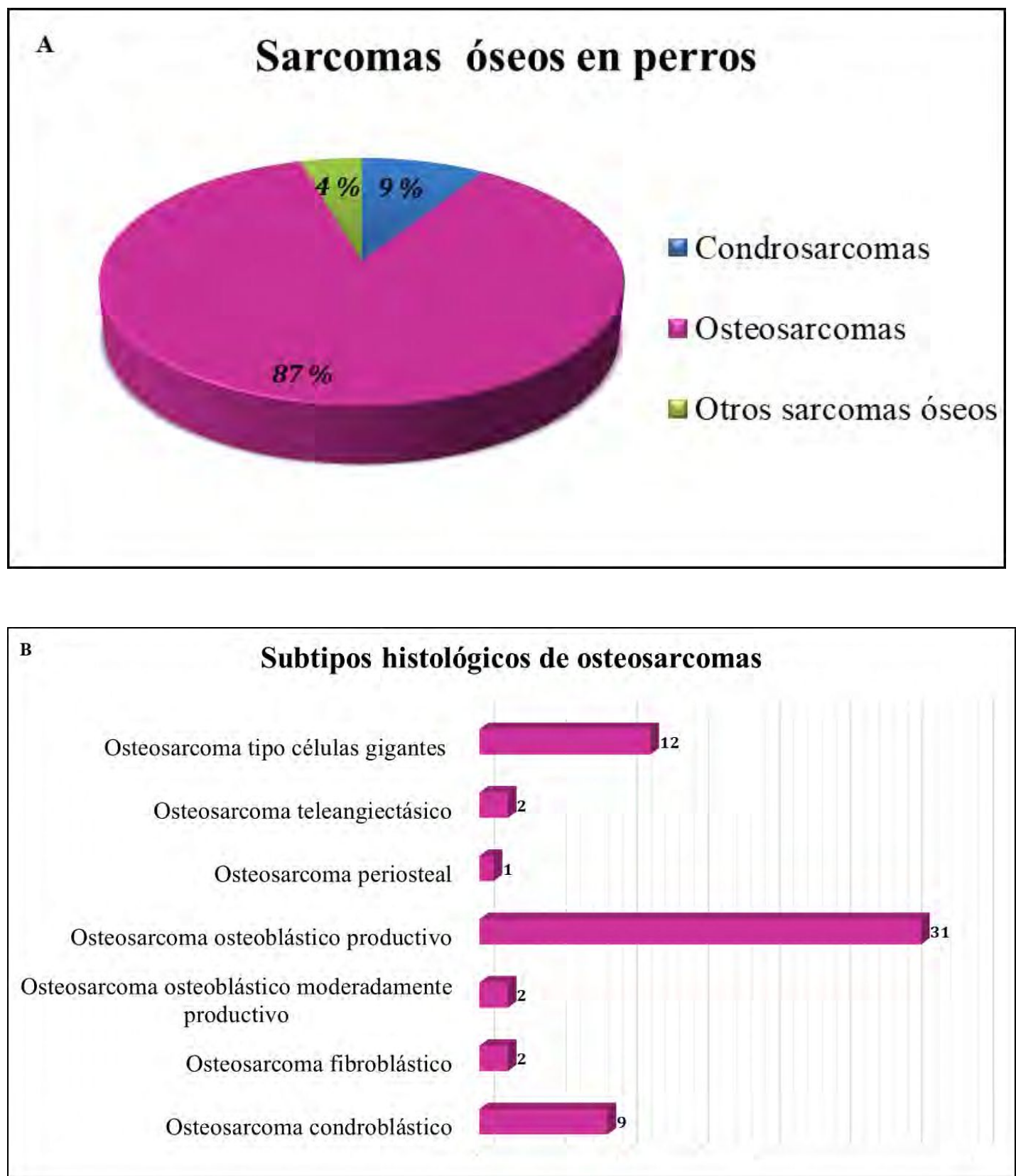

Figura 17. A. Sarcomas óseos en perros: distribución de los subtipos histológicos. Valores expresados en porcentaje (\%) B. Osteosarcomas en perros: frecuencia de los subtipos histológicos, los valores fueron expresados como números enteros. 
La localización apendicular de los SOs fue más frecuente que la localización axial. Entre los SOs, el osteosarcoma tuvo una mayor frecuencia en la localización apendicular 78,95\% (45/57) mientras que en la localización axial fue del 21,05 \% (12/57). Para el condrosarcoma, la frecuencia fue del $50 \%$ para cada localización (3/6). El tumor de células gigantes se presentó con una frecuencia del $100 \%$ para la localización apendicular. La localización del fibrosarcoma fue apendicular (Fig. 18; Tabla 6). De acuerdo con el análisis estadístico realizado (prueba de $\chi^{2}$ ), no se encontró asociación entre los subtipos de SOs y la localización anatómica $\left(\mathrm{F}_{(0,05,3)}\right.$ $=3,51 ; \mathrm{P}>0,05)($ Tabla 6$)$. En la tabla 6 se expresa la frecuencia de los subtipos de SOs con sus respectivos porcentajes, con respecto a la localización anatómica. La cantidad total de SOs analizados para estas dos variables fue 66, ya que en dos casos no fue especificado el sitio anatómico.

Tabla 6. Frecuencia de los sarcomas óseos con respecto a la localización anatómica

\begin{tabular}{|c|c|c|c|c|c|}
\hline Sitio anatómico & Osteosarcoma & Condrosarcoma & Tumor de células gigantes & Fibrosarcoma & $\mathrm{T}$ \\
\hline Localización apendicular & $45(78,95 \%)$ & $3(50 \%)$ & $2(100 \%)$ & $1(100 \%)$ & 51 \\
\hline Localización axial & $12(21,05 \%)$ & $3(50 \%)$ & & & 15 \\
\hline $\mathrm{T}$ & 57 & 6 & 2 & 1 & 66 \\
\hline & & & & $\begin{array}{l}\mathrm{F}= \\
\mathrm{Fc}(0.053)=\end{array}$ & $\begin{array}{l}3,51 \\
7,81\end{array}$ \\
\hline
\end{tabular}

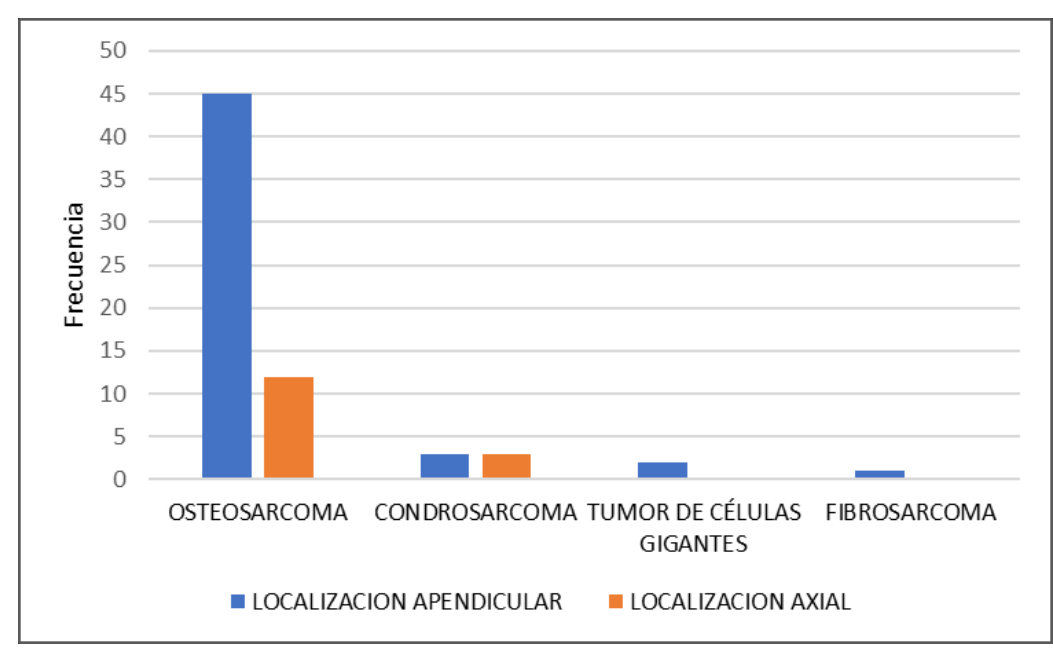

Figura 18. Distribución de los sarcomas óseos según la localización anatómica. 
La edad de presentación de los SOs estuvo entre los 7 y 11 años, con una edad promedio de 8 años. El OSA se presentó con mayor frecuencia entre los 8 y 9 años (21,05 \%-12/57 y 22,8\%-13/57, respectivamente), seguido por el condrosarcoma, con una alta frecuencia entre los 8 y 10 años $(3,33 \%-2 / 6)$. La mayor frecuencia de presentación para el tumor de células gigantes fue entre los 2 y 6 años $(50 \%-1 / 2)$ y el fibrosarcoma se desarrolló en un animal de 12 años (Fig. 19). Los resultados del análisis estadístico entre los subtipos histológicos y la edad de presentación revelaron que existe una fuerte asociación entre ambas variables $\left(\mathrm{F}_{(0,05,33)}=\right.$ $\left.77,83^{* *} ; \mathrm{P}<0,05\right)$. En la tabla 7 se expresa la frecuencia de los subtipos de SOs con sus respectivos porcentajes, con respecto a la edad de los perros. La cantidad total de SOs analizados fue de 66, ya que en dos casos no fue especificada la edad. 
Tabla 7. Frecuencia de los sarcomas óseos con respecto a la edad

\begin{tabular}{|c|c|c|c|c|c|}
\hline Edad & Osteosarcoma & Condrosarcoma & Tumor de células gigantes & Fibrosarcoma & $\mathrm{T}$ \\
\hline 1 & $1(1,75 \%)$ & & & & 1 \\
\hline 2 & & & $1(50 \%)$ & & 1 \\
\hline 5 & $4(7,01 \%)$ & & & & 4 \\
\hline 6 & $4(7,01 \%)$ & & $1(50 \%)$ & & 5 \\
\hline 7 & $9(15,79 \%)$ & & & & 9 \\
\hline 8 & $12(21,05 \%)$ & $2(33,33 \%)$ & & & 14 \\
\hline 9 & $13(22,80 \%)$ & & & & 13 \\
\hline 10 & $9(15,79 \%)$ & $2(33,33 \%)$ & & & 11 \\
\hline 11 & $2(3,50 \%)$ & & & & 2 \\
\hline 12 & $1(1,75 \%)$ & $1(16,66 \%)$ & & $1(100 \%)$ & 3 \\
\hline 13 & $2(3,50 \%)$ & & & & 2 \\
\hline 15 & & $1(16,66 \%)$ & & & 1 \\
\hline $\mathrm{T}$ & 57 & 6 & 2 & 1 & 66 \\
\hline ore. & 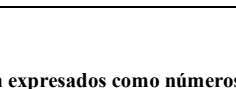 & & & $\begin{array}{l}\mathrm{F}= \\
\mathrm{Fc}(0,05,33)=\end{array}$ & $\begin{array}{l}77,83 \text { ** } \\
47,40 \\
\end{array}$ \\
\hline
\end{tabular}

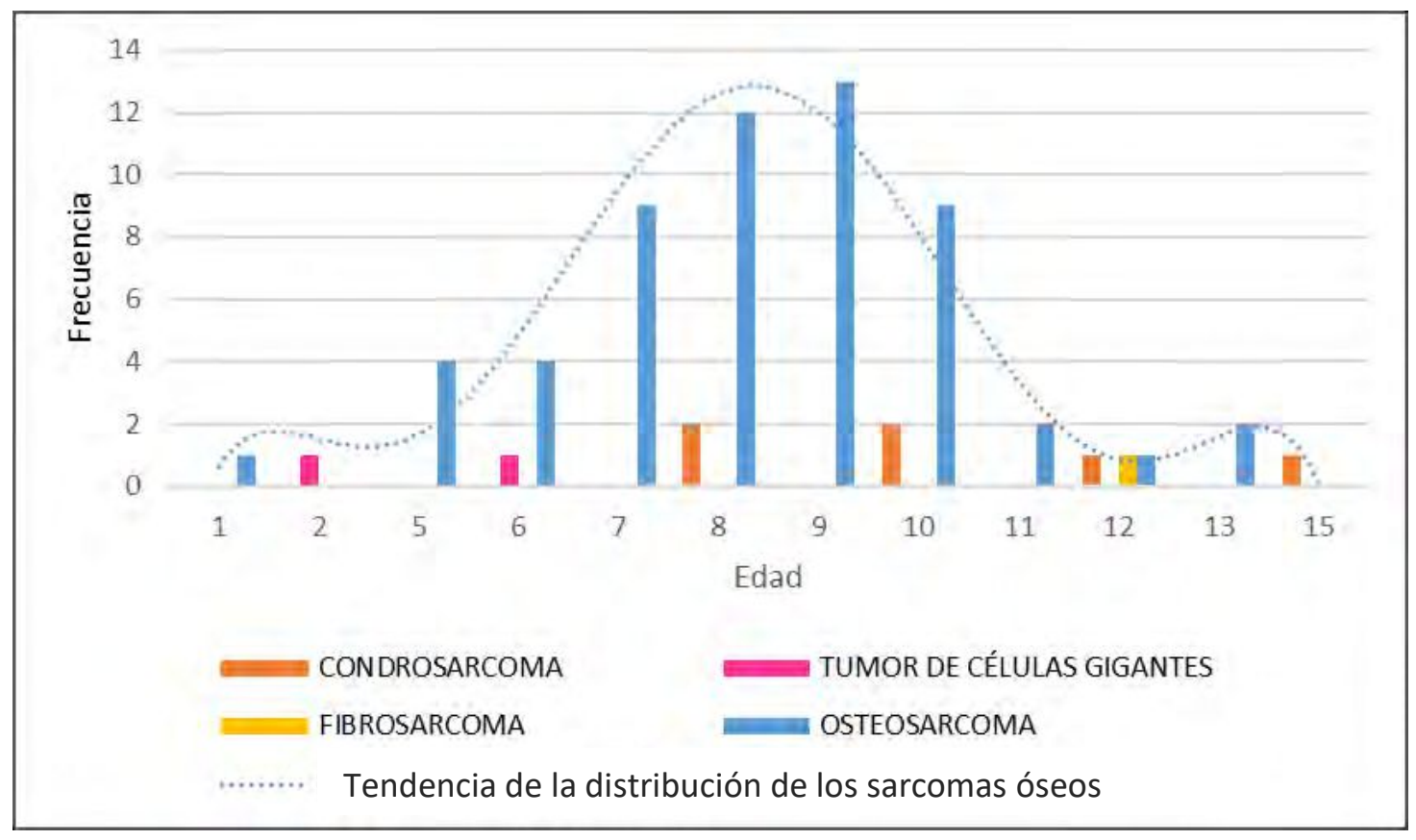

Figura 19. Distribución de los sarcomas óseos según la edad. 
Con referencia al sexo, la frecuencia de SOs fue mayor en los machos con respecto a las hembras: en los primeros representaron el 53,85\% (35/65), mientras que en las hembras fue del 46,16\% (30/65). Principalmente, el OSA se presentó más en los machos con una frecuencia de 57,89\% (33/57), mientras que en las hembras la frecuencia fue de $42,10 \%(24 / 57)$. En cambio, en el condrosarcoma la frecuencia fue mayor en las hembras con respecto a los machos, $60 \%(3 / 5)$ y $40 \%(2 / 5)$, respectivamente (Fig. 20). El tumor de células gigantes y el fibrosarcoma se presentaron en hembras. Los resultados del análisis estadístico demostraron que no existe asociación entre los subtipos histológicos de $\mathrm{SOs}$ y el sexo $\left(\mathrm{F}_{(0,05,33)}=4,26\right.$; $\mathrm{P}>0,05)$. La cantidad total de SOs analizados para estas dos variables fue de 65 , ya que en tres casos no fue especificado el sexo. En la tabla 8 se expresa la frecuencia de los subtipos de SOs con sus respectivos porcentajes, con respecto al sexo.

Tabla 8. Frecuencia de los sarcomas óseos con respecto al sexo

\begin{tabular}{|c|c|c|c|c|c|}
\hline Sexo & Osteosarcoma & Condrosarcoma & Tumor de células gigantes & Fibrosarcoma & $\mathrm{T}$ \\
\hline Macho & $33(57,89 \%)$ & $2(40 \%)$ & & & 35 \\
\hline Hembra & $24(42,10 \%)$ & $3(60 \%)$ & $2(100 \%)$ & $1(100 \%)$ & 30 \\
\hline $\mathrm{T}$ & 57 & 5 & 2 & 1 & 65 \\
\hline valores están & sados como números & teros y porcentaje (\%). T, & & $\begin{array}{l}\mathrm{F}= \\
\mathrm{Fc}(0,05,3)=\end{array}$ & $\begin{array}{l}4,26 \\
7,81 \\
\end{array}$ \\
\hline
\end{tabular}

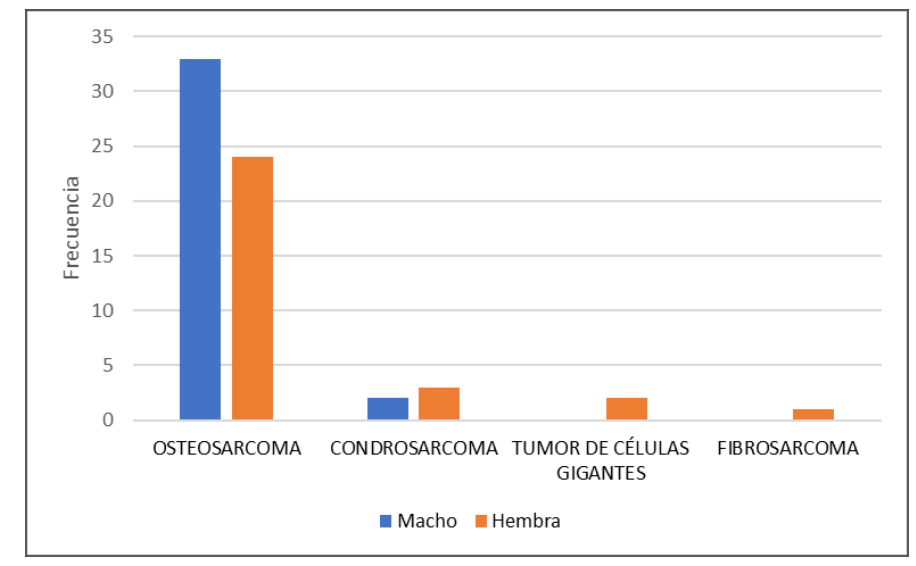

Figura 20. Distribución de los sarcomas óseos según el sexo. 
En cuanto a las razas de perros la frecuencia de SOs fue mayor en el rottweiler. También se presentó una mayor frecuencia en los mestizos. Se observó que en los casos analizados el OSA se presentó con mayor frecuencia en las razas rottweiler (31,58 \%-18/57), ovejero alemán (10,52\%-6/57), dóberman y gran danés $(5,26 \%$ 3/57). Los mestizos tuvieron una frecuencia de 22,80 \% (13/57). El condrosarcoma tuvo una frecuencia de $83,33 \%(5 / 6)$ para los mestizos y $16,66 \%(1 / 6)$ en el rottweiler. Para el tumor de células gigantes se presentó uno en mestizos y uno en rottweiler. El único caso de fibrosarcoma se encontró en un mestizo (Fig. 21). Los resultados del análisis estadístico demostraron que no existe asociación entre los subtipos histológicos de SOs y la raza $\left(\mathrm{F}_{(0,05,54)}=13,54 ; \mathrm{P}>0,05\right)$. En la tabla 9 se expresa la frecuencia de los subtipos de SOs con sus respectivos porcentajes, con respecto a la raza. La cantidad total de SOs analizados para estas dos variables fue de 66 , ya que en dos casos no fue especificada la raza. 
Tabla 9. Frecuencia de los sarcomas óseos con respecto a la raza (se incluyen mestizos).

\begin{tabular}{|c|c|c|c|c|c|}
\hline Razas y mestizo & Osteosarcoma & Condrosarcoma & Tumor de células gigantes & Fibrosarcoma & $\mathrm{T}$ \\
\hline airedale terrier & $1(1,75 \%)$ & & & & 1 \\
\hline bóxer & $1(1,75 \%)$ & & & & 1 \\
\hline bretón español & $1(1,75 \%)$ & & & & 1 \\
\hline bull terrier & $1(1,75 \%)$ & & & & 1 \\
\hline cocker español & $1(1,75 \%)$ & & & & 1 \\
\hline doberman & $3(5,26 \%)$ & & & & 3 \\
\hline galgo & $1(1,75 \%)$ & & & & 1 \\
\hline gran danés & $3(5,26 \%)$ & & & & 3 \\
\hline Labrador & $1(1,75 \%)$ & & & & 1 \\
\hline mastin napolitano & $1(1,75 \%)$ & & & & 1 \\
\hline mestizo & $13(22,80 \%)$ & $5(83,33 \%)$ & $1(50 \%)$ & $1(100 \%)$ & 20 \\
\hline ovejero alemán & $6(10,52 \%)$ & & & & 6 \\
\hline ovejero belga & $1(1,75 \%)$ & & & & 1 \\
\hline pitbull & $1(1,75 \%)$ & & & & 1 \\
\hline pointer & $1(1,75 \%)$ & & & & 1 \\
\hline rottweiler & $18(31,58 \%)$ & $1(16,66 \%)$ & $1(50 \%)$ & & 20 \\
\hline San Bernardo & $1(1,75 \%)$ & & & & 1 \\
\hline schnauzer & $1(1,75 \%)$ & & & & 1 \\
\hline setter irlandés & $1(1,75 \%)$ & & & & 1 \\
\hline $\mathrm{T}$ & 57 & 6 & 2 & 1 & 66 \\
\hline & & & & $\begin{array}{l}\mathrm{F}= \\
\mathrm{Fc}(0,05,54)=\end{array}$ & $\begin{array}{l}13,54 \\
72,15 \\
\end{array}$ \\
\hline
\end{tabular}

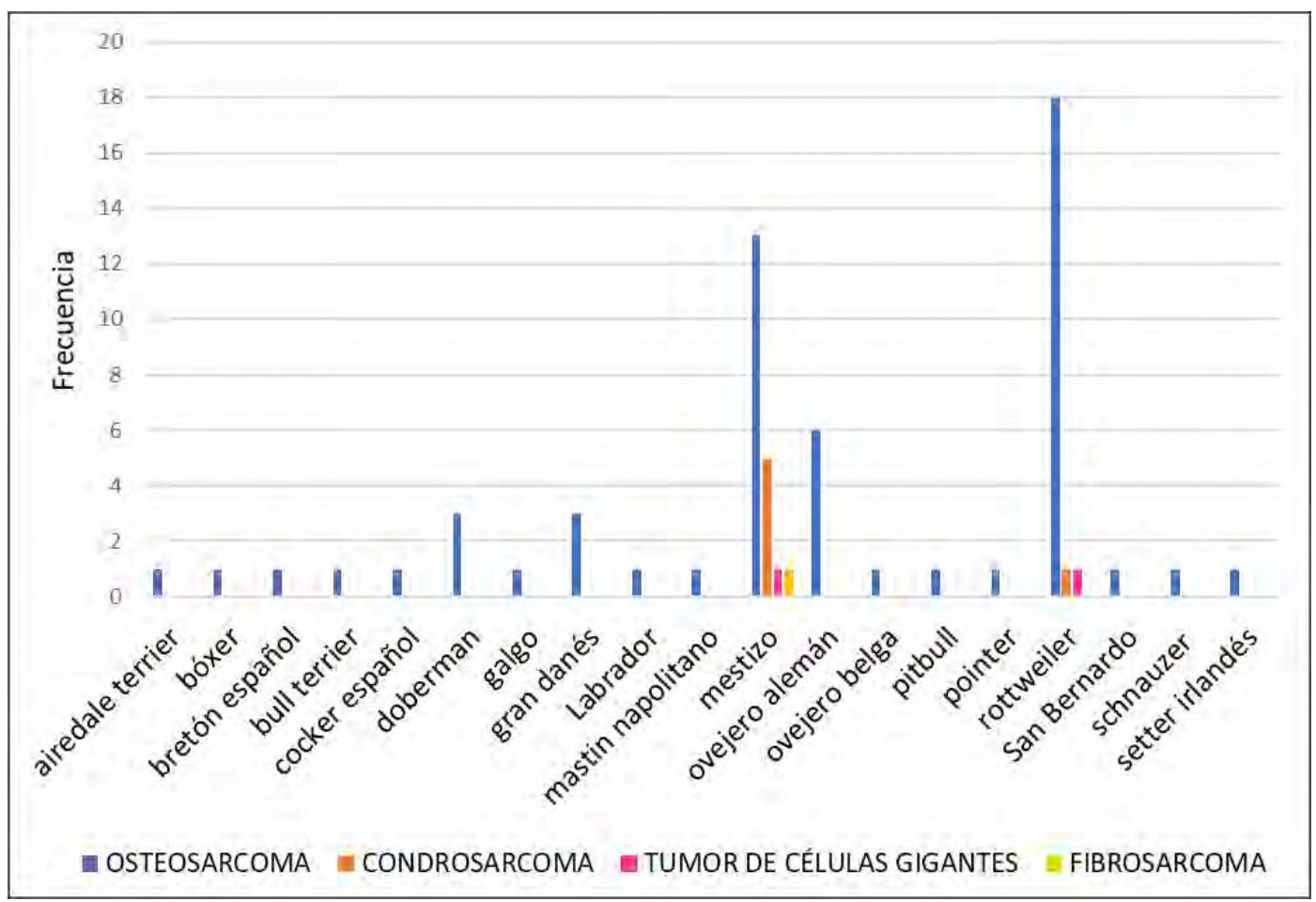

Figura 21. Distribución de los sarcomas óseos según la raza (se incluyen mestizos). 


\section{2. Estudio de la gradación tumoral}

De un total de 51 SOs analizados, 45 correspondieron a OSA. Entre ellos, el $11 \%$ (5/45) de grado (G) I, $33 \%$ (15/45) de grado II y $56 \%$ (25/45) fue de grado III. El análisis se completó con 4 condrosarcomas, de los cuales uno era de grado I, dos de grado II y uno de grado III; y dos tumores de células gigantes, de los cuales uno era de grado II y otro de grado III (Fig. 22 A; Tabla 10). Los resultados del análisis estadístico demostraron que no existe asociación entre los subtipos histológicos de SOs y los tres grados tumorales $\left(\mathrm{F}_{(0,05,4)}=1,91 ; \mathrm{P}>0,05\right)$ (Fig. 23; Tabla 10). La gradación tumoral entre los subtipos histológicos de OSAs se detalla en la figura 22 B. Los resultados del análisis estadístico entre los subtipos de OSAs y los tres grados tumorales revelaron que existe una fuerte asociación entre ambas variables $\left(\mathrm{F}_{(0,05,12)}=23^{* *} ; \mathrm{P}<0,05\right)($ Fig. 24; Tabla 11). En la tabla 12 se detalla el análisis cuantitativo de los parámetros pleomorfismo nuclear, índice mitótico y porcentaje de necrosis en los subtipos histológicos de los SOs. Las figuras 25, 26 y 27 muestran el pleomorfismo, las figuras mitóticas y la zona de necrosis respectivamente, en los subtipos de OSAs. 

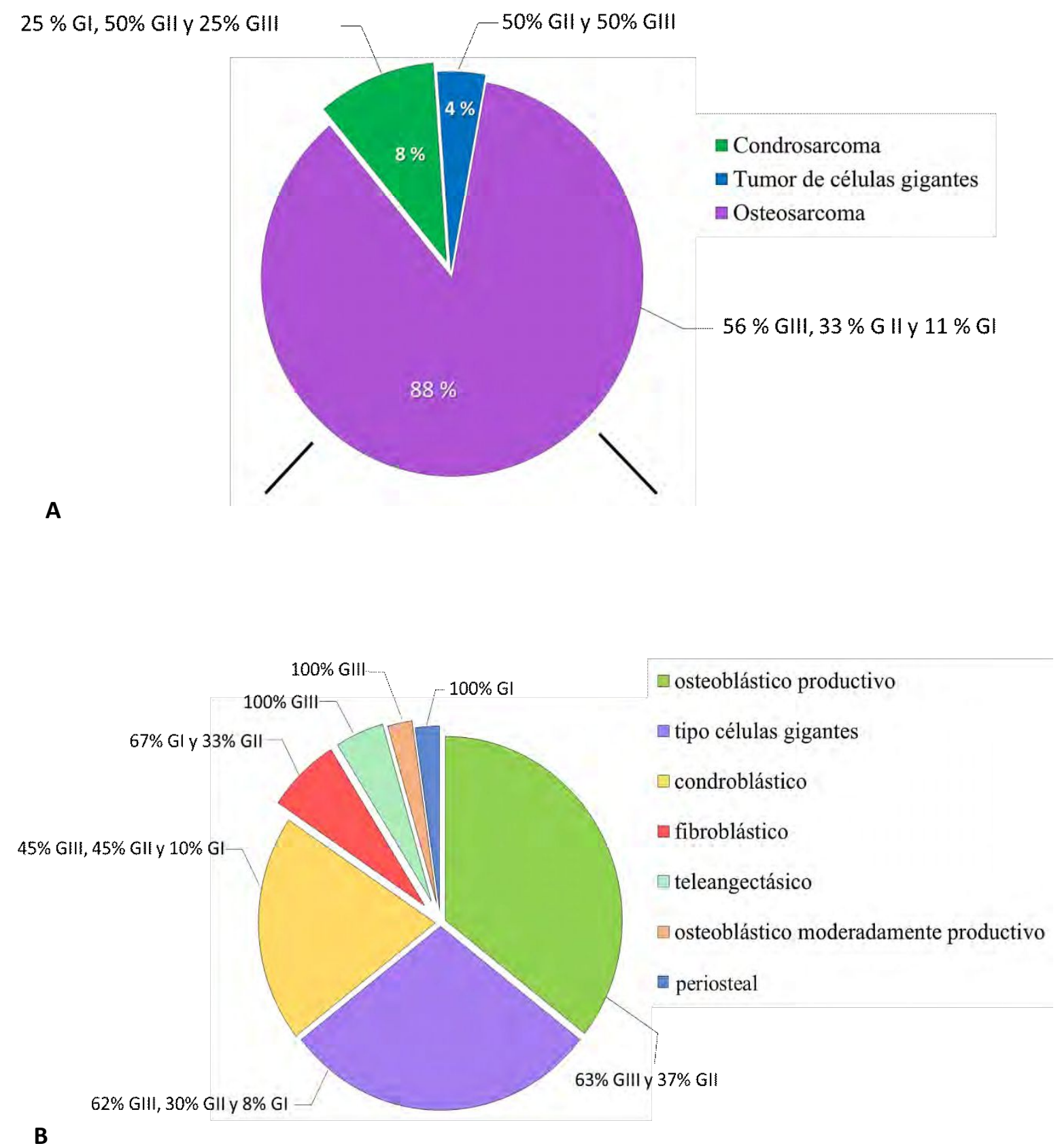

Figura 22. A. Gradación tumoral: porcentaje de los subtipos histológicos de sarcomas óseos en perros. B. Gradación tumoral: porcentaje de los subtipos histológicos de osteosarcomas en perros. 
Tabla 10. Distribución de los sarcomas óseos según los tres grados tumorales

\begin{tabular}{|c|c|c|c|c|}
\hline Sarcomas óseos & Grado I & Grado II & Grado III & $\mathrm{T}$ \\
\hline Condrosarcoma & 1 & 2 & 1 & 4 \\
\hline Tumor de células gigantes & & 1 & 1 & 2 \\
\hline Osteosarcoma & 5 & 15 & 25 & 45 \\
\hline $\mathrm{T}$ & 6 & 18 & 27 & 51 \\
\hline Los valores están expresados como números & & & \multicolumn{2}{|c|}{$\begin{array}{l}F=r, \quad 1,91 \\
F c=(0,05,4)=9,49\end{array}$} \\
\hline
\end{tabular}

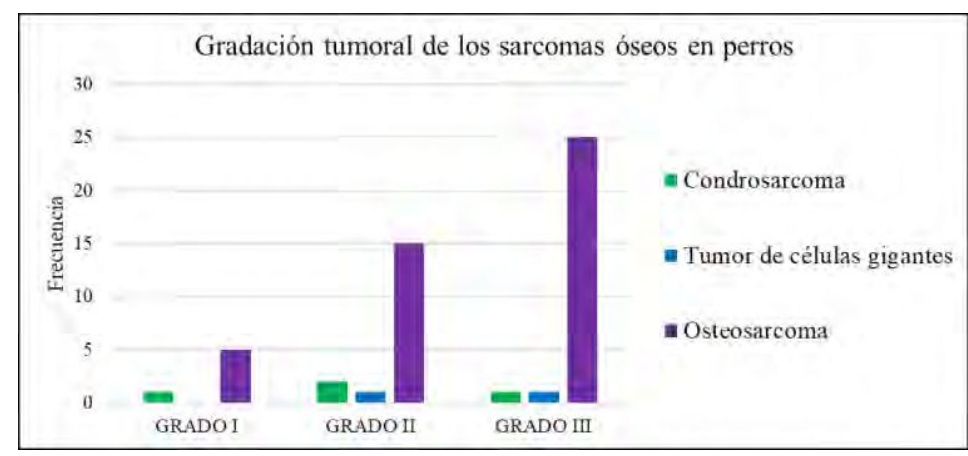

Figura 23 . Frecuencia de los sarcomas óseos según los tres grados tumorales

Tabla 11. Distribución de los subtipos de osteosarcomas según los tres grados tumorales

\begin{tabular}{|lcccc|}
\hline \multicolumn{1}{|c}{ Subtipos histológicos de osteosarcomas } & Grado I & Grado II & Grado III & T \\
Osteosarcoma tipo células gigantes & 1 & 4 & 8 & 13 \\
Osteosarcoma osteoblástico productivo & & 6 & 10 & 16 \\
Osteosarcoma teleangiectásico & & & 2 & 2 \\
Osteosarcoma condroblástico & 1 & 4 & 4 & 9 \\
Osteosarcoma fibroblástico & 2 & 1 & 3 \\
Osteosarcoma periosteal & 1 & & 1 & 1 \\
Osteosarcoma osteoblástico moderadamente productivo & & & 25 & 45 \\
T & 5 & 15 & $\mathbf{F =}$ & $\mathbf{2 3} * *$ \\
\hline Los valores están expresados como números enteros. T= total & & & $\mathbf{F c}(\mathbf{0 , 0 5 , \mathbf { 1 2 } ) =} \mathbf{2 1}$ \\
\hline
\end{tabular}

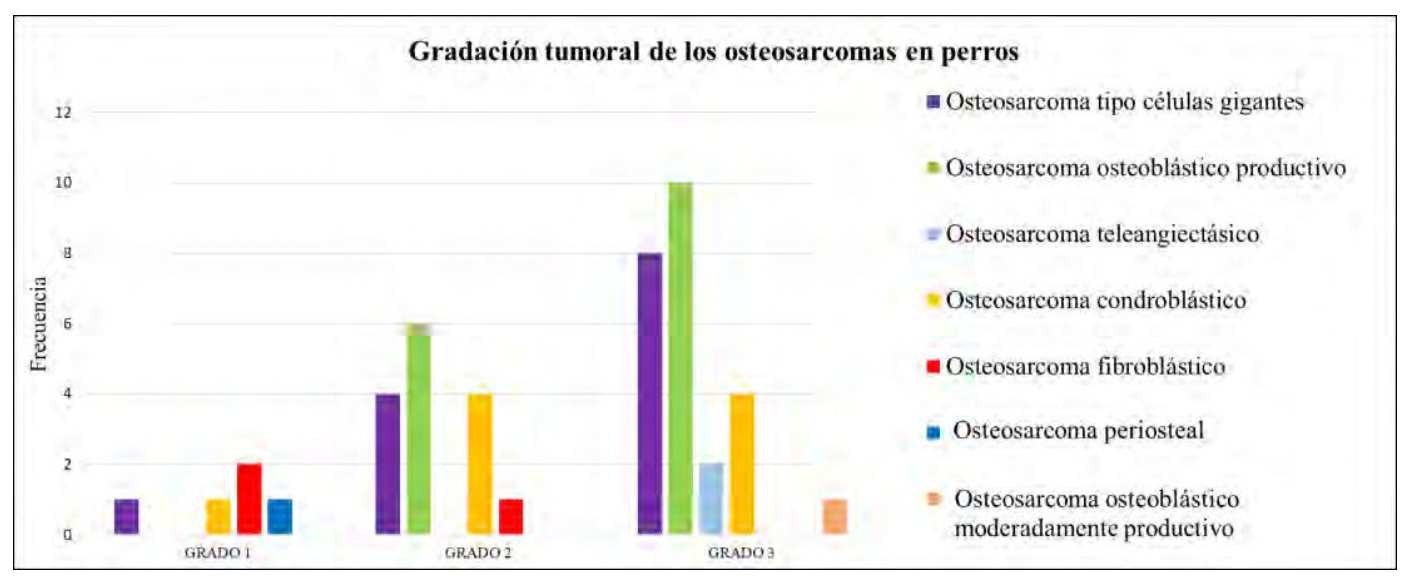

Figura 24. Frecuencia de los subtipos de osteosarcomas según los tres grados tumorales 
Tabla 12. Gradación tumoral de los sarcomas óseos en perros. Análisis cuantitativo de los parámetros histológicos pleomorfismo nuclear, índice mitótico y porcentaje de necrosis.

\begin{tabular}{|c|c|c|c|c|c|}
\hline $\mathrm{N}^{\circ}$ caso & diagnóstico & $\begin{array}{c}\text { pleomorfismo } \\
\text { nuclear }\end{array}$ & $\begin{array}{c}\text { índice } \\
\text { mitótico }\end{array}$ & necrosis & $\begin{array}{l}\text { puntuación total } \\
\text { grado tumoral }\end{array}$ \\
\hline 1 & osteosarcoma fibroblástico & 2 & 1 & 0 & 3 grado 1 \\
\hline 2 & osteosarcoma tipo células gigantes & 3 & 4 & 1 & 8 grado 3 \\
\hline 3 & osteosarcoma osteoblástico productivo & 2 & 3 & 1 & 6 grado 2 \\
\hline 4 & osteosarcoma tipo células gigantes & 3 & 4 & 1 & 8 grado 3 \\
\hline 5 & osteosarcoma teleangiectásico & 3 & 3 & 3 & 9 grado 3 \\
\hline 6 & osteosarcoma tipo células gigantes & 2 & 4 & 1 & 7 grado 3 \\
\hline 7 & osteosarcoma osteoblástico productivo & 3 & 3 & 1 & 7 grado 3 \\
\hline 8 & osteosarcoma tipo células gigantes & 3 & 2 & 1 & 6 grado 2 \\
\hline 9 & osteosarcoma condroblástico & 3 & 2 & 1 & 6 grado 2 \\
\hline 10 & osteosarcoma condroblástico & 3 & 4 & 1 & 8 grado 3 \\
\hline 11 & osteosarcoma fibroblástico & 1 & 1 & 1 & 3 grado 1 \\
\hline 12 & osteosarcoma osteoblástico productivo & 3 & 2 & 1 & 6 grado 2 \\
\hline 13 & osteosarcoma tipo células gigantes & 3 & 2 & 1 & 6 grado 2 \\
\hline 14 & osteosarcoma condroblástico & 3 & 2 & 1 & 6 grado 2 \\
\hline 15 & osteosarcoma condroblástico & 3 & 4 & 1 & 8 grado 3 \\
\hline 16 & osteosarcoma osteoblástico productivo & 3 & 3 & 2 & 8 grado 3 \\
\hline 17 & osteosarcoma osteoblástico productivo & 3 & 3 & 2 & 8 grado 3 \\
\hline 18 & osteosarcoma tipo células gigantes & 3 & 4 & 1 & 8 grado 3 \\
\hline 19 & osteosarcoma condroblástico & 2 & 1 & 0 & 3 grado 1 \\
\hline 20 & osteosarcoma tipo células gigantes & 3 & 4 & 1 & 8 grado 3 \\
\hline 21 & osteosarcoma periosteal & 3 & 4 & 1 & 8 grado 3 \\
\hline 22 & osteosarcoma tipo células gigantes & 2 & 3 & 1 & 6 grado 2 \\
\hline 23 & osteosarcoma tipo células gigantes & 2 & 1 & 0 & 3 grado 1 \\
\hline 24 & osteosarcoma osteoblástico productivo & 3 & 4 & 1 & 8 grado 3 \\
\hline 25 & osteosarcoma osteoblástico productivo & 3 & 4 & 2 & 9 grado 3 \\
\hline 26 & osteosarcoma tipo células gigantes & 3 & 4 & 2 & 9 grado 3 \\
\hline 27 & osteosarcoma tipo células gigantes & 3 & 3 & 2 & 8 grado 3 \\
\hline 28 & osteosarcoma teleangiectásico & 3 & 4 & 1 & 8 grado 3 \\
\hline 29 & osteosarcoma fibroblástico & 2 & 3 & 1 & 7 grado 2 \\
\hline 30 & osteosarcoma osteoblástico productivo & 2 & 3 & 1 & 7 grado 2 \\
\hline 31 & osteosarcoma osteoblástico productivo & 3 & 4 & 1 & 8 grado 3 \\
\hline 32 & osteosarcoma osteoblástico productivo & 3 & 3 & 0 & 6 grado 2 \\
\hline 33 & osteosarcoma osteoblástico productivo & 3 & 3 & 3 & 9 grado 3 \\
\hline 34 & osteosarcoma condroblástico & 3 & 3 & 3 & 9 grado 3 \\
\hline 35 & osteosarcoma condroblástico & 3 & 4 & 1 & 8 grado 3 \\
\hline 36 & osteosarcoma tipo células gigantes & 2 & 4 & 1 & 7 grado 2 \\
\hline 37 & osteosarcoma osteoblástico productivo & 3 & 4 & 2 & 9 grado 3 \\
\hline 38 & osteosarcoma osteoblástico productivo & 3 & 4 & 2 & 9 grado 3 \\
\hline 39 & osteosarcoma osteoblástico moderadamente productivo & 2 & 4 & 2 & 8 grado 3 \\
\hline
\end{tabular}


Tabla 12. (Cont.) Gradación tumoral de los sarcomas óseos en perros. Análisis cuantitativo de los parámetros histológicos pleomorfismo nuclear, índice mitótico y porcentaje de necrosis.

\begin{tabular}{cccccc}
\hline Ncaso & diagnóstico & $\begin{array}{c}\text { pleomorfismo } \\
\text { nuclear }\end{array}$ & $\begin{array}{c}\text { índice } \\
\text { mitótico }\end{array}$ & $\begin{array}{c}\text { necrosis } \\
\text { puntuación total } \\
\text { grado tumoral }\end{array}$ \\
\hline 40 & osteosarcoma osteoblástico productivo & 2 & 2 & 2 & 6 grado 2 \\
41 & osteosarcoma tipo células gigantes & 2 & 4 & 3 & 9 grado 3 \\
42 & osteosarcoma osteoblástico productivo & 2 & 4 & 1 & 7 grado 2 \\
43 & osteosarcoma condroblástico & 2 & 4 & 0 & 6 grado 2 \\
44 & osteosarcoma condroblástico & 2 & 4 & 0 & 6 grado 2 \\
45 & osteosarcoma osteoblástico productivo & 3 & 4 & 2 & 9 grado 3 \\
46 & condrosarcoma & 1 & 1 & 0 & 2 grado 1 \\
47 & condrosarcoma & 2 & 4 & 0 & 6 grado 2 \\
48 & condrosarcoma & 2 & 4 & 2 & 8 grado 3 \\
49 & condrosarcoma & 2 & 4 & 0 & 6 grado 2 \\
50 & tumor de células gigantes & 3 & 4 & 3 & 10 grado 3 \\
51 & tumor de células gigantes & 3 & 3 & 1 & 7 grado 2 \\
\hline
\end{tabular}



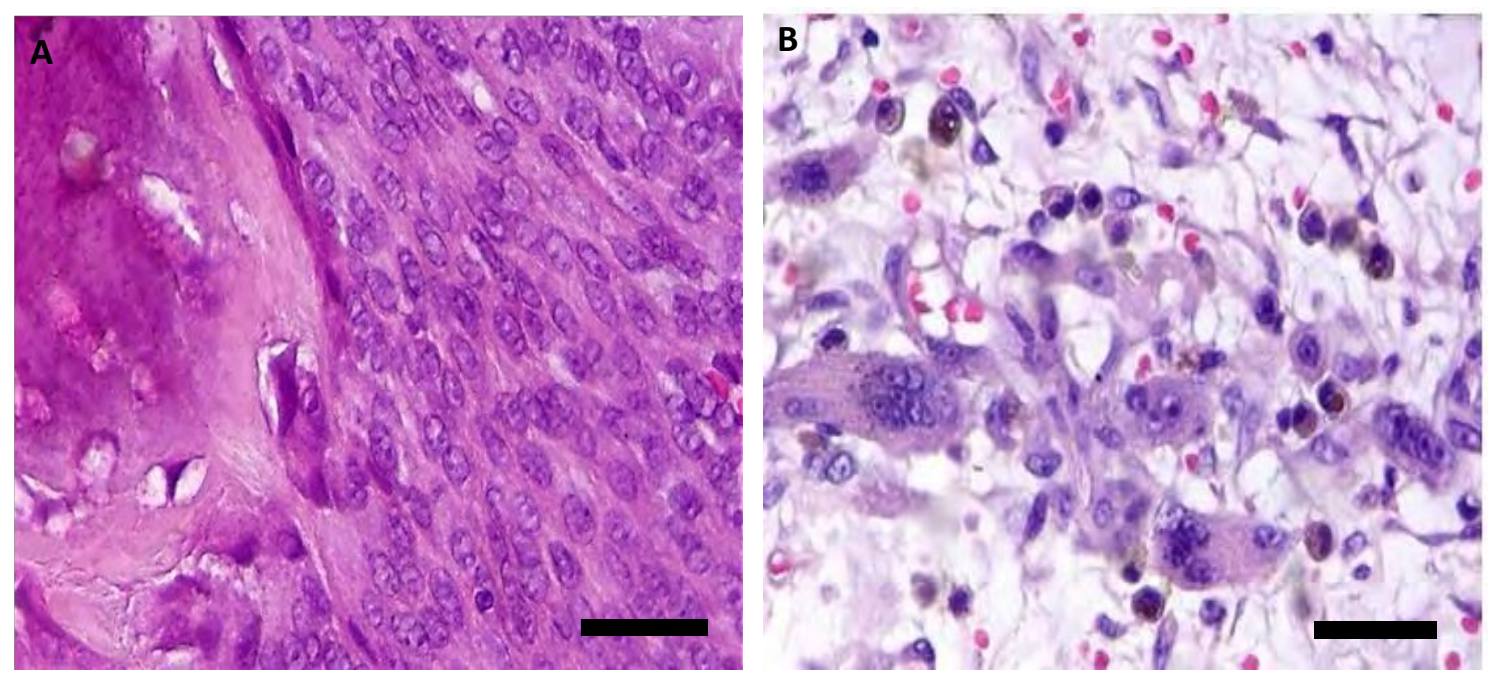

Figura 25. Osteosarcoma en perros: pleomorfismo.

A. Osteosarcoma osteoblástico productivo. Pleomorfismo 1 (leve): células neoplásicas con escaso pleomorfismo, H-E. La barra de escala representa $20 \mu \mathrm{m}$.

B. Osteosarcoma tipo células gigantes. Pleomorfismo 3 (acentuado): células neoplásicas con marcado pleomorfismo, H-E. La barra de escala representa $20 \mu \mathrm{m}$.
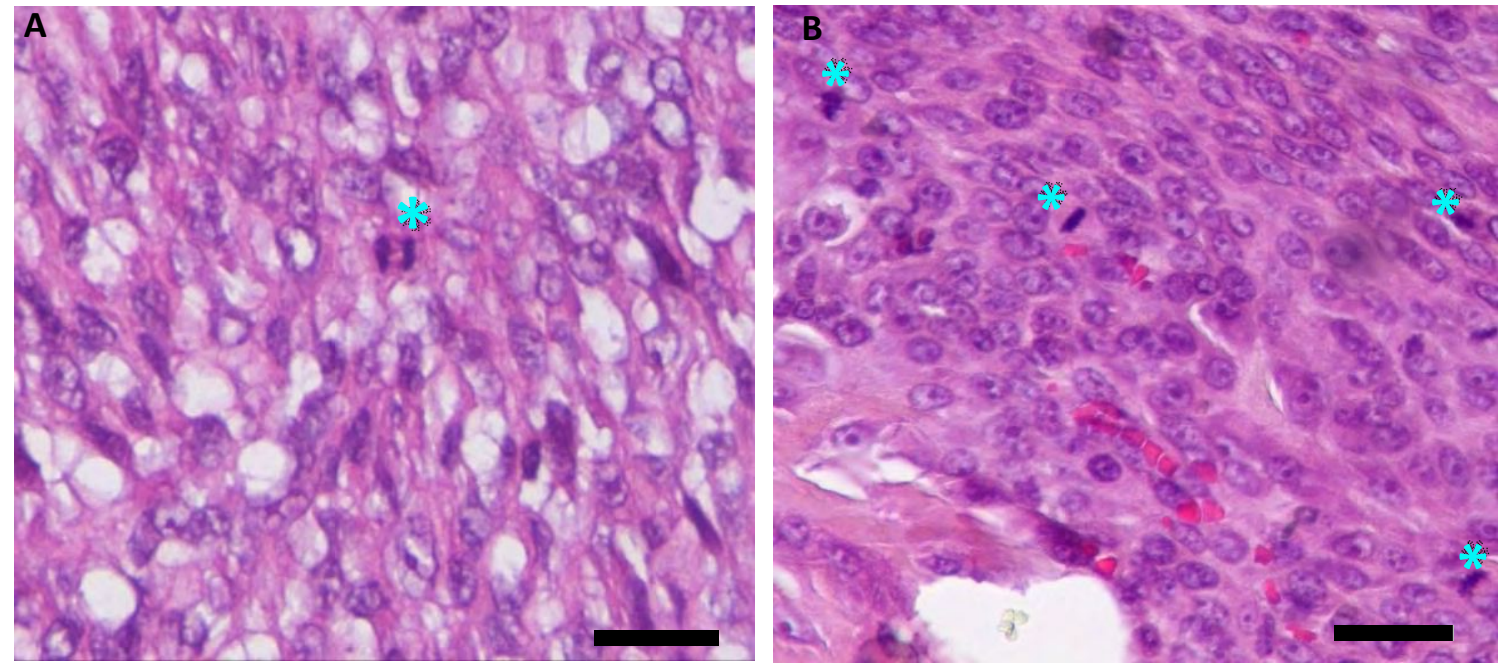

Figura 26. Osteosarcoma en perros: mitosis.

A. Osteosarcoma osteoblástico moderadamente productivo. Índice mitótico 1: figura mitótica (*), H-E. La barra de escala representa $20 \mu \mathrm{m}$.

B. Osteosarcoma osteoblástico productivo. Índice mitótico 3: abundantes figuras mitóticas (*), H-E. La barra de escala representa $20 \mu \mathrm{m}$. 

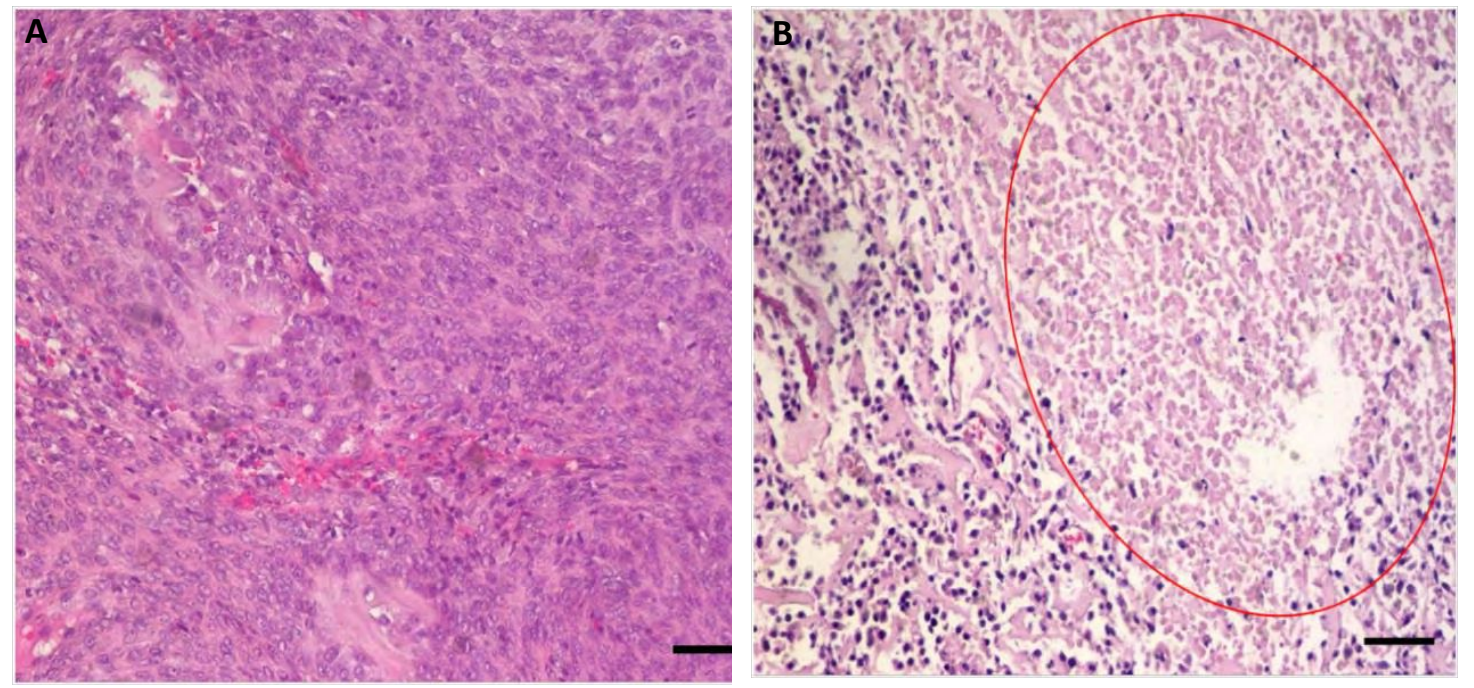

Figura 27. Osteosarcoma en perros: necrosis.

A. Osteosarcoma osteoblástico productivo. Porcentaje de necrosis 0: no se observan áreas de necrosis, H-E. La barra de escala representa $50 \mu \mathrm{m}$.

B. Osteosarcoma tipo células gigantes. Porcentaje de necrosis 3: extensa área de necrosis $(\bigcirc)$, H-E. La barra de escala representa $50 \mu \mathrm{m}$. 
III.3. Estudio de la localización anatómica con respecto a los tres grados tumorales

Los SOs de localización apendicular fueron 38 (76\%), de los cuales el 10,52\% (4/38) fue de grado I, el 31,58 \% (12/38) de grado II y el 57,9\% (22/38) de grado III. Los SOs de localización axial fueron 12 (24 \%), de los cuales el 16,7 \% (2/12) fueron de grado I; el $50 \%(6 / 12)$ de grado II y el 33,33 \% (4/12) de grado III (Fig. 28). Los resultados del análisis estadístico demostraron que no existe asociación entre la localización anatómica y los tres grados tumorales $\left(\mathrm{F}_{(0,05,2)}=2,20 ; \mathrm{P}>\right.$ 0,05). En tabla 13 se expresa la frecuencia de la localización anatómica con sus respectivos porcentajes, con respecto a los tres grados tumorales.

Tabla 13. Distribución de la localización anatómica según los tres grados tumorales

\begin{tabular}{|cccc|}
\hline $\begin{array}{c}\text { Gradación tumoral } \\
\text { GI }\end{array}$ & Localización Apendicular & Localización Axial & T \\
GII & $4(10,52 \%)$ & $2(16,70 \%)$ & $6(12 \%)$ \\
GIII & $12(31,58 \%)$ & $6(50 \%)$ & $18(36 \%)$ \\
T & $22(57,90 \%)$ & $4(33,33 \%)$ & $26(52 \%)$ \\
Los valores están expresados como números enteros y porcentaje (\%). G, gradación. T, totales & $12(24 \%)$ & $50(100 \%)$ \\
\hline
\end{tabular}

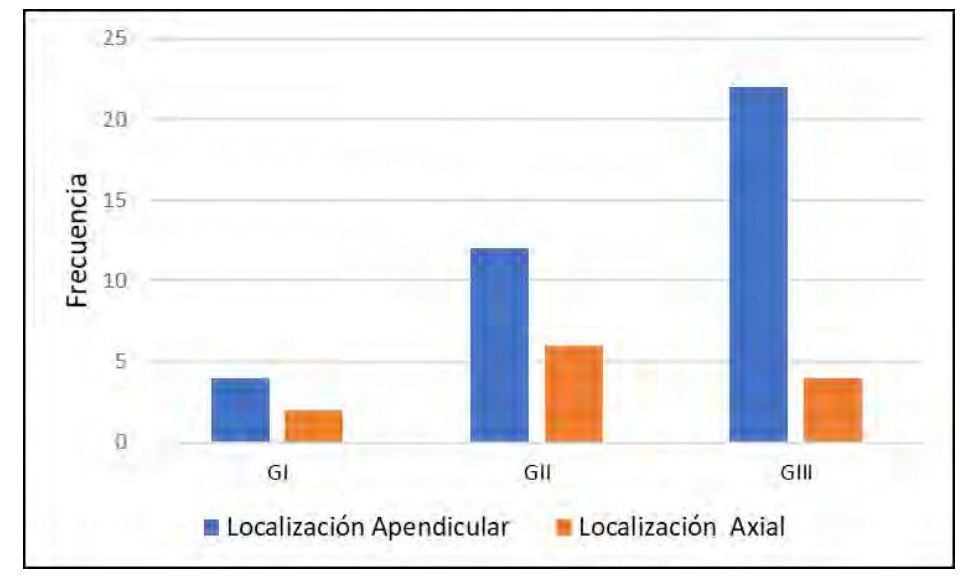

Figura 28. Frecuencia de la localización anatómica según los tres grados tumorales 


\section{4. Estudios inmunohistoquímicos cualitativos y cuantitativos}

\section{III.4.1. PCNA}

En todos los casos de SOs se encontró inmunomarcación para el PCNA. La inmunomarcación mostró un patrón limitado al núcleo (Fig. 29). El porcentaje de células que expresaron el PCNA en los diferentes subtipos histológicos de SOs se muestra en la tabla 14. Asimismo, dentro del grupo de OSA, el porcentaje de células positivas para el PCNA se detalla en la tabla 19.

Tabla 14. Porcentaje de células que expresaron el PCNA en los subtipos de sarcomas óseos

\begin{tabular}{|c|c|cccc|}
\hline \multirow{7}{*}{ PCNA } & Valores asignados* & Osteosarcoma & Condrosarcoma & Tumor de células gigantes & Fibrosarcoma \\
\cline { 2 - 6 } & 0 & $5 \%$ & & & NR \\
& 1 & $52 \%$ & $25 \%$ & $50 \%$ & \\
& 2 & $40 \%$ & $75 \%$ & $50 \%$ & \\
& 3 & & & & \\
\hline
\end{tabular}

*Valores asignados: 0 , menos del $10 \%$ de las células positivas; 1 , entre el 10 y el $25 \%$; 2 entre el 25 y el $50 \%$; 3 , entre 50 y $75 \%$; 4, entre 75 y $100 \%$. NR: muestra no representativa.

No se observaron diferencias estadísticamente significativas en el porcentaje de células atípicas positivas para el PCNA entre los subtipos histológicos de $\mathrm{SOs}(\mathrm{P}=$ $0,33754 ; \mathrm{P}>0,05)$. 

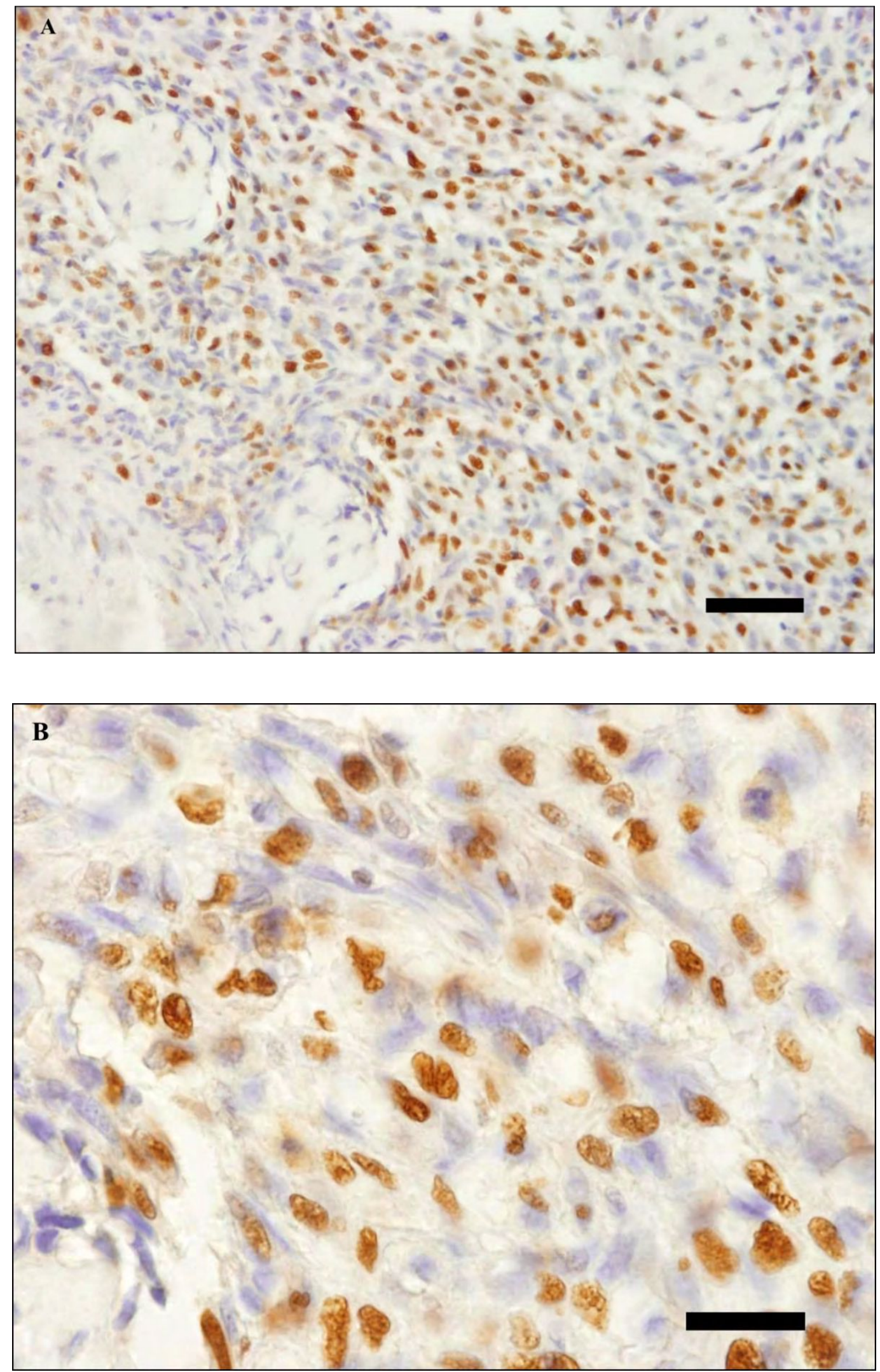

Figura 29. (A) Inmunohistoquímica anti-PCNA. Inmunorreactividad intranuclear en células neoplásicas (marrón). (B) Inmunohistoquímica anti-PCNA. Mayor detalle de la inmunorreactividad intranuclear (marrón) en las células neoplásicas de la figura 29 A. La barra de escala representa 50 $\mu \mathrm{m}$ (A) у $20 \mu \mathrm{m}$ (B). 


\section{III.4.2. VEGF-A}

La inmunomarcación para el VEGF-A mostró un patrón limitado al citoplasma (Fig. 30). El porcentaje de células que expresaron el VEGF-A en los diferentes subtipos histológicos de SOs se muestra en la tabla 15. Asimismo, el porcentaje de células positivas para el VEGF-A dentro del grupo de OSA se detalla en la tabla 19.

Tabla 15. Porcentaje de células que expresaron el VEGF-A en los subtipos de sarcomas óseos

\begin{tabular}{|c|ccccc|}
\hline \multirow{5}{*}{ VEGF-A } & Valores asignados* & Osteosarcoma & Condrosarcoma & Tumor de células gigantes & Fibrosarcoma \\
\cline { 2 - 5 } & 0 & & $20 \%$ & $50 \%$ & $\mathrm{NR}$ \\
& 1 & $36 \%$ & $60 \%$ & $50 \%$ & \\
& 2 & $32 \%$ & $20 \%$ & & \\
& 3 & $21 \%$ & & & \\
\hline
\end{tabular}

*Valores asignados: 0 , menos del $10 \%$ de las células positivas; 1 , entre el 10 y el $25 \%$; 2 , entre el 25 y el $50 \%$; 3 , entre 50 y $75 \%$; 4 , entre 75 y $100 \%$. NR: muestra no representativa.

Se observaron diferencias estadísticamente significativas en el porcentaje de células atípicas positivas para el VEGF-A entre los subtipos histológicos de $\mathrm{SOs}(\mathrm{P}=$ $\left.0,016425^{* *} ; \mathrm{P}<0,05\right)$. 

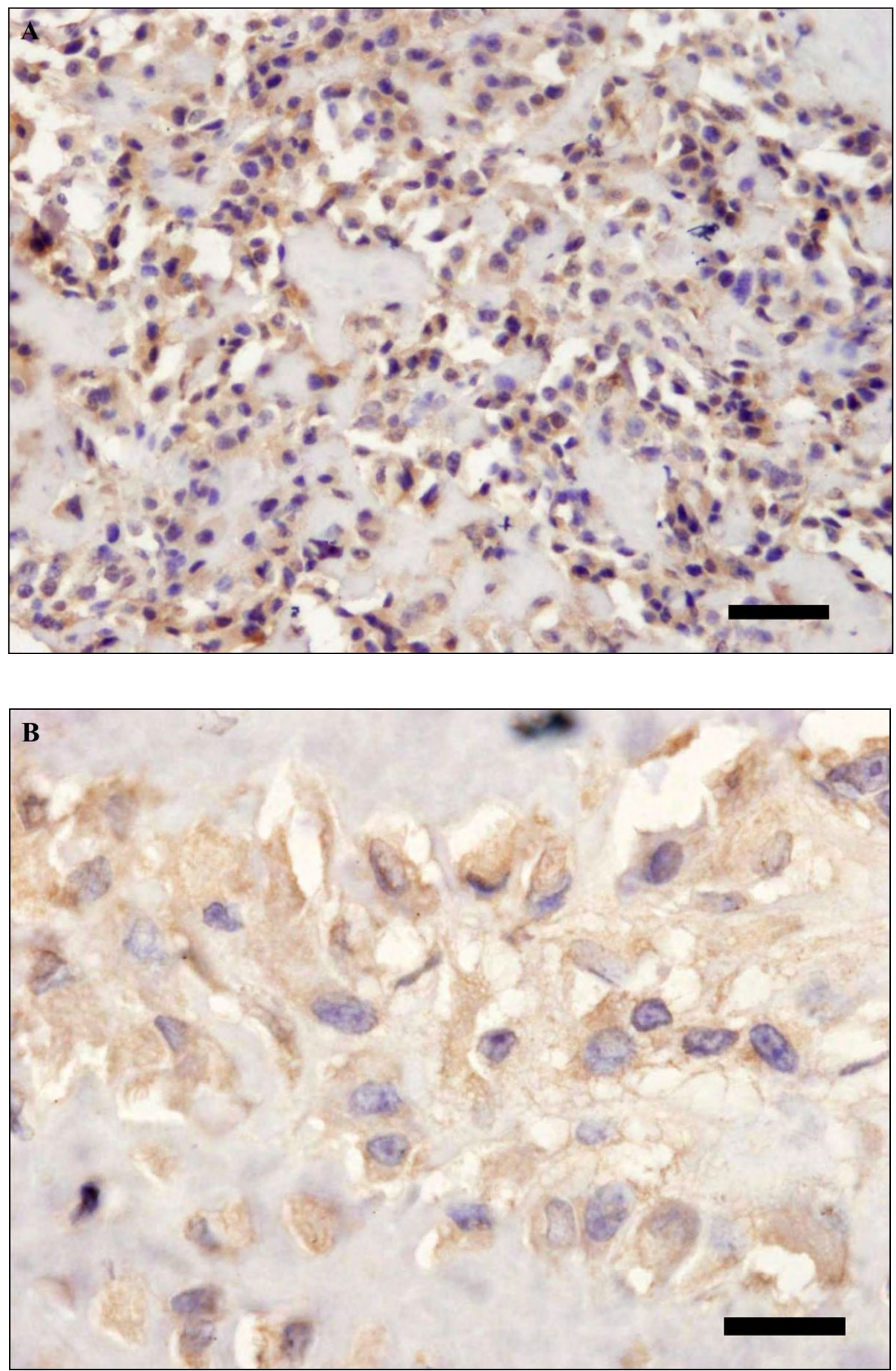

Figura 30. (A) Inmunohistoquímica anti-VEGF-A. Inmunorreactividad intracitoplasmática en células neoplásicas (marrón). (B) Inmunohistoquímica anti-VEGF-A. Mayor detalle de la inmunorreactividad intracitoplasmática (marrón) en las células neoplásicas de la figura $30 \mathrm{~A}$. La barra de escala representa $50 \mu \mathrm{m}$ (A) y $20 \mu \mathrm{m}$ (B). 


\section{III.4.3. VEGFR-1}

La inmunomarcación para el VEGFR-1 mostró un patrón limitado al citoplasma (Fig. 31). El porcentaje de células que expresaron el VEGFR-1 en los diferentes subtipos histológicos de SOs se muestra en la tabla 16. Asimismo, el porcentaje de células positivas para el VEGFR-1 dentro del grupo de OSA se detalla en la tabla 19.

Tabla 16. Porcentaje de células que expresaron el VEGFR-1 en los subtipos de sarcomas óseos

\begin{tabular}{|c|c|c|c|c|c|}
\hline \multirow{6}{*}{ VEGFR-1 } & Valores asignados* & Osteosarcoma & Condrosarcoma & Tumor de células gigantes & Fibrosarcoma \\
\hline & 0 & & & & \multirow[t]{5}{*}{ NR } \\
\hline & 1 & $19 \%$ & & $50 \%$ & \\
\hline & 2 & $38 \%$ & $25 \%$ & $50 \%$ & \\
\hline & 3 & $16 \%$ & & & \\
\hline & 4 & $47 \%$ & $75 \%$ & & \\
\hline
\end{tabular}

*Valores asignados: 0 , menos del $10 \%$ de las células positivas; 1 , entre el 10 y el $25 \%$; 2 , entre el 25 y el $50 \%$; 3 , entre 50 y $75 \%$; 4 , entre 75 y $100 \%$. NR: muestra no representativa.

No se observaron diferencias estadísticamente significativas en el porcentaje de células atípicas positivas para el VEGFR-1 entre los subtipos histológicos de SOs $(\mathrm{P}=0,385022 ; \mathrm{P}>0,05)$. 

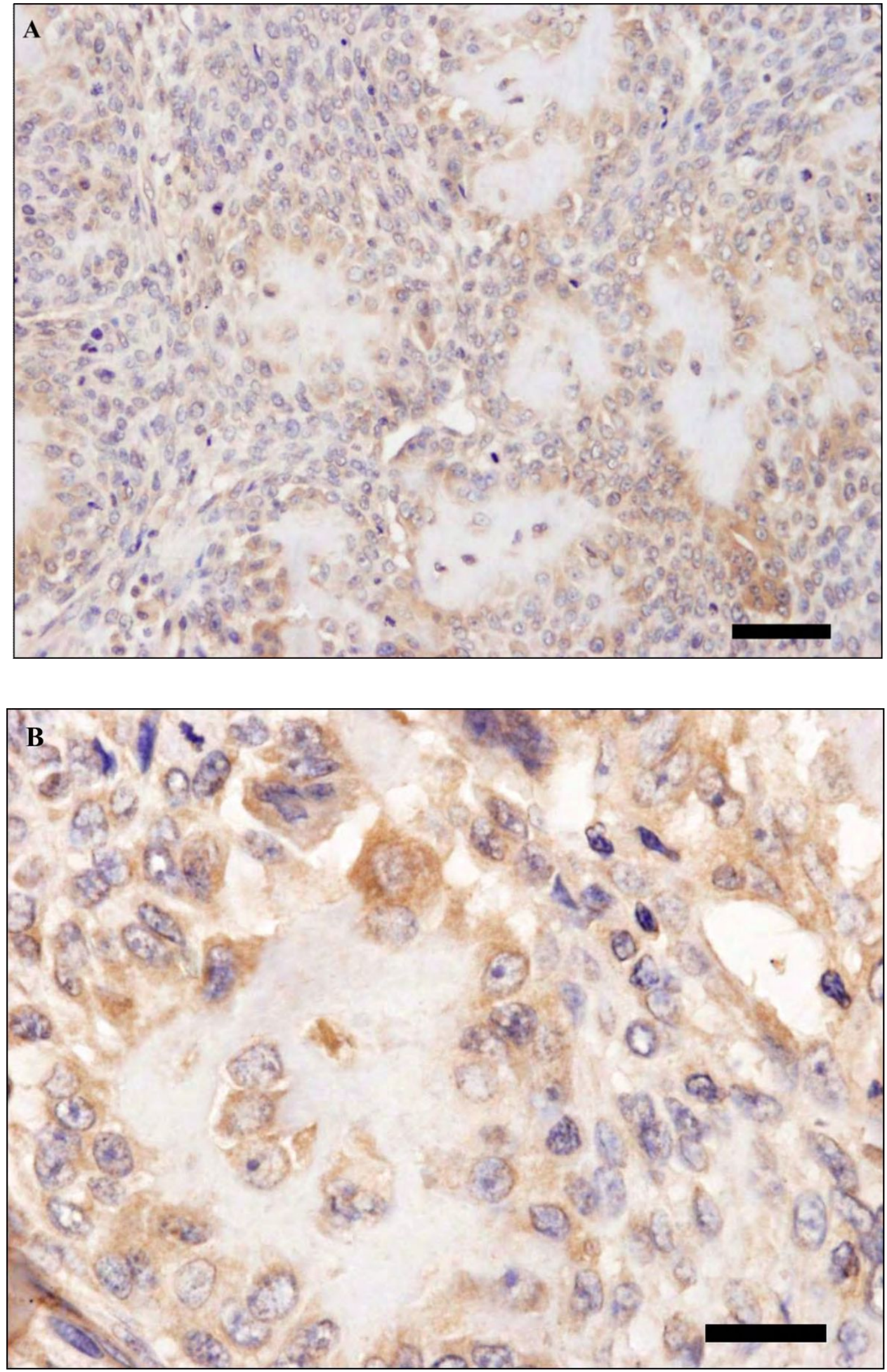

Figura 31. (A) Inmunohistoquímica anti-VEGFR-1. Inmunorreactividad intracitoplasmática en células neoplásicas (marrón). (B) Inmunohistoquímica anti-VEGFR-1. Mayor detalle de la inmunorreactividad intracitoplasmática (marrón) en las células neoplásicas de la figura $31 \mathrm{~A}$. La barra de escala representa $50 \mu \mathrm{m}$ (A) y $20 \mu \mathrm{m}$ (B). 


\section{III.4.4. BMP-9}

La inmunomarcación de BMP-9 mostró un patrón limitado al citoplasma (Fig. 32).

El porcentaje de células que expresaron la BMP-9 en los diferentes subtipos histológicos de SOs se muestra en la tabla 17. Asimismo, dentro del grupo de OSA, el porcentaje de células positivas para la BMP-9 se detalla en la tabla 19.

Tabla 17. Porcentaje de células que expresaron el BMP-9 en los subtipos de sarcomas óseos

\begin{tabular}{|c|c|cccc|}
\hline & Valores asignados* & Osteosarcoma & Condrosarcoma & Tumor de células gigantes & Fibrosarcoma \\
\cline { 2 - 6 } & 0 & $3 \%$ & & & \\
BMP-9 & 1 & $24 \%$ & & $50 \%$ & \\
& 2 & $36 \%$ & $25 \%$ & $50 \%$ & $100 \%$ \\
& 3 & $12 \%$ & $50 \%$ & & \\
& 4 & $24 \%$ & $25 \%$ & & \\
\hline
\end{tabular}

*Valores asignados: 0 , menos del $10 \%$ de las células positivas; 1 , entre el 10 y el $25 \%$; 2 , entre el 25 y el $50 \%$; 3 , entre 50 y $75 \%$; 4, entre 75 y $100 \%$. NR: muestra no representativa.

No se observaron diferencias estadísticamente significativas en el porcentaje de células atípicas positivas para la BMP-9 entre los subtipos histológicos de $\mathrm{SOs}(\mathrm{P}=$ 0,10852; $\mathrm{P}>0,05)$. 

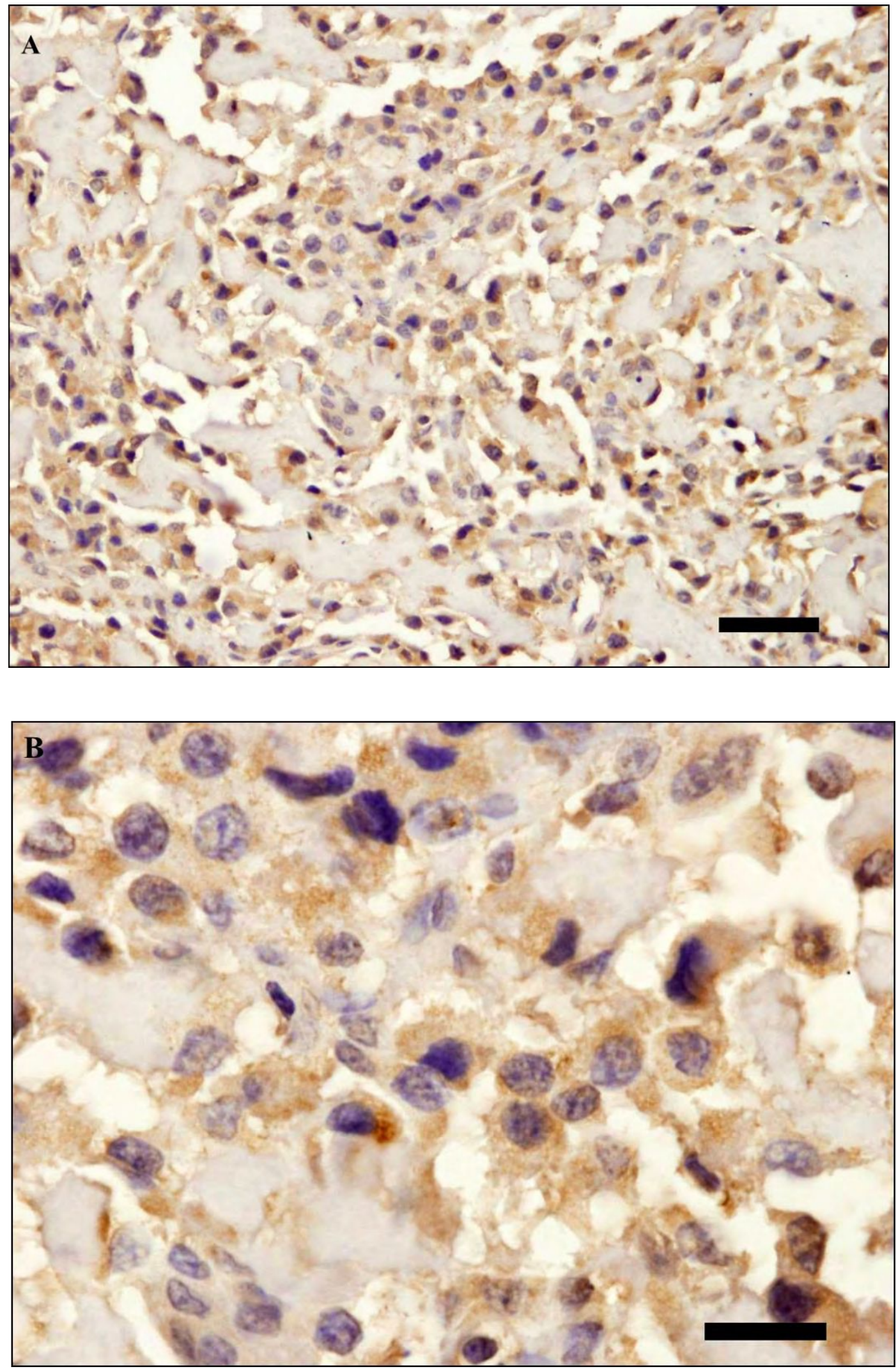

Figura 32. (A) Inmunohistoquímica anti-BMP-9. Inmunorreactividad intracitoplasmática en células neoplásicas (marrón). (B) Inmunohistoquímica anti-BMP-9. Mayor detalle de la inmunorreactividad intracitoplasmática (marrón) en las células neoplásicas de la figura $32 \mathrm{~A}$. La barra de escala representa 50 $\mu \mathrm{m}$ (A) y $20 \mu \mathrm{m}$ (B). 


\section{III.4.5. COX-2}

La inmunomarcación para la COX-2 mostró un patrón limitado al citoplasma (Fig. 33). El porcentaje de células que expresaron la COX-2 en los diferentes subtipos histológicos de SOs se muestra en la tabla 18. Dentro del grupo de OSA, el porcentaje de células positivas para la COX-2 se detalla en la tabla 19.

Tabla 18. Porcentaje de células que expresaron el COX-2 en los subtipos de sarcomas óseos

\begin{tabular}{|c|c|cccc|}
\hline \multirow{4}{*}{ COX-2 } & Valores asignados* & Osteosarcoma & Condrosarcoma & Tumor de células gigantes & Fibrosarcoma \\
\cline { 2 - 6 } & 0 & $71 \%$ & $50 \%$ & $100 \%$ & NR \\
& 1 & $25 \%$ & $25 \%$ & & \\
& 2 & $4 \%$ & $25 \%$ & & \\
& 3 & & & & \\
\hline
\end{tabular}

*Valores asignados: 0 , menos del $10 \%$ de las células positivas; 1 , entre el 10 y el $25 \%$; 2 entre el 25 y el $50 \%$; 3 , entre 50 y $75 \%$; 4, entre 75 y $100 \%$. NR: muestra no representativa.

No se observaron diferencias estadísticamente significativas en el porcentaje de células atípicas positivas para la $\mathrm{COX}-2$ entre los subtipos histológicos de $\mathrm{SOs}(\mathrm{P}=$ $0,601222 ; \mathrm{P}>0,05)$. 

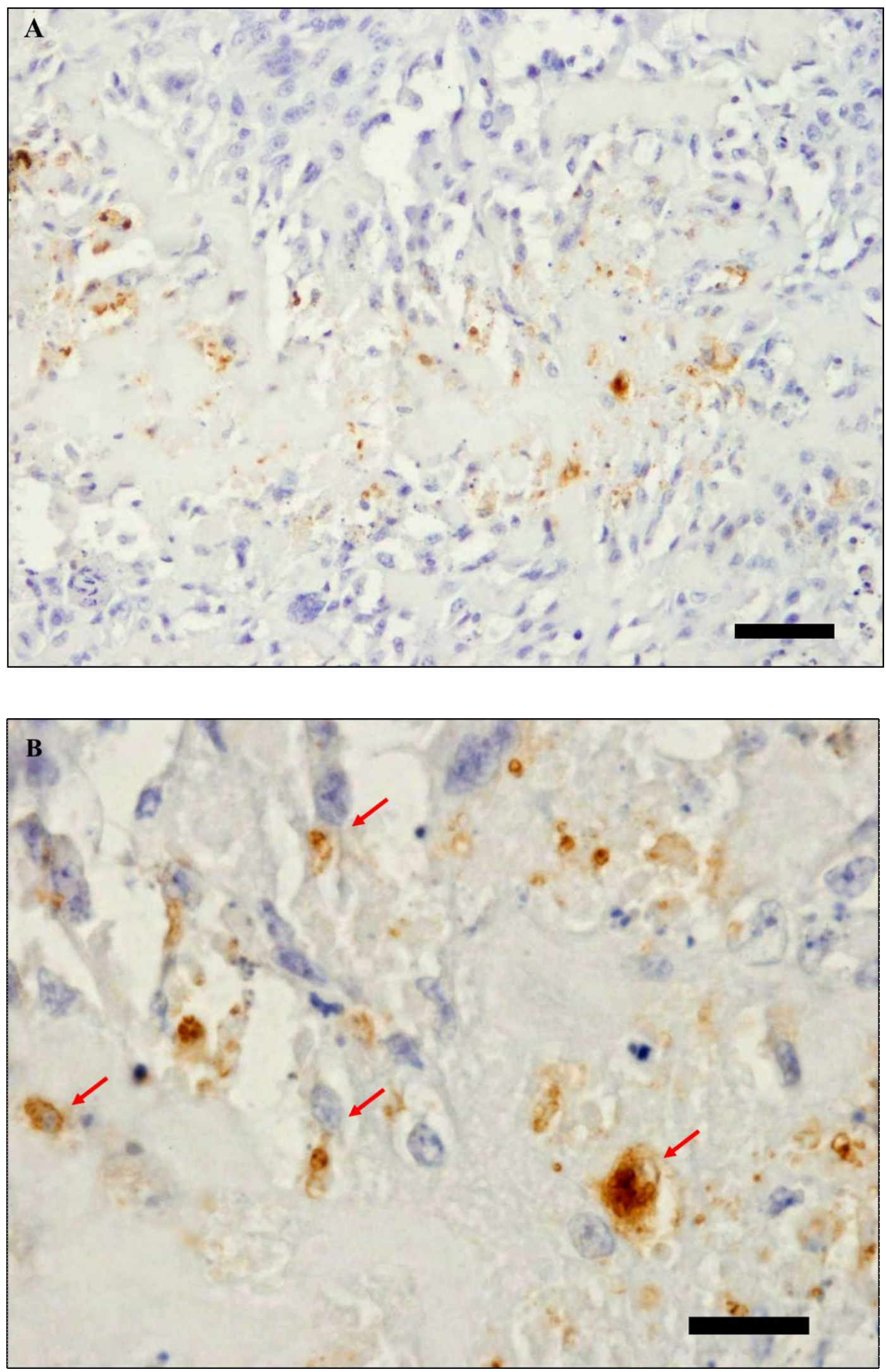

Figura 33. Inmunohistoquímica anti-COX-2. (A) Inmunorreactividad intracitoplasmática en células neoplásicas (marrón). (B) Inmunohistoquímica anti-COX-2. Mayor detalle de la inmunorreactividad intracitoplasmática (marrón) en las células neoplásicas de la figura $33 \mathrm{~A}(\rightarrow)$. La barra de escala representa $50 \mu \mathrm{m}$ (A) y $20 \mu \mathrm{m}$ (B). 
Tabla 19. Análisis cuantitativo de la marcación inmunohistoquímica de PCNA, VEGF-A, VEGFR-1, BMP-9 y COX-2 de los sarcomas óseos en perros.

\begin{tabular}{|c|c|c|c|c|c|c|}
\hline $\mathbf{N}^{\circ}$ caso & diagnóstico & PCNA & VEGF-A & VEGFR-1 & BMP-9 & COX-2 \\
\hline 1 & OSA osteoblástico productivo & 1 & 1 & 1 & 1 & 0 \\
\hline 2 & OSA osteoblástico productivo & 1 & 1 & 1 & 1 & 0 \\
\hline 3 & OSA osteoblástico productivo & 1 & 1 & 2 & 1 & 0 \\
\hline 4 & OSA osteoblástico productivo & 1 & 2 & 2 & 2 & 0 \\
\hline 5 & OSA osteoblástico productivo & 1 & 2 & 2 & 2 & 0 \\
\hline 6 & OSA osteoblástico productivo & 1 & 2 & 3 & 2 & 0 \\
\hline 7 & OSA osteoblástico productivo & 1 & 2 & 4 & 2 & 0 \\
\hline 8 & OSA osteoblástico productivo & 1 & 3 & 4 & 2 & 0 \\
\hline 9 & OSA osteoblástico productivo & 1 & 4 & 4 & 2 & 1 \\
\hline 10 & OSA osteoblástico productivo & 1 & 4 & 4 & 2 & 1 \\
\hline 11 & OSA osteoblástico productivo & 2 & 4 & 4 & 2 & 1 \\
\hline 12 & OSA osteoblástico productivo & 2 & NR & 4 & 4 & NR \\
\hline 13 & OSA osteoblástico productivo & 2 & NR & NR & 4 & NR \\
\hline 14 & OSA osteoblástico productivo & 2 & NR & NR & NR & NR \\
\hline 15 & OSA osteoblástico productivo & 2 & NR & NR & NR & NR \\
\hline 16 & OSA osteoblástico productivo & 2 & NR & NR & NR & NR \\
\hline 17 & OSA osteoblástico productivo & 2 & NR & NR & NR & NR \\
\hline 18 & OSA osteoblástico productivo & 2 & NR & NR & NR & NR \\
\hline 19 & OSA osteoblástico productivo & 4 & NR & NR & NR & NR \\
\hline 20 & OSA osteoblástico productivo & NR & NR & NR & NR & NR \\
\hline 21 & OSA osteoblástico productivo & NR & NR & NR & NR & NR \\
\hline 22 & OSA osteoblástico no productivo & 1 & NR & 4 & 1 & 0 \\
\hline 23 & OSA tipo células gigantes & 1 & 1 & 2 & 1 & 0 \\
\hline 24 & OSA tipo células gigantes & 1 & 1 & 2 & 1 & 0 \\
\hline 25 & OSA tipo células gigantes & 1 & 1 & 2 & 1 & 0 \\
\hline 26 & OSA tipo células gigantes & 1 & 1 & 2 & 1 & 0 \\
\hline 27 & OSA tipo células gigantes & 1 & 1 & 3 & 2 & 0 \\
\hline 28 & OSA tipo células gigantes & 1 & 1 & 3 & 2 & 0 \\
\hline 29 & OSA tipo células gigantes & 2 & 2 & 3 & 3 & 0 \\
\hline 30 & OSA tipo células gigantes & 2 & 2 & 3 & 3 & 1 \\
\hline 31 & OSA tipo células gigantes & 2 & 2 & 4 & 3 & 1 \\
\hline 32 & OSA tipo células gigantes & 2 & 3 & 4 & 4 & 2 \\
\hline 33 & OSA tipo células gigantes & 2 & NR & 4 & 4 & NR \\
\hline 34 & OSA tipo células gigantes & 2 & NR & NR & 4 & NR \\
\hline 35 & OSA tipo células gigantes & NR & NR & NR & NR & NR \\
\hline 36 & OSA condroblástico & 1 & 1 & 1 & 0 & 0 \\
\hline 37 & OSA condroblástico & 1 & 2 & 2 & 3 & 0 \\
\hline
\end{tabular}

Valores asignados: 0 , menos del $10 \%$ de las células positivas; 1 , entre el 10 y el $25 \%$; entre el 25 y el $50 \%$; 3 , entre 50 y $75 \%$; 4 , entre 75 y $100 \%$; NR, muestra no representativa. OSA: osteosarcoma. 
Tabla 19. (Cont.) Análisis cuantitativo de la marcación inmunohistoquímica de PCNA, VEGF-A, VEGFR-1, BMP-9 y COX-2 de los sarcomas óseos en perros.

\begin{tabular}{ccccccc}
\hline N $^{\circ}$ caso & diagnóstico & PCNA & VEGF-A & VEGFR-1 & BMP-9 & COX-2 \\
\hline 38 & OSA condroblástico & 1 & 3 & 2 & 4 & 1 \\
39 & OSA condroblástico & 1 & 3 & 4 & 4 & 1 \\
40 & OSA condroblástico & 2 & 3 & 4 & 4 & NR \\
41 & OSA condroblástico & 2 & NR & NR & NR & NR \\
42 & OSA condroblástico & NR & NR & NR & NR & NR \\
43 & OSA condroblástico & NR & NR & NR & NR & NR \\
44 & OSA fibroblástico & 0 & 2 & 1 & 2 & 0 \\
45 & OSA fibroblástico & 1 & 3 & 2 & 2 & NR \\
46 & OSA teleangiectásico & 0 & NR & 1 & NR & 0 \\
47 & OSA teleangiectásico & 2 & NR & NR & NR & NR \\
48 & OSA periosteal & NR & NR & NR & NR & NR \\
49 & condrosarcoma & 1 & 0 & 2 & 2 & 0 \\
50 & condrosarcoma & 2 & 1 & 4 & 3 & 0 \\
51 & condrosarcoma & 2 & 1 & 4 & 3 & 1 \\
52 & condrosarcoma & 2 & 1 & 4 & 4 & 2 \\
53 & condrosarcoma & NR & 2 & NR & NR & NR \\
54 & tumor de células gigantes & 1 & 0 & 1 & 1 & 0 \\
55 & tumor de células gigantes & 2 & 1 & 2 & 2 & 0 \\
56 & fibrosarcoma & NR & NR & NR & 3 & NR \\
\hline
\end{tabular}

Valores asignados: 0 , menos del $10 \%$ de las células teñidas; 1 , entre el 10 y el $25 \%$; , entre el 25 y el $50 \%$; 3, entre 50 y $75 \%$; 4, entre 75 y $100 \%$; NR, muestra no representativa. OSA: osteosarcoma. 
III.5. Estudio de la localización anatómica con respecto a la inmunomarcación PCNA, VEGF-A, VEGFR-1, BMP-9 y COX-2

\section{III.5.1. Localización anatómica y PCNA}

El valor promedio de expresión del PCNA en los SOs fue $27 \%$ en aquellos de localización apendicular y de $19 \%$ en los de localización axial (Fig. 34). El análisis estadístico mostró diferencias significativas en el porcentaje de expresión del PCNA con respecto a la localización anatómica de los $\mathrm{SOs}\left(\mathrm{P}=0,046286^{*}\right.$; $\mathrm{P}$ $<0,05)$

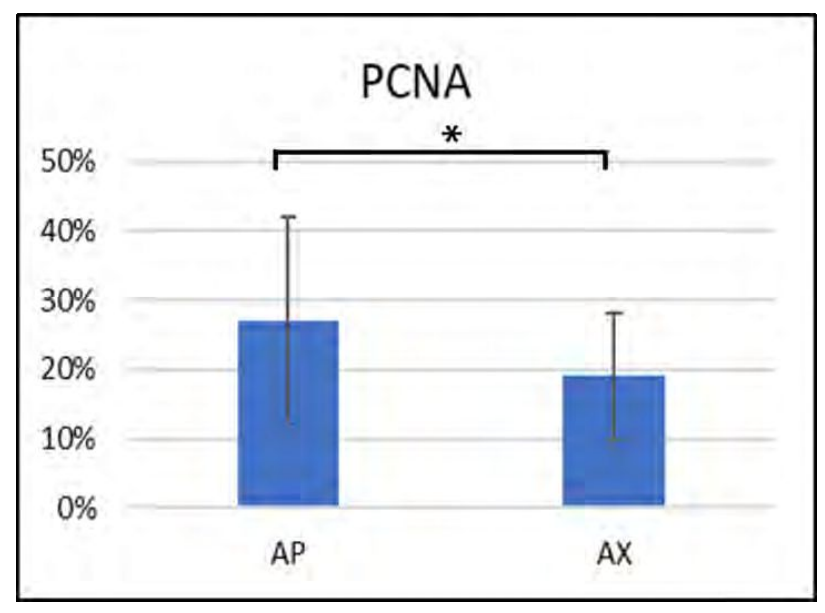

Figura 34. Porcentaje de expresión del PCNA con respecto a la localización anatómica. $\mathrm{AP}=$ apendicular; $\mathrm{AX}=$ axial. Valores expresados en promedio \pm desvío estándar.

\section{III.5.2. Localización anatómica y VEGF-A}

El valor promedio de expresión del VEGF-A en los SOs fue $34 \%$ en aquellos de localización apendicular y $37 \%$ en los de localización axial (Fig. 35). El análisis estadístico no mostró diferencias significativas en el porcentaje de expresión del VEGF-A con respecto a la localización anatómica de los $\mathrm{SOs}(\mathrm{P}=0,815945 ; \mathrm{P}$ $>0,05)$. 


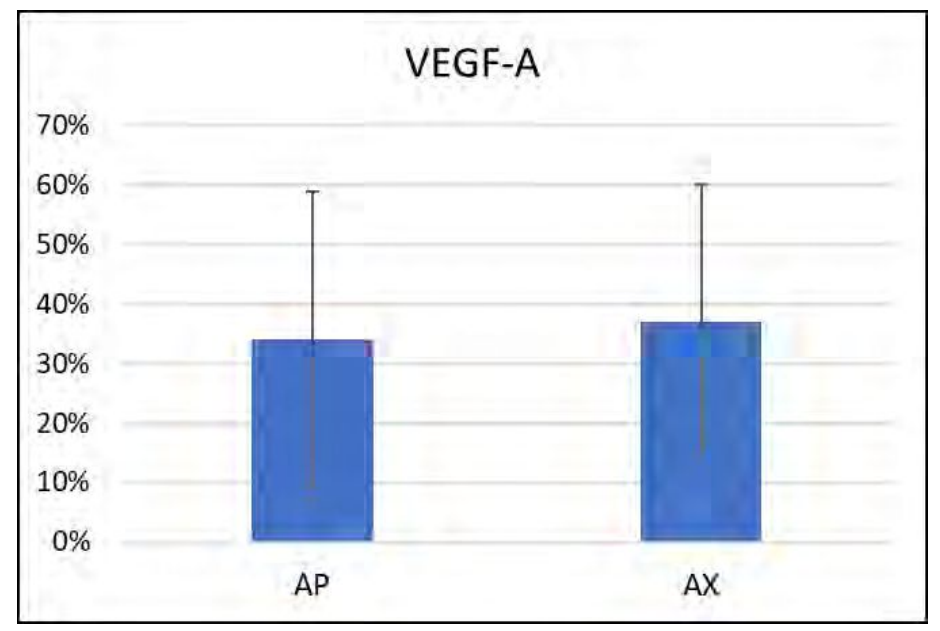

Figura 35. Porcentaje de expresión del VEGF-A con respecto a la localización anatómica. $\mathrm{AP}=$ apendicular; $\mathrm{AX}=$ axial. Valores expresados en promedio \pm desvío estándar.

\section{III.5.3. Localización anatómica y VEGFR-1}

El valor promedio de la expresión del VEGFR-1 en los SOs fue $60 \%$ en aquellos de localización apendicular y $53 \%$ en aquellos con localización axial (Fig. 36). El análisis estadístico no mostró diferencias significativas en el porcentaje de expresión del VEGFR-1 con respecto a la localización anatómica de los $\mathrm{SOs}(\mathrm{P}=$ $0,345893 ; \mathrm{P}>0,05)$. 


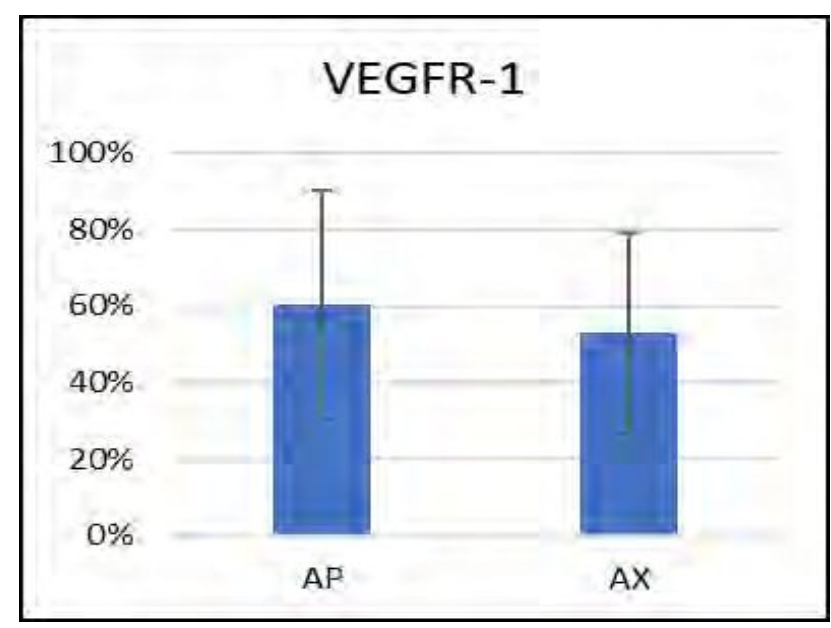

Figura 36. Porcentaje de expresión del VEGFR-1 con respecto a la localización anatómica. $\mathrm{AP}=$ apendicular; $\mathrm{AX}=$ axial. Valores expresados en promedio \pm desvío estándar.

\section{III.5.4. Localización anatómica y BMP-9}

El valor promedio de la expresión de la BMP-9 en los SOs fue 47 \% en aquellos de localización apendicular y $53 \%$ en los de localización axial (Fig. 37). El análisis estadístico no mostró diferencias significativas en el porcentaje de expresión de la BMP-9 con respecto a la localización anatómica de los $\mathrm{SOs}(\mathrm{P}=0,73 ; \mathrm{P}>0,05)$.

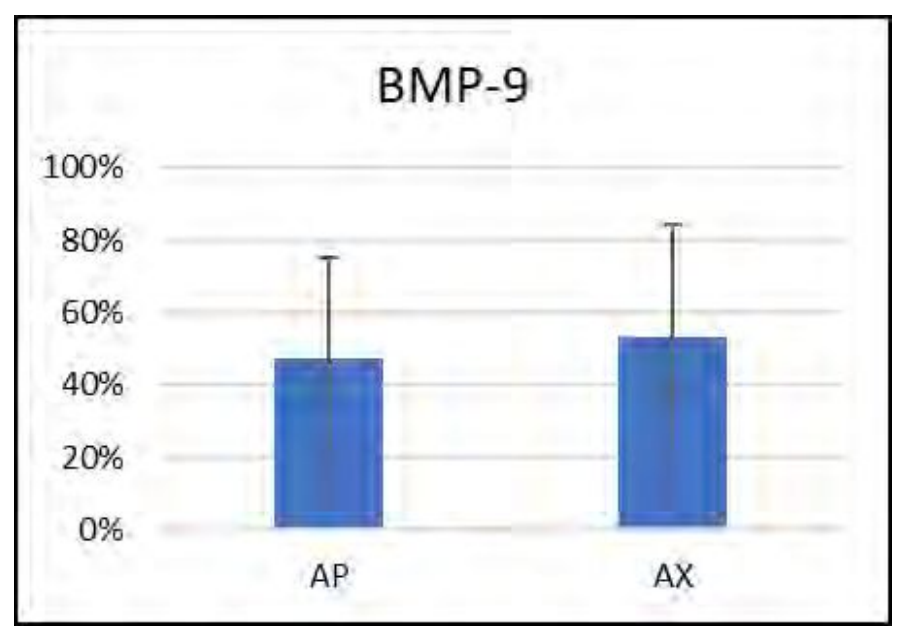

Figura 37. Porcentaje de expresión de la BMP-9 con respecto a la localización anatómica. $\mathrm{AP}=$ apendicular; $\mathrm{AX}=$ axial. Valores expresados en promedio \pm desvío estándar. 


\section{III.5.5. Localización anatómica y COX-2}

El valor promedio de la expresión de la COX-2 en los SOs fue $8 \%$ en aquellos de localización apendicular y $8 \%$ en aquellos con localización axial (Fig. 38). El análisis estadístico no mostró diferencias significativas en el porcentaje de expresión de la $\mathrm{COX}-2$ con respecto a la localización anatómica de los $\mathrm{SOs}(\mathrm{P}=$ 0,696134; $\mathrm{P}>0,05)$.

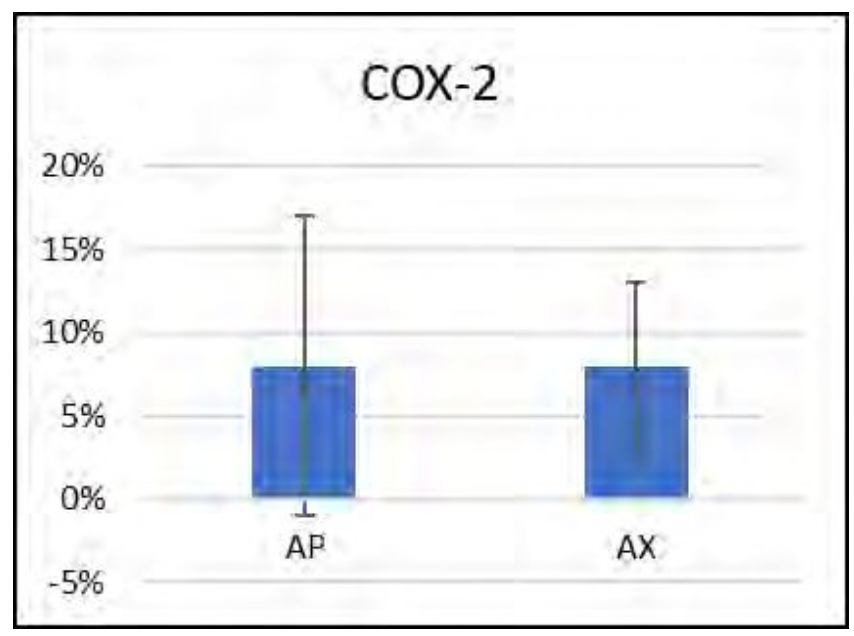

Figura 38. Porcentaje de expresión de la COX-2 con respecto a la localización anatómica. $\mathrm{AP}=$ apendicular; $\mathrm{AX}=$ axial. Valores expresados en promedio \pm desvío estándar. 
III.6. Estudio de la gradación tumoral con respecto a la inmunomarcación PCNA, VEGF-A, VEGFR-1, BMP-9 y COX-2

\section{III.6.1. Gradación tumoral y PCNA}

El valor promedio de la expresión del PCNA en los SOs de grado I fue de $24 \%$, en los de grado II fue de $23 \%$ y en los de grado III fue de $23 \%$ (Fig. 39). No se observaron diferencias estadísticamente significativas en el porcentaje de expresión del PCNA entre los tres grados tumorales $\left(\mathrm{F}_{(2,41)}=0,01, \mathrm{P}=0,9941\right)$.

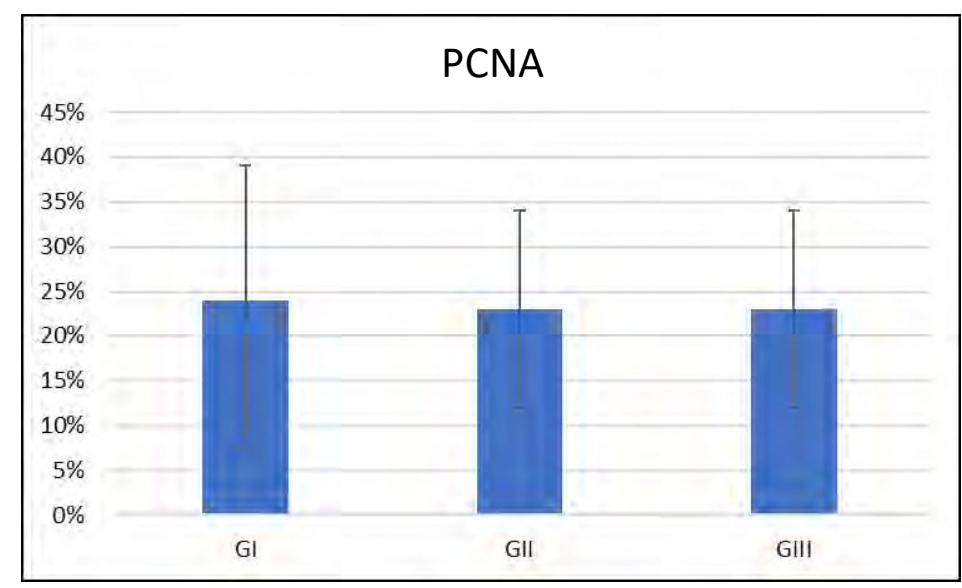

Figura 39. Porcentaje de expresión del PCNA con respecto a los tres grados tumorales. $\mathrm{G}=$ grado. Valores expresados en promedio \pm desvío estándar.

\section{III.6.2. Gradación tumoral y VEGF-A}

El valor promedio de la expresión del VEGF-A en los SOs de grado I fue de 41 $\%$, en los de grado II fue de $33 \%$ y en los de grado III fue de $30 \%$ (Fig. 40). No se observaron diferencias estadísticamente significativas en el porcentaje de 
expresión del VEGF-A entre los tres grados tumorales $\left(\mathrm{F}_{(2,29)}=0,39 ; \mathrm{P}=\right.$ 0,679973).

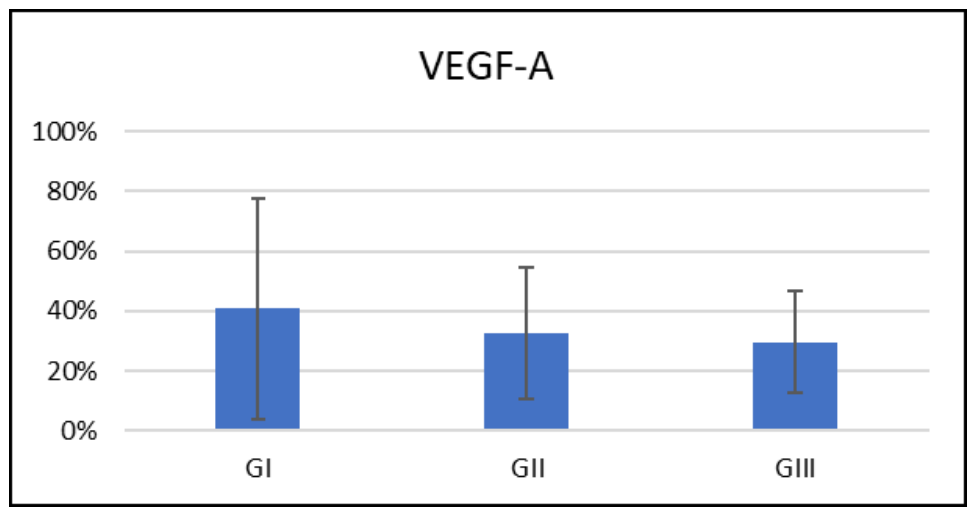

Figura 40. Porcentaje de expresión del VEGF-A con respecto a los tres grados tumorales. $\mathrm{G}=$ grado. Valores expresados en promedio \pm desvío estándar.

\section{III.6.3. Gradación tumoral y VEGFR-1}

El valor promedio de la expresión del VEGFR-1 en los SOs de grado I fue $35 \%$, en los de grado II fue $45 \%$ y en los de grado III fue $68 \%$ (Fig. 41). El análisis estadístico con respecto al porcentaje de expresión del VEGFR-1 entre los tres grados tumorales reveló diferencias significativas $\left(\mathrm{F}_{(2,30)}=4,29, \mathrm{P}=0,022968^{*}\right)$

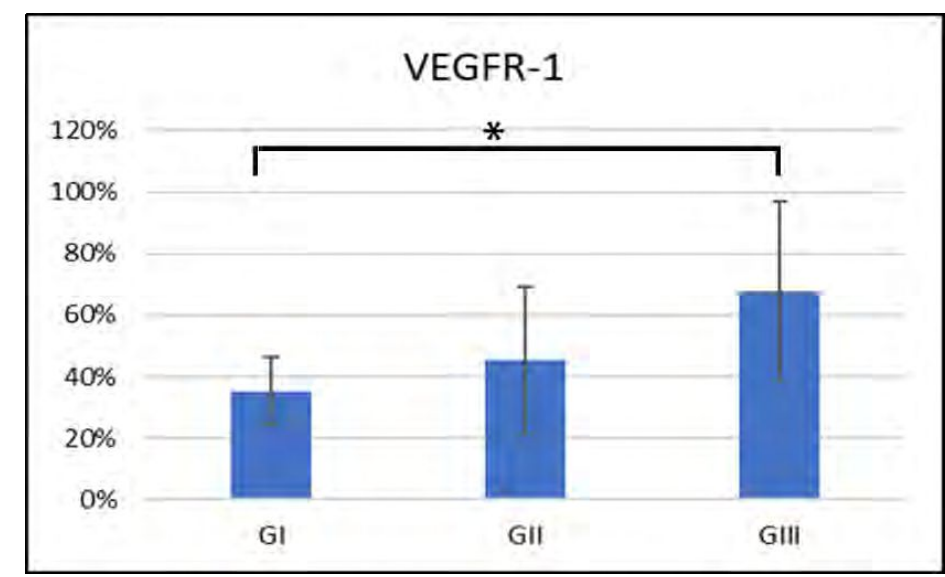

Figura 41. Porcentaje de expresión del VEGFR-1 con respecto a los tres grados tumorales. $\mathrm{G}=$ grado. Valores expresados en promedio \pm desvío estándar. 


\section{III.6.4. Gradación tumoral y BMP-9}

El valor promedio de expresión de la BMP-9 en los SOs fue $45 \%$ en los de grado I, $42 \%$ en los de grado II y $55 \%$ en los de grado III (Fig. 42). No se observaron diferencias estadísticamente significativas en el porcentaje de expresión de la BMP9 entre los tres grados tumorales $\left(\mathrm{F}_{(2,34)}=0,94 ; \mathrm{P}=0,39901\right)$.

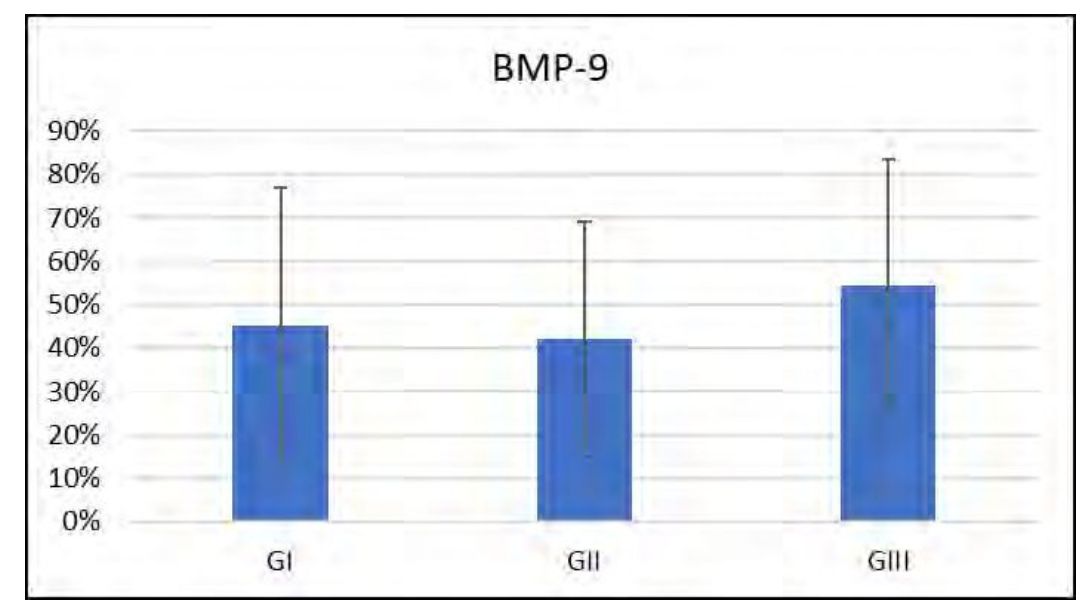

Figura 42. Porcentaje de expresión de la BMP-9 con respecto a los tres grados tumorales. $\mathrm{G}=$ grado. Valores expresados en promedio \pm desvío estándar.

\section{III.6.5. Gradación tumoral y COX-2}

El valor promedio de la expresión de la COX-2 en los SOs fue $7 \%$ en los de grado I; $7 \%$ en los de grado II y $9 \%$ en los de grado III (Fig. 43). No se observaron diferencias estadísticamente significativas en el porcentaje de expresión de la COX2 entre los tres grados tumorales $\left(\mathrm{F}_{(2,29)}=0,11 ; \mathrm{P}=0,896373\right)$. 


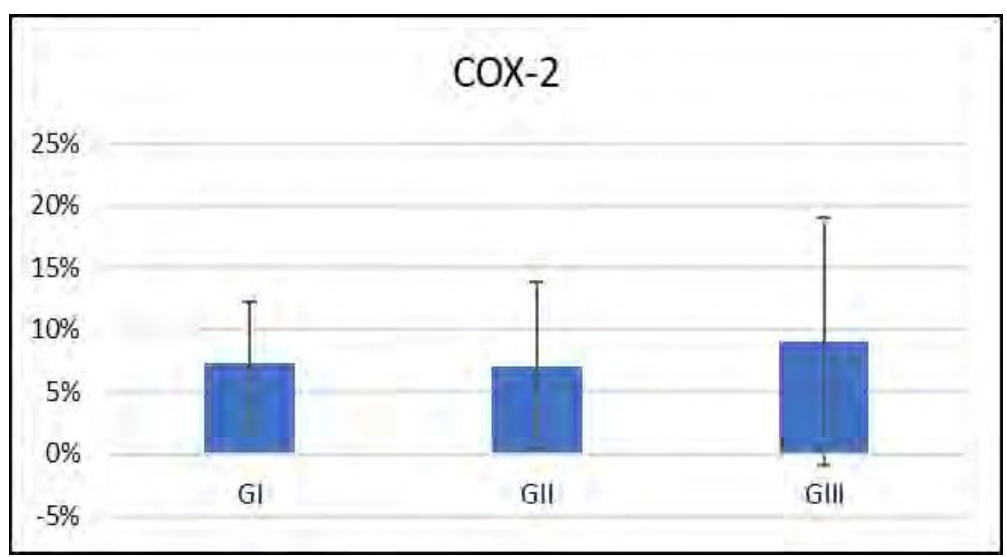

Figura 43. Porcentaje de expresión de la COX-2 con respecto a los tres grados tumorales. $\mathrm{G}=$ grado. Valores expresados en promedio \pm desvío estándar. 


\section{Seguimiento clínico}

\section{IV.1. Pacientes: su selección y seguimiento}

Se seleccionaron tres perros con diagnóstico clínico y anatomopatológico de SO ingresados al Hospital Escuela de la Facultad de Ciencias Veterinarias de la UNLP en el período comprendido entre 2015 y 2017. Se elaboró una planilla que fue entregada a los/as profesionales veterinarios/as del Hospital Escuela para su seguimiento y cuyos datos se detallan en el anexo VI.

Los/las médicos/as veterinarios/as realizaron controles semestrales (o más frecuentes cuando se consideró necesario en función de la evolución clínica). Estos controles consistieron en el examen físico y en estudios de laboratorio, radiográficos y/o ultrasonográficos correspondientes en los casos en que se detectaron signos atribuibles a la presencia de metástasis.

\section{IV.2. Constatación de la muerte relacionada con la neoplasia}

En ningún caso se obtuvo el consentimiento de los propietarios para la realización de la necropsia de los animales.

Luego de culminado el período de seguimiento, las pacientes se clasificaron según su supervivencia ${ }^{*}$ en uno de los siguientes grupos (Diessler, 2009):

\footnotetext{
* Excepto que se realice alguna aclaración en contrario, la palabra "supervivencia" alude a la supervivencia global y no a la supervivencia libre de enfermedad.
} 
- Pacientes con supervivencia baja (SB): muerte dentro de los primeros seis meses a partir del diagnóstico histopatológico.

- Pacientes con supervivencia media (SM): muerte entre seis y dieciocho meses.

- Pacientes con supervivencia alta (SA): muerte luego de dieciocho meses, o vivo en el momento de completar los resultados.

\section{IV.3. Información obtenida de cada uno de los pacientes (casos)}

Caso 1. Se presentó a la consulta (septiembre de 2015) un perro bóxer, macho, de 4 años. El motivo de consulta fue la claudicación del miembro torácico izquierdo. Se solicitaron radiografías de la zona de la articulación escápulo-humeral izquierda. En el estudio radiológico se observó lisis ósea y reacción perióstica incipiente de la diáfisis y de la epífisis proximal del húmero. En el diagnóstico presuntivo se consideraron que estas lesiones podrían ser compatibles con un proceso inflamatorio o neoplásico. En octubre de 2015 se realizó un tratamiento quirúrgico con amputación alta del miembro torácico izquierdo. Se remitió la muestra al Laboratorio de Patología Especial Veterinaria Dr. Bernardo Epstein y el diagnóstico anatomopatológico fue OSA osteoblástico productivo, con una gradación tumoral alta (GIII). Por consiguiente, se inició tratamiento médico con quimioterapia. El tratamiento quimioterápico consistió en 3 dosis de carboplatino $(300 \mathrm{mg} / \mathrm{m} 2)$ con un intervalo de 21 días entre cada dosis. Los propietarios decidieron discontinuar el tratamiento durante 2 meses. Posteriormente, se retomó el tratamiento inicial con 3 dosis de carboplatino $(300 \mathrm{mg} / \mathrm{m} 2)$ cada 21 días; por decisión de los propietarios no se continuó con el tratamiento. 
Durante el seguimiento se realizaron controles iniciales una vez al mes y luego cada 2 meses, que consistieron en hemogramas, radiografías de tórax y del miembro torácico derecho. En el séptimo control (mayo de 2017) se solicitó un nuevo estudio radiológico del miembro torácico derecho y se halló una reacción perióstica en húmero, radio, cúbito y metacarpianos, compatible con una osteopatía hipertrófica. Por otra parte, en el estudio radiológico del tórax se evidenció un nódulo (menos de 2 mm de diámetro) en el campo medio caudal izquierdo. Posteriormente se realizó la eutanasia con el consentimiento de los propietarios, que no accedieron a realizar la necropsia. Este paciente se consideró dentro del grupo SA.

Caso 2. Se presentó a la consulta (junio de 2016) un perro, mestizo, macho, de 10 años. El motivo de la consulta fue claudicación del miembro pelviano derecho y neoformación en distal de la tibia. En el estudio radiológico se observó una lesión osteolítica agresiva en el extremo distal de la tibia compatible con una neoplasia ósea. Se realizó un tratamiento quirúrgico con la amputación alta del miembro. Se remitió la muestra al Laboratorio de Patología Especial Veterinaria Dr. Bernardo Epstein y el diagnóstico anatomopatológico fue OSA osteoblástico productivo, con una gradación tumoral alta (GIII). Continuaron con un tratamiento médico en base a drogas quimioterápicas. El tratamiento quimioterápico consistió en una primera aplicación de doxorrubicina $(30 \mathrm{mg} / \mathrm{m} 2)$ que se repitió a los 21 días. Sin embargo, el animal tuvo que ser hospitalizado debido a una descompensación que sufrió posterior al tratamiento motivo por el cual se discontinuó definitivamente con el tratamiento quimioterápico. Continuó con los seguimientos y controles clínicos respectivos. En agosto de 2017 se realizó un control clínico que incluyó una ecografía abdominal y radiografía de tórax. Las imágenes ecográficas no 
evidenciaron metástasis a nivel abdominal y no presentó hallazgos radiológicos compatible con metástasis en el momento del estudio. Actualmente se encuentra estable con controles clínicos cada 6 meses. El último control del paciente se realizó en diciembre de 2019. Este paciente se consideró dentro del grupo SA.

Caso 3. Se presentó a la consulta (abril de 2017) un perro rottweiler, macho, de 8 años. El motivo de la consulta fue claudicación del miembro torácico derecho, de tres semanas de evolución. Se solicitó realizar un estudio radiológico del miembro, donde se observó una lesión osteomielítica de la epífisis proximal del húmero derecho, sugestiva de neoplasia ósea. En principio, se procedió a realizar un tratamiento quirúrgico que consistió en la amputación alta del miembro. Se remitió la muestra al Laboratorio de Patología Especial Veterinaria Dr. Bernardo Epstein y el diagnóstico anatomopatológico fue OSA osteoblástico productivo, con una gradación tumoral alta (GIII). El tratamiento médico consistió en 7 aplicaciones de doxorrubicina $(30 \mathrm{mg} / \mathrm{m} 2)$ con un intervalo de 21 días. Previamente a cada dosis se realizó un ecocardiograma de control debido a la cardiotoxicidad que produce la doxorrubicina en esta raza. En mayo de 2018 el paciente ingresó a la consulta por decaimiento e inapetencia. Se realizó un examen clínico y se indicó análisis de sangre, ecografía abdominal y radiografía de tórax. En el estudio ecográfico se halló una neoformación en el riñón derecho y linfadenomegalia ilíaca. Bajo sedación se realizó una punción ecoguiada de la neoformación en riñón y del linfonódulo para su estudio citológico. El diagnóstico citológico fue neoplasia mesenquimática maligna compatible con metástasis del tumor primario OSA. Por otra parte, no se encontraron hallazgos radiológicos en el tórax. A continuación, los propietarios 
decidieron la eutanasia y no accedieron a realizarle la necropsia. Este paciente se consideró dentro del grupo SM.

Si bien la cantidad de casos clínicos fue solamente de tres casos, dos de ellos correspondieron a razas con alto riesgo de desarrollo de OSA, el rottweiler y el bóxer (Thompson y Dittmer, 2017). En los tres casos, el diagnóstico fue OSA osteoblástico productivo. En coincidencia con lo citado por los diferentes autores, fue el subtipo histológico de presentación más frecuente (Brodey y col., 1969; Thompson y Dittmer, 2017). En todos los casos la gradación fue alta (GIII). En dos de los casos la edad de presentación fue entre los 8 y 10 años y la localización anatómica fue en el miembro torácico, en coincidencia con otros autores (Misdorp y Hart, 1979; Heyman y col., 1992; Ehrhart y col., 2013; Craig y col., 2016). De acuerdo con el estudio realizado por Belda y col., (2016) el tiempo promedio de sobrevida luego de la amputación seguida de quimioterapia adyuvante varían entre 104 y 413 días, sin diferencias significativas para doxorubicina con respecto al carboplatino como agentes quimioterápicos únicos, con tasas de supervivencia media al año del 34 al $50 \%$. Sin embargo, el tiempo de sobrevida a los dos años es más alta con carboplatino (Kent y col., 2004). Según Belda y col., (2016) no se hallaron diferencias en el tiempo de supervivencia alternando el tratamiento con carboplatino y doxorrubicina, tampoco con la aplicación de quimioterapia antes, durante o hasta 3 semanas después de la cirugía. En los casos clínicos evaluados en esta tesis se encontró que el caso 1 presentó un tiempo de sobrevida más extenso (600 días) comparado con el caso 3 (390 días). En coincidencia con lo descripto por Kent y col., (2004), la sobrevida fue mayor en aquel paciente tratado con carboplatino. De acuerdo con lo descripto por Saam y col., (2011), la quimioterapia 
adyuvante extiende la supervivencia de los perros con OSA apendicular, sin embargo, en medicina veterinaria no se ha establecido un protocolo óptimo. Además, Saam y col., (2011) hallaron que el tratamiento con carboplatino adyuvante fue bien tolerado y el tiempo promedio de sobrevida fue de 277 días con una tasa de supervivencia al año, dos años y tres años del $36 \%, 22 \%$ y $19 \%$ respectivamente. Según Szewczyk y col., (2015) actualmente el método más eficaz para el tratamiento del OSA en los perros es combinar el tratamiento quirúrgico con quimioterapia y radioterapia. Sin embargo, para los/las profesionales veterinarios/as sigue siendo un desafío mejorar la actividad antitumoral y la frecuencia de metástasis con los mínimos efectos secundarios de estos fármacos citostáticos (Szewczyk y col., 2015). En medicina humana y veterinaria el estudio IHQ no es utilizado habitualmente para el diagnóstico de los SOs como sí lo es para los sarcomas de tejidos blandos, sin embargo, es utilizado en circunstancias que así lo requieran (Thompson y Dittmer, 2017). Creemos que el estudio IHQ podría evidenciar blancos terapéuticos y, en este sentido, ajustar una terapéutica adecuada para cada perro con SO de manera similar a lo que en la actualidad se está realizando sobre pacientes humanos (Czerniak y Dorfman, 2016). 


\section{Discusión}

Los SOs primarios se observan con frecuencia en perros y gatos, aunque también se presentan ocasionalmente en otros animales domésticos (Slayter y col., 1994). Dentro de los principales subtipos de SOs, el OSA es el más común que se desarrolla en perros y gatos, con una frecuencia del $80 \%$ y $50 \%$ respectivamente (Brodey y col., 1969; Ehrhart y col., 2013). En nuestro estudio, el OSA fue la neoplasia de presentación más frecuente, seguido por el condrosarcoma, el tumor de células gigantes y el fibrosarcoma que representaron un porcentaje bajo entre los SOs analizados. Estos resultados concuerdan con lo comunicado previamente por otros autores (Brodey y col., 1969; Ehrhart y col., 2013; Craig y col., 2016; Thompson y Dittmer, 2017). Asimismo, en el presente trabajo se halló que, dentro de los subtipos histológicos de OSAs, el OSA osteoblástico productivo fue el más frecuente, seguido por el OSA tipo células gigantes y el OSA condroblástico. En este sentido, Craig y col., (2016) destacaron el OSA osteoblástico productivo como el subtipo de presentación más frecuente, lo que concuerda con lo hallado en este estudio. En este contexto, para arribar a un diagnóstico definitivo, es preciso considerar las características histológicas, aspectos de la reseña, tales como la raza, la edad, el sexo; como así también el sitio anatómico de la lesión, la evolución y los estudios radiológicos. Dichos datos constituyen aportes necesarios, especialmente 
cuando se trata de material de biopsia poco representativo de la lesión que podría conducir a errores en el diagnóstico (Thompson y Dittmer, 2017). Diferentes autores mencionaron que la localización anatómica más frecuente de los SOs, particularmente del OSA, es el esqueleto apendicular, con un comportamiento más agresivo con respecto al OSA axial (Loukopoulos y Robinson, 2007; Craig y col., 2016; Thompson y Dittmer, 2017). En coincidencia con estos autores, en el presente estudio los SOs se presentaron con mayor frecuencia en el esqueleto apendicular. Asimismo, dentro de los subtipos de SOs, el OSA con localización apendicular fue el de presentación más frecuente. El condrosarcoma, el tumor de células gigantes y el fibrosarcoma se presentaron con una baja frecuencia en ambas localizaciones.

En este trabajo la edad promedio hallada para los SOs fue de 8,7 años. Además, para el OSA y condrosarcoma, se encontró una mayor frecuencia entre los 8 y 10 años, en coincidencia con lo hallado por otros autores (Misdorp y Hart, 1979; Heyman y col., 1992; Craig y col., 2016; Thompson y Dittmer, 2017). Por otro lado, observamos para el tumor de células gigantes y el fibrosarcoma mayor frecuencia de presentación entre los 2 y 6 años y a los 12 años, respectivamente. Dichos resultados demostraron una asociación estadísticamente significativa entre el subtipo histológico de SOs y la edad. Schmidt y col., (2013) consideraron la edad como un factor pronóstico asociado con la mortalidad y alta incidencia de metástasis. No obstante, en el presente estudio no se incluyeron estudios de seguimiento y sobrevida.

Según se consignó en "Resultados” los SOs fueron más frecuentes en los machos. Igualmente, se observó que, dentro de los principales subtipos de SOs, el OSA se presentó con mayor frecuencia en machos. Estos resultados concuerdan con 
diferentes estudios previos que encontraron una mayor frecuencia de OSA en los machos (Brodey y col., 1969; Misdorp y Hart, 1979; Spodnick y col., 1992; Kirpensteijn y col., 2002; Craig y col., 2016; Thompson y Dittmer, 2017). Para el caso del condrosarcoma, la presentación en este estudio fue mayor en las hembras en coincidencia con lo mencionado por otros autores (Craig y col., 2016; Thompson y Dittmer, 2017). El tumor de células gigantes y el fibrosarcoma se presentaron también con mayor frecuencia en las hembras.

Por otra parte, en los casos estudiados en el presente trabajo la frecuencia de los SOs, en particular el OSA, fue mayor en razas grandes en coincidencia con lo hallado en estudios previos (Ehrhart y col., 2013; Craig y col., 2016; Thompson y Dittmer, 2017). Conjuntamente, se encontró que el OSA se presentó con mayor frecuencia en el rottweiler, seguido por mestizos, ovejero alemán, gran danés y dóberman. El condrosarcoma tuvo una mayor frecuencia en mestizos seguido por el rottweiler; mientras que el tumor de células gigantes se presentó con una frecuencia similar en mestizos y rottweiler. El único caso de fibrosarcoma se presentó en un mestizo.

Por otra parte, en el presente trabajo de tesis se evaluó la GT de los SOs en perros. En este sentido, se demostró que los OSAs GIII tuvieron una mayor frecuencia, sin embargo, no se halló una asociación estadísticamente significativa entre los subtipos histológicos de SOs y los tres grados tumorales. Se analizó, además, la GT en el grupo de OSAs. Dentro de los subtipos de OSAs, el osteoblástico productivo y el tipo células gigantes tuvieron una mayor frecuencia de GIII. Asimismo, nuestros resultados demostraron que los subtipos de OSAs con respecto a los tres grados tumorales tuvieron una asociación estadísticamente significativa. Los 
resultados presentados coinciden con los hallados por Kirpensteijn y col., (2002) y Loukopoulos y Robinson, (2007) quienes demostraron que la mayoría de los subtipos de OSAs presentaron una GIII. Al mismo tiempo, la existencia de una fuerte asociación entre el grupo de OSAs y la GT demostrada en la presente tesis, coincide ampliamente con los resultados de Loukopoulos y Robinson, (2007). Estos autores enfatizaron la importancia de clasificar a los OSAs en subtipos histológicos y evaluarlos como entidades individuales. De modo similar, Wang y col., (2006) hallaron una correlación significativa entre los subtipos de OSAs humanos y la gradación tumoral. En este sentido, diferentes estudios referidos a OSA en perros y humanos demostraron que existe una correlación entre la GT, el tiempo de sobrevida y la frecuencia de metástasis y recidivas. En consecuencia, estas condiciones estuvieron asociadas con un pronóstico desfavorable (Kirpensteijn y col., 2002; Loukopoulos y y Robinson, 2007; Mangham y Athanasou, 2011; Coyle y col., 2015). Sin embargo, en el estudio realizado por Kruse y col., (2013) y Schott y col., (2018) sobre OSAs en perros, la GT no tuvo relación con la presencia de metástasis, ni tampoco operó como un predictor de supervivencia. Asimismo, Schott y col., (2018) proponen implementar mejores herramientas para brindar un pronóstico apropiado debido a que, en la actualidad, no existe un sistema de gradación validado universalmente para los OSAs en los perros. Por otra parte, Kruse y col., (2013) evaluaron perros con OSA axial y demostraron que la localización anatómica y los niveles de FAS actúan como predictores del tiempo de sobrevida, no así el grado histológico. En el presente trabajo de tesis se evaluaron, además, los condrosarcomas de los cuales dos fueron GII, uno GI y uno GIII. La mayoría de estos tumores manifestaron un alto índice mitótico $(>30$ mitosis por 
campo) y un marcado pleomorfismo. Además, en este estudio se evaluó el tumor de células gigantes, uno fue GII y uno GIII, sin embargo, no se encontraron casos de baja gradación (GI) debido a que la cantidad de estos tipos fue insuficiente. No obstante, en medicina veterinaria existen estudios previos que evalúan la GT en los OSAs, no así en el resto de los SOs. En medicina humana no se han descripto criterios histológicos y, por consiguiente, no se ha generado un sistema de gradación para el tumor de células gigantes que sea predictivo de la progresión tumoral o de valor pronóstico (Gouin y col., 2012). Sin embargo, en los SOs humanos, de manera similar a lo que ocurre en muchos sarcomas de tejido blando, el tipo histológico, por sí mismo, determina el comportamiento biológico, define la GT y es utilizado entonces como un predictor de supervivencia libre de recidiva y supervivencia general (Bispo Júnior y Camargo, 2009; Rubin y col., 2010; Czerniak y Dorfman, 2016). El sarcoma de Ewing, el condrosarcoma mesenquimatoso y el OSA convencional son considerados tumores muy agresivos y de elevada gradación. Además, el OSA parosteal, un subtipo de OSA periférico, es definido como un tumor de baja gradación (Czerniak y Dorfman, 2016). Los informes histopatológicos de muestras óseas humanas son realizados, actualmente, considerando el protocolo del College of American Pathology (CAP) (Rubin y col., 2010). En medicina veterinaria hasta el momento no se ha podido homologar la información que permita establecer un protocolo, en general debido a la falta de información y recopilación de datos. En este sentido, son insuficientes los datos sobre supervivencia e intervalos libres de enfermedad en los estudios retrospectivos debido a que muchos propietarios de animales eligen la eutanasia poco después del diagnóstico. No obstante, la investigación dirigida a identificar nuevos blancos 
moleculares implicados en el desarrollo y la progresión del cáncer en los perros podría ayudar a estadificar con precisión un tumor y predecir el comportamiento clínico, el pronóstico y la respuesta a la terapia (Mukaratirwa, 2005). En este sentido, la búsqueda de mejores marcadores predictivos de pronóstico se centra en los mecanismos moleculares que subyacen el comportamiento del tumor tales como la progresión alterada del ciclo celular, la proliferación, la apoptosis y la angiogénesis (Mukaratirwa, 2005).

La técnica de inmunonohistoquímica es utilizada para detectar los patrones de expresión de antígenos específicos en diferentes tejidos. Existen cambios en el patrón de expresión antigénico que se producen durante el desarrollo embrionario y ontogenético o durante procesos patológicos, incluido el cáncer (Duraiyan y col., 2012). En el presente trabajo de tesis se evaluó la expresión de diferentes moléculas implicadas en el comportamiento biológico de los SOs que podrían ayudar a una correcta estadificación, estimar el comportamiento clínico, como también contribuir en el desarrollo de nuevas estrategias terapéuticas para los perros con SOs. Conjuntamente, los datos obtenidos en el presente estudio permitirán avanzar sobre la elaboración de un protocolo que aproxime a un pronóstico preciso para los perros con SOs.

Por tanto, en el presente trabajo de tesis fueron evaluados la localización anatómica, el subtipo histológico, la GT y la inmunomarcación con PCNA, VEGF-A, VEGFR1, BMP-9 y COX-2. Se realizó un análisis sobre la localización anatómica y su relación con la GT debido a que ambas variables fueron descriptas por diferentes autores como predictores de pronóstico (Kirpensteijn y col., 2002; Loukopoulos y Robinson, 2007; Boerman y col., 2012; Schmidt y col., 2013). Nuestros resultados 
demostraron que los SOs de localización apendicular manifestaron elevada gradación tumoral (GIII) respecto de los SOs con localización axial. En un estudio previo, se ha comunicado un resultado similar pero considerando solamente el grupo de OSAs (Loukopoulos y Robinson, 2007). Si bien la relación de ambas variables (localización anatómica y gradación tumoral) con respecto al pronóstico es controvertida, se considera que los resultados del presente trabajo de tesis serán un aporte valioso para la comprensión del comportamiento y la evolución de la enfermedad, si bien no fueron incluidos datos de seguimiento.

El estudio histopatológico convencional es suficiente para identificar y clasificar adecuadamente a los SOs. Sin embargo, la última década se caracterizó por los significativos avances en medicina humana sobre el estudio de ciertos biomarcadores de importancia para el diagnóstico diferencial de los tumores óseos (Czerniak y Dorfman, 2016). Surgieron nuevas técnicas moleculares y hubo adelantos en el campo de la citogenética y las técnicas IHQs. La utilización de técnicas IHQs para la detección de biomarcadores en los tumores óseos y las lesiones pseudotumorales en humanos se ha convertido en un método auxiliar aceptado y ampliamente utilizado para el diagnóstico histopatológico. De esta manera, proporcionan un pronóstico más certero al paciente (Czerniak y Dorfman, 2016). No obstante, en medicina veterinaria se dispone de una cantidad limitada de anticuerpos de uso específico para las especies domésticas. A causa de ello, en ciertas circunstancias se hace necesario utilizar aquellos producidos para uso humano, en los casos en que se haya probado la existencia de reactividad cruzada entre antígenos humanos y animales. Asimismo, debe considerarse que los anticuerpos monoclonales producidos contra antígenos humanos reconocen un 
epítope específico de ese antígeno y éste puede o no variar entre las especies (Rhind, 2002; Vilches Moure y Ramos Vara, 2005).

El PCNA es un marcador de proliferación celular ampliamente utilizado, que se encuentra presente en todas las etapas del ciclo celular menos en $\mathrm{G}_{0}$ (Wang y col., 2006). En el presente trabajo de tesis, todos los casos de SOs mostraron inmunomarcación para el PCNA, sin embargo, en gran parte de los SOs, el porcentaje de células atípicas positivas por campo de observación no superó el 50 \%. Asimismo, se analizó la relación entre la expresión del PCNA y las diferentes variables tales como la localización anatómica, el tipo histológico y la GT. Se encontraron diferencias estadísticamente significativas entre la expresión del PCNA y la localización anatómica, con mayor expresión del PCNA en los SOs con localización apendicular. Esto resultados coinciden, en parte, con los hallazgos informados en estudios previos, que describen a los OSAs apendiculares con una mayor capacidad proliferativa (Loukopoulos y Robinson, 2007; Ehrhart y col., 2013; Schmidt y col., 2013). Asimismo, en medicina humana la sobreexpresión del PCNA en los OSAs se ha asociado con un peor pronóstico y un corto tiempo de sobrevida (Torres Bernal y col., 2006; Wang y col., 2017). Sin embargo, la expresión del PCNA no tuvo significación estadística con respecto al tipo histológico y la GT en los SOs de perros incluidos en este estudio. Es probable que la cantidad de SOs haya sido insuficiente para poner de manifiesto la relación entre la actividad proliferativa y la GT.

Por otra parte, nuestros resultados demostraron, además, que la expresión del VEGF-A tuvo diferencias de significación estadística entre los subtipos de SOs en perros. Dentro del grupo de OSA, más de la mitad presentó una inmunomarcación 
que superó el $50 \%$ de células atípicas por campo de observación. Estos resultados coinciden con los estudios realizados por DuBois y Demetri, (2007) en humanos. Conjuntamente, en el presente trabajo de tesis se evaluó la expresión del VEGFR1 en los SOs. De esta manera, se demostró que la expresión del VEGFR-1 no tuvo diferencias de significación estadística entre los subtipos de SOs. Sin embargo, gran parte de los OSAs presentaron más del $50 \%$ de células neoplásicas positivas por campo de observación. Asimismo, en tres condrosarcomas la inmunomarcación superó el $75 \%$ de células atípicas por campo de observación. De hecho, los hallazgos de la presente tesis apoyan lo propuesto por Rivera Valentin y col., (2015), Saavedra Torres y col., (2017) y Xie y col., (2017), quienes indicaron que el VEGF es un factor angiogénico clave y probablemente la vía de señalización más importante en la angiogénesis tumoral en el OSA. Dos estudios en medicina humana describen al VEGF como un blanco terapéutico para el tratamiento de pacientes con sarcomas e igualmente, como un potencial predictor del curso clínico de la enfermedad (Akatsu y col., 2017; Xie y col., 2017). En este contexto, fue analizada aquí la expresión de VEGF-A y VEGFR-1 con respecto a los tres grados tumorales y la localización anatómica con interesantes resultados. Los hallazgos demostraron mayor expresión del VEGFR-1 en los SOs con localización apendicular. Sin embargo, la expresión de VEGF-A y VEGFR-1 respecto de la localización anatómica no fue estadísticamente significativa. No obstante, se demostró que la expresión del VEGFR-1 fue mayor en aquellos SOs de GIII, comprobándose de esta manera una asociación estadísticamente significativamente en la expresión del VEGFR-1 entre los tres grados tumorales. Los resultados expresados coinciden, en parte, con lo descripto por Kirpensteijn y col., (2002), 
Loukopoulos y Robinson, (2007), Dimopoulou y col., (2008), Coyle y col., (2015), que demostraron que el OSA de mayor gradación (GIII) presentó un comportamiento más agresivo, alta frecuencia de metástasis y, en consecuencia, un tiempo de sobrevida muy corto. En este contexto, la expresión del VEGF y VEGFR en los SOs de GIII analizados en este estudio podría sugerir mayor capacidad proliferativa, infiltrativa y metastásica, considerando que el VEGF es un regulador clave en el proceso de angiogénesis. No hemos encontrado estudios en medicina veterinaria que establezcan una relación entre la localización anatómica, la GT y la expresión del VEGF con los SOs. Por lo tanto, en la medida de nuestro conocimiento, estos hallazgos son inéditos y podrían constituir un aporte valioso para la comprensión de la biología tumoral de los SOs en perros. Asimismo, los resultados de este estudio son consistentes con trabajos previos donde fue demostrado que el OSA apendicular tuvo un comportamiento más agresivo, mayor incidencia de metástasis y un pronóstico desfavorable (Kirpensteijn y col., 2002; Loukopoulos y Robinson, 2007; Schmidt y col., 2013; Xie y col., 2017)

Diferentes trabajos científicos han mencionado el rol que presentan ciertos miembros de la familia de las BMPs en la angiogénesis tumoral y la progresión del cáncer. En este sentido, las alteraciones en la vía de señalización de estas proteínas, en particular las BMP-9 y BMP-10, han sido asociadas con la angiogénesis tumoral y con un peor pronóstico en pacientes humanos con OSA (Oh y col., 2000; Cunha y col., 2010; Miyazono y col., 2010; Cunha y Pietras, 2011; Nguyen y col., 2014; Cunha y col., 2015; Ye y Jiang, 2016; Akatsu y col., 2017). Teniendo en cuenta el rol que exhiben las BMP-9 y BMP-10 en la angiogénesis tumoral en humanos, en el presente trabajo, se ha evaluado la expresión de la BMP-9 en los SOs de perros. 
Nuestros resultados demostraron que la BMP-9 fue expresada en todos los SOs analizados con una inmunomarcación localizada en el citoplasma de las células atípicas. Sin embargo, no se encontraron diferencias estadísticamente significativas con respecto a la expresión de la BMP-9 entre los diferentes subtipos de SOs. No obstante, la mayoría de los OSAs presentaron una gran cantidad de células neoplásicas positivas para la BMP-9 respecto de los otros subtipos de SOs. De los cuatro condrosarcomas analizados en este trabajo, tres presentaron más de la mitad de las células neoplásicas con inmunomarcación. Con respecto a los dos tumores de células gigantes analizados, uno de ellos presentó menos de la mitad de las células atípicas positivas y el otro tuvo una inmunomarcación que superó el 50 \% de células neoplásicas por campo de observación. El único caso de fibrosarcoma superó el 75 \% de células neoplásicas positivas. David y col., (2007) y Ye y Jiang, (2016) demostraron en humanos que las señales mediadas por el VEGF y las BMP9 y -10 están involucradas en la angiogénesis tumoral. Por consiguiente, los resultados obtenidos en este estudio podrían sugerir que la señalización mediada por el VEGF o la BMP-9 también podría estar involucrada en la angiogénesis y la progresión de los SOs en perros. No obstante, se necesitan mayor cantidad de estudios en perros para poder obtener datos más concluyentes. Si bien el rol de las BMPs en la patogénesis de los tumores óseos no es del todo claro y existe información muy diversa, se considera que la activación de la vía de señalización mediada por las BMPs está relacionada con un peor pronóstico en pacientes humanos con OSA (Nguyen y col., 2014). Al mismo tiempo, estos pacientes presentaron mayor incidencia de metástasis, resistencia a la quimioterapia y una sobrevida más corta (Yoshikawa y col., 1985, 1988; Nguyen y col., 2014). En este 
sentido, Akatsu y col., (2017) demostraron en humanos que las terapias antiangiogénicas dirigidas contra ambos factores de crecimiento, el VEGF y la BMP-9, son más efectivas para detener el crecimiento tumoral en contraste con la utilización de los mismos blancos moleculares de manera individual. Consideramos que los resultados obtenidos en este trabajo son inéditos y proporcionarán una base para el estudio de ambos factores de crecimiento como blancos terapéuticos en el tratamiento oncológico de los perros con SOs.

Por otro lado, las células tumorales de distintas neoplasias, incluidos los SOs, expresan la COX-2 y el aumento significativo de esta enzima en el tejido tumoral sustenta la idea de que esta isoforma juega un papel importante en el proceso de carcinogénesis (Fosslien, 2000; Xiong y col., 2003). Fosslien, (2000) informó la sobreexpresión de la COX-2 en el cáncer de colon y colorrectal, dos tumores de suma importancia en los seres humanos. Sin embargo, los niveles de la COX-2 fueron variables en diferentes tipos de tumores incluso, dentro del propio tejido tumoral (Fosslien, 2000). Por otra parte, Davar (2001) indicó que la inhibición de la COX-2 redujo la carga tumoral y, por ende, los factores liberados por el tumor responsables de inducir el dolor. En el presente trabajo de tesis fue evaluada la expresión de la COX-2 en los subtipos de SOs en perros. Los resultados en este estudio demostraron que la COX-2 fue expresada en todos los SOs analizados con una inmunomarcación localizada preferentemente en el citoplasma de las células atípicas. No obstante, no se encontraron diferencias estadísticamente significativas en la expresión de la COX-2 entre los subtipos de SOs. La expresión de la COX-2 para el caso de OSA, condrosarcoma y tumor de células gigantes, fue menor al 50 \% de células neoplásicas positivas. El único caso de fibrosarcoma no mostró 
inmunomarcación para la COX-2. Sin embargo, se demostró que la expresión de la COX-2 fue mayor en los SOs con localización apendicular y, en aquellos con una GIII. Consideramos que estos hallazgos podrían estar vinculados con un comportamiento más agresivo del tumor y peor pronóstico. Existen pocos estudios que relacionen los parámetros analizados aquí conjuntamente con la expresión de la COX-2 tanto en los animales como en los seres humanos. En este sentido, creemos que el uso de los inhibidores de la COX-2 será un tratamiento promisorio para el manejo del dolor que produce el cáncer óseo y, además, podrán disminuir la carga tumoral. 


\section{Conclusiones}

Sobre la base de los resultados obtenidos a partir del presente trabajo de tesis podemos concluir que:

- De los SOs en perros analizados en este estudio, el OSA fue el de presentación más frecuente, seguido por el condrosarcoma, el tumor de células gigantes y el fibrosarcoma.

- Entre los OSAs, el osteoblástico productivo fue el de presentación más frecuente, seguido por el OSA tipo células gigantes y el OSA condroblástico.

- La localización apendicular fue el sitio anatómico más habitual entre los SOs analizados. En este sentido, el OSA tuvo una mayor frecuencia en la localización apendicular y, el condrosarcoma, el tumor de células gigantes y el fibrosarcoma se presentaron con una frecuencia similar en ambas localizaciones.

- La edad de presentación de los SOs estuvo entre los 7 y 11 años, con una edad promedio de 8 años. En el grupo de los OSAs, se observó una mayor frecuencia entre los 8 y 9 años de edad. Asimismo, se demostró una fuerte asociación entre los SOs y la edad de presentación.

- La frecuencia de SOs fue mayor en los machos. También, el OSA se presentó con mayor frecuencia en los machos. Para el condrosarcoma, el tumor de células gigantes y el fibrosarcoma la frecuencia fue mayor en las hembras. 
- Los perros grandes a gigantes mostraron mayor frecuencia de SOs. Los mestizos tuvieron una mayor frecuencia y las razas principalmente afectadas fueron: rottweiler, ovejero alemán, dóberman y gran danés. Asimismo, se encontró una mayor frecuencia de OSA en el rottweiler y mestizos. Además, el condrosarcoma tuvo una mayor frecuencia en mestizos; el tumor de células gigantes se presentó con una frecuencia similar en mestizos y rottweiler y, el único caso de fibrosarcoma se presentó en un mestizo.

- Los SOs analizados presentaron una gradación tumoral alta (GIII). Sin embargo, no se hallaron diferencias estadísticamente significativas entre la GT y el subtipo histológico de SOs. Asimismo, la GT fue evaluada en el grupo de OSAs y se halló una fuerte asociación entre ambas variables. Dentro de los subtipos de OSAs, el osteoblástico productivo y el tipo células gigantes evidenciaron una mayor frecuencia de GIII.

- La mayoría de los SOs con localización apendicular tuvieron GIII, sin embargo, los análisis estadísticos no evidenciaron asociación entre ambas variables.

- La expresión del PCNA fue mayor en aquellos SOs de localización apendicular y se encontró una significación estadística entre la expresión de PCNA y la localización anatómica.

- La expresión del VEGF-A se evidenció en una gran cantidad de células atípicas, particularmente, en los OSAs. Además, se encontró una asociación entre la expresión de VEGF-A y los SOs.

- VEGFR-1 se expresó en una gran cantidad de células atípicas, especialmente en el OSA y el condrosarcoma. Sin embargo, no se hallaron diferencias 
estadísticamente significativas entre la expresión del VEGFR-1 y los subtipos de SOs. Asimismo, el porcentaje de expresión del VEGFR-1 fue mayor en los SOs con localización apendicular y en aquellos que manifestaron una GIII. En este sentido, el análisis estadístico reveló una diferencia significativa entre la expresión del VEGFR-1 respecto de los tres grados tumorales.

- La expresión de la BMP-9 se observó en una cantidad considerable de células atípicas en el OSA y el condrosarcoma. La expresión de la BMP-9 no tuvo significación estadística entre los subtipos de SOs.

- La expresión de la COX-2 fue observada en los diferentes SOs analizados, sin embargo, la cantidad de células atípicas con inmunomarcación fue baja. La expresión de la COX-2 fue mayor en aquellos SOs con localización apendicular y con una GIII. En este último caso, sin embargo, no se comprobó una asociación entre la expresión de la COX-2, la localización anatómica y los tres grados tumorales.

La oportunidad de analizar diversas características y moléculas relacionadas con el comportamiento biológico en un número considerable de SOs de perros reveló que podrían estar asociadas con un comportamiento muy agresivo y peor pronóstico. Sin embargo, creemos que deben realizarse estudios que vinculen las características analizadas en este trabajo y el tiempo de supervivencia. Un objetivo futuro sustancial en medicina veterinaria será la construcción de perfiles tumorales basados en una serie de características tales como la edad, la gradación tumoral, la localización anatómica y la expresión de PCNA, VEGF y BMP-9 a los fines de predecir el comportamiento tumoral para pacientes individuales, en lugar de subpoblaciones de pacientes. De esta manera, las diferencias estadísticamente 
significativas halladas en el presente estudio entre los OSAs y la GT respaldan la visión que los subtipos histológicos representan distintas entidades individuales y subrayan la validez del esquema utilizado para clasificar a los OSAs en subtipos. En este sentido, los hallazgos de este estudio refuerzan la idea que la GT está relacionada con el potencial maligno y el pronóstico, sin embargo, deberán realizarse estudios futuros que investiguen la relación entre la GT y el tiempo de supervivencia.

Por otra parte, los hallazgos de la presente tesis permitieron evidenciar que los SOs en los perros expresan ciertas moléculas que están vinculadas con el comportamiento biológico maligno y representan blancos moleculares en la terapéutica de los SOs humanos. En este sentido, consideramos que los resultados del presente estudio referidos a la expresión del VEGF y la BMP-9, podrían sugerir un fuerte rol de estos factores de crecimiento en la angiogénesis y la progresión de los SOs en perros. Asimismo, creemos que estos hallazgos podrán ser de utilidad para comprender aún más la compleja biología de estos tumores y de interés en la búsqueda futura de posibles blancos moleculares para generar agentes terapéuticos que tengan mejores posibilidades de éxito en el tratamiento de los SOs que afectan a los perros. Sin embargo, consideramos que es de suma importancia continuar con los estudios en este sentido. 


\section{Bibliografía}

(1) Aco Alburqueque, P.R. Caracterización de las neoplasias caninas diagnosticadas por histopatología en el Laboratorio de Histología y Patología Veterinaria de la Universidad Peruana Cayetano Heredia: período 2003-2015. Tesis para título de Médico Veterinario Zootecnista. Facultad de Medicina Veterinaria y Zootecnia. Universidad Peruana Cayetano Heredia. 2016. http://repositorio.upch.edu.pe/handle/upch/317

(2) Akatsu Y., Yasuhiro Y., Taishi T., Kazuki T., Akihiro K., Kohei M., Tetsuro Watabe., 2017. Dual targeting of vascular endothelial growth factor and bone morphogenetic protein-9/10 impairs tumor growth through inhibition of angiogenesis. Cancer Sci. 108: 151-155.

(3) Alberts, B., Johnson, A., Lewis, J., Morgan, D., Raff, M., Roberts, K., Walter, P., 2015a. Cell Signaling, en: Molecular biology of the cell: 6th edición. Garland Science, Taylor \& Francis Group, p. 813-888.

(4) Alberts, B., Johnson, A., Lewis, J., Morgan, D., Raff, M., Roberts, K., Walter, P., 2015b. Cancer, en: Molecular biology of the cell: 6th edición. Garland Science, Taylor \& Francis Group, p. 1091-1144.

(5) Alonso, D.F., 2006. El desafío del cangrejo: Avances en el conocimiento, prevención y tratamiento del cáncer: $2^{\mathrm{a}}$ edición-Buenos Aires: Siglo XXI Editores Argentina. 
(6) Álvarez San Martín R., 2018. Bone morphogenetic proteins. Basic science and surgical orthopedic applications. An Med (Mex). 63: 273-282.

(7) Baba A.I., Câtoi C., 2007. Bone and joint tumors, en: Baba A.I., Câtoi C. (ed) Comparative oncology. Bucharest: The Publishing House of the Romanian Academy. Disponible en: https://www.ncbi.nlm.nih.gov/books/NBK9551/

(8) Bavcar, S., Argyle, D.J. 2012. Receptor Tyrosine Kinase Inhibitors: Molecularly targeted drugs for veterinary cancer therapy. Vet Comp Oncol. 10: 163-173.

(9) Bechtel, P.E., Hickey, R.J., Schnaper, L., Sekowski, J.W., Long, B.J., Freund, R., Ni, L., Rodriguez-Valenzuela, C., Malkas, L.H., 1998. A unique form of proliferating cell nuclear antigen is present in malignant breast cells. Cancer Res. 58: 3264-3269.

(10) Belda, B., Lara, A., Lafuente, P., 2016. Osteosarcoma apendicular canino: ¿qué opciones tenemos? Clin. Vet. Peq. Anim. 36: 241-255.

(11) Bendell, J.C., Gordon, M.S., Hurwitz, H.I., Jones, S.F., Mendelson, D.S., Blobe, G.C., Agarwal, N., Condon, C.H., Wilson, D., Pearsall, A.E., Yang, Y., McClure, T., Attie, K.M., Sherman, M.L., Sharma, S., 2014. Safety, pharmacokinetics, pharmacodynamics, and antitumor activity of dalantercept, an activin receptor-like kinase-1 ligand trap, in patients with advanced cancer. Clin Cancer Res. 20: 480-489.

(12) Bispo Júnior, R.Z., Camargo, O.P., 2009. Prognostic factors in the survival of patients diagnosed with primary non-metastatic osteosarcoma with a poor response to neoadjuvant chemotherapy. Clinics. 64: 1177-1186. 
(13) Boerman, I., Selvarajah, G.T., Nielen, M., Kirpensteijn. J., 2012. Prognostic factors in canine appendicular osteosarcoma - a meta-analysis. BMC Vet Res. 8: 56.

(14) Bourboulia, D., Stetler Stevenson, W.G. 2010. Matrix metalloproteinases (MMPs) and tissue inhibitors of metalloproteinases (TIMPs): positive and negative regulators in tumor cell adhesion. Semin Cancer Biol. 20: 161-168.

(15) Bragdon, B., Moseychuk, O., Saldanha, S., King, D., Julian, J., Nohe, A., 2011. Bone morphogenetic proteins: a critical review. Cell Signal. 23: 609620.

(16) Brodey, R.S.; Riser, W.H. 1969. Canine osteosarcoma. A clinicopathologic study of 194 cases. Clin Orthop Relat Res. 62: 52-62.

(17) Brønden, L. B., Flagstad, A., Kristensen, A. T., 2007. Registries in companion animal cancer: a review. Vet Comp Oncol. 5: 133-144.

(18) Bronson, R.T., 1982. Variation in age at death of dogs of different sexes and breeds. Am J Vet Res. 43: 2057-2059.

(19) Butler, L.M., Bonnett, B.N., Page, R.L., 2013. Epidemiology and the evidence based medicine approach, en: Withrow and MacEwen's Small animal clinical oncology: 5th Edition. Elsevier, p. 68-82.

(20) Campuzano Maya, G., 2010. Utilidad clínica de los marcadores tumorales. Medicina \& Laboratorio. 16: 411-445.

(21) Castellano, V.M., Sotelo, T., Ballestín, C., López Encentra, A., Varela, G., 1996. Análisis de la expresión del antígeno nuclear de proliferación celular ( PCNA ) en 24 carcinomas primarios de pulmón de células no pequeñas y correlación con la supervivencia. Arch Bronconeumol. 32: 127-131. 
(22) Castells, A., Balaguer, F., Gonzalo, V., Castellví Bel, S., 2007. Ciclooxigenasa 2 y cáncer colorrectal: implicaciones terapéuticas [Cyclooxygenase 2 and colorectal cancer: therapeutic implications]. Gastroenterol Hepatol. 30: 280-284.

(23) Clohisy, D.R., Ogilvie, C.M., Carpenter, R.J., Ramnaraine, M.L.R., 1996. Localized, tumor associated osteolysis involves the recruitment and activation of osteoclasts. J Orthop Res. 14: 2-6.

(24) Coronato, S., Laguens, G.E., Spinelli, O.M., Di Girolamo, W., 2002. Marcadores en cáncer de mama. Medicina (Buenos Aires) 62: 73-82.

(25) Coyle, V.J., Rassnick, K.M., Borst, L.B., Rodriguez, C.O. Jr, Northrup, N.C., Fan, T.M., Garrett, L.D., 2015. Biological behaviour of canine mandibular osteosarcoma. A retrospective study of 50 cases (1999-2007). Vet Comp Oncol. 13: 89-97.

(26) Craig, L.E., 2001. Cause of death in dogs according to breed: a necropsy survey of five breeds. J Am Anim Hosp Assoc. 37: 438-443.

(27) Craig, L.E., Dittmer, K.E., Thompson, K.G., 2016. Bones and Joints, en: MGrant Maxie (Ed.), Jubb, Kennedy, and Palmer's Pathology of domestic animals: 6th edition. Elsevier, p. 16-163.

(28) Cullen, J.M., Breen, M., 2017. An overview of molecular cancer pathogenesis, prognosis, and diagnosis, en: Meuten, D.J. (Ed.), Tumors in domestic animals. 5th edition. John Wiley \& Sons Inc, p: 1-26.

(29) Cunha, S.I., Bocci, M., Lövrot, J., Eleftheriou, N., Roswall, P., Cordero, E., Lindström, L., Bartoschek, M., Haller, B.K., Pearsall, R.S., Mulivor, A.W., Kumar, R., Larsson, C., Bergh, J., Pietras, K., 2015. Endothelial ALK-1 is 
a therapeutic target to block metastatic dissemination of breast cancer. Cancer Res. 75: 2445-2456.

(30) Cunha, S.I., Pardali, E., Thorikay, M., Anderberg, C., Hawinkels, L., Goumans, M.J., Seehra, J., Heldin, C.H., ten Dijke, P., Pietras, K., 2010. Genetic and pharmacological targeting of activin receptor-like kinase 1 impairs tumor growth and angiogenesis. J Exp Med. 207: 85-100.

(31) Cunha, S.I., Pietras, K., 2011. ALK1 as an emerging target for antiangiogenic therapy of cancer. Blood. 117: 6999-7006.

(32) Czerniak, B., Dorfman, H.D., 2016. Dorfman and Czerniak's bone tumours: 2nd Edition. Elsevier.

(33) Davar, G., 2001. Endothelin-1 and metastatic cancer pain. Pain Med. 2: 2427.

(34) David, L., Mallet, C., Mazerbourg, S., Feige, J.J., Bailly, S., 2007. Identification of BMP9 and BMP10 as functional activators of the orphan activin receptor-like kinase 1 (ALK1) in endothelial cells. Blood. 109: 1953-1961.

(35) Dejana, E., Orsenigo, F., Lampugnani, M.G., 2008. The role of adherens junctions and VE-cadherin in the control of vascular permeability. J Cell Sci. 121: 2115-2122.

(36) Diessler, M.E. Carcinomas mamarios de caninos: influencia de variables histológicas e inmunohistoquímicas en el pronóstico. Tesis Doctoral. Facultad de Ciencias Veterinarias. Universidad Nacional de la Plata. 2009.

(37) Dimopoulou, M., Kirpensteijn, J., Moens, H., Kik, M., 2008. Histologic prognosticators in feline osteosarcoma: a comparison with phenotypically 
similar canine osteosarcoma. Vet Surg. 37: 466-471.

(38) Dorn, C.R., Taylor, D.O., Schneider, R., Hibbard, H.H., Klauber, M.R., 1968. Survey of animal neoplasms in Alameda and Contra Costa counties, California. II. Cancer morbidity in dogs and cats from Alameda county. J Natl Cancer Inst. 40: 307-318.

(39) DuBois, S., Demetri, G., 2007. Markers of angiogenesis and clinical features in patients with sarcoma. Cancer. 109: 813-819.

(40) Ducy, P., Karsenty, G., 2000. The family of bone morphogenetic proteins. Kidney Int. 57: 2207-2214.

(41) Duraiyan, J., Govindarajan, R., Kaliyappan, K., Palanisamy, M., 2012. Applications of immunohistochemistry. J Pharm Bioallied Sci. 4: 307-309.

(42) Egenvall, A., Nødtvedt, A., von Euler, H., 2007. Bone tumors in a population of 400000 insured swedish dogs up to $10 \mathrm{y}$ of age: incidence and survival. Can J Vet Res. 71: 292-299.

(43) Ehrhart, N.P., Ryan, S.D., Fan T.M., 2013. Tumors of the skeletal system, en: Withrow and MacEwen's (Eds.), Withrow and MacEwen's Small animal clinical oncology: 5th edition. Elsevier, p: 464-495.

(44) Enneking, W.F., 1986. A system of staging musculoskeletal neoplasms. Clin Orthop Relat Res. 204: 9-24.

(45) Falcon, B.L., Chintharlapalli, S., Uhlik, M.T., Pytowski, B., 2016. Antagonist antibodies to vascular endothelial growth factor receptor 2 (VEGFR-2) as anti-angiogenic agents. Pharmacol Ther. 164: 204-225.

(46) Ferrara, N., Davis Smyth, T., 1997. The biology of vascular endothelial growth factor. Endocr Rev. 18: 4-25. 
(47) Finotello, R., Monné Rodriguez, J.M., Vilafranca, M., Altimira, J., Ramirez, G.A., Haines, A., Ressel, L., 2016. Immunohistochemical expression of MDR1-Pgp 170 in canine cutaneous and oral melanomas: pattern of expression and association with tumour location and phenotype. Vet Comp Oncol. 15: 1393-1402.

(48) Fosslien, E., 2000. Biochemistry of cyclooxygenase (COX)-2 inhibitors and molecular pathology of COX-2 in neoplasia. Crit Rev Clin Lab Sci. 37: 431-502.

(49) Gomez Puerto, M.C., Iyengar, P.V., García de Vinuesa, A., Ten Dijke, P., Sanchez Duffhues, G., 2019. Bone morphogenetic protein receptor signal transduction in human disease. J Pathol. 247: 9-20.

(50) Gorlick, R., Khanna, C., 2010. Osteosarcoma. J Bone Miner Res. 25: 683691.

(51) Gouin, F., Odri, G., Revert, R., Heymann, M.F., Rédini, F., 2012. Tumores de células gigantes de los huesos. EMC - Aparato Locomotor. 45: 113[Artículo E-14-186].

(52) Granjeiro, J.M., Oliveira, R.C., Bustos Valenzuela, J.C., Sogayar, M.C., Taga. R., 2005. Bone morphogenetic proteins: from structure to clinical use. Braz J Med Biol Res. 38: 1463-1473.

(53) Grgurevic, L., Pecina, M., Vukicevic, S., 2017. Marshall R. Urist and the discovery of bone morphogenetic proteins. Int Orthop. 41: 1065-1069.

(54) Grundmann, E., Ueda, Y., Schneider Stock, R., Roessner, A., 1995. New aspects of cell biology in osteosarcoma. Path. Res. Pract. 191: 563-570.

(55) Gupta, S., Gill, D., Pal, S.K., Agarwal, N., 2015. Activin receptor inhibitors 
dalantercept. Curr Oncol Rep. 17: 14.

(56) Hernández Cortés, P., Aneiros Cachaza, J., Ramírez Tortosa, C., Nogales, F., O’valle Ravasa, F., 2000. Expresión inmunohistoquímica de glicoproteína P como factor pronóstico en sarcomas óseos. Rev Ortop Traumatol. 1: 41-48.

(57) Herrera, B., Dooley, S., Breitkopf-Heinlein, K., 2014. Potential roles of bone morphogenetic protein (BMP)-9 in human liver diseases. Int J Mol Sci. 15: 5199-5220.

(58) Heyman, S.J., Diefenderfer, D.L., Goldschmidt, M.H., Newton, C.D., 1992. Canine axial skeletal osteosarcoma a retrospective study of 116 cases (1986 to 1989). Vet Surg. 21: 304-310.

(59) Hillers, K.R., Dernell, W.S., Lafferty, M.H., Withrow, S.J., Lana, S.E., 2005. Incidence and prognostic importance of lymph node metastases in dogs with appendicular osteosarcoma: 228 cases ( 1986 - 2003 ). J Am Vet Med Assoc. 226: 1364-1367.

(60) Hu Lowe, D.D., Chen, E., Zhang, L., Watson, K.D., Mancuso, P., Lappin, P., Wickman, G., Chen, J.H., Wang, J., Jiang, X., Amundson, K., Simon, R., Erbersdobler, A., Bergqvist, S., Feng, Z., Swanson, T.A., Simmons, B.H., Lippincott, J., Casperson, G.F., Levin, W.J., Stampino, C.G, Shalinsky, D.R., Ferrara, K.W., Fiedler, W., Bertolini, F., 2011. Targeting activin receptor-like kinase 1 inhibits angiogenesis and tumorigenesis through a mechanism of action complementary to anti-VEGF therapies. Cancer Res. 71: 1362-1373.

(61) Ildefonso Cruz, R.S. Clasificación histológica según la Organización 
Mundial de la Salud y frecuencia de neoplasias en animales domésticos, aves y peces durante el periodo 1967-1995. Tesis de grado para optar al título de Licenciado en Medicina Veterinaria. Facultad de Ciencias Veterinarias, Universidad Austral de Chile. 1997.

(62) Inwards, C.Y., Unni, K.K., 1995. Classification and grading of bone sarcomas. Hematol Oncol Clin North Am. 9: 545-569.

(63) Jimenez Andrade, J.M., Mantyh, W.G., Bloom, A.P., Ferng, A.S., Geffre, C.P., Mantyh, P.W., 2010. Bone cancer pain. Ann N Y Acad Sci. 1198: 173181.

(64) Katagiri, T., Watabe, T., 2016. Bone Morphogenetic Proteins. Cold Spring Harb Perspect Biol. 8: a021899.

(65) Kent, M.S., Strom, A., London, C.A., Seguin, B., 2004. Alternating carboplatin and doxorubicin as adjunctive chemotherapy to amputation or limb-sparing surgery in the treatment of appendicular osteosarcoma in dogs. J Vet Intern Med. 18: 540-544.

(66) Kirpensteijn, J., Kik, M., Rutteman, G.R., Teske, E., 2002. Prognostic significance of a new histologic grading system for canine osteosarcoma. Vet Pathol. 39: 240-246.

(67) Kruse, M.A., Holmes, E.S., Balko, J.A., Fernandez, S., Brown, D.C., Goldschmidt, M.H., 2013. Evaluation of clinical and histopathologic prognostic factors for survival in canine osteosarcoma of the extracranial flat and irregular bones. Vet Pathol. 50: 704-708.

(68) Lazcano Hermida, I., Sánchez, E., Nerín, C., Cordero, R., Mora, I., Pinar, J., 2016. Marcadores tumorales. Rev Clin Med Fam. 9: 31-42. 
(69) Fino, M., Brunetti, B., Sarli, G., Benazzi, C. 2016. Immunohistochemical expression of P-glycoprotein and breast cancer resistance protein in canine mammary hyperplasia, neoplasia and supporting stroma. J Comp Pathol. 155: $277-285$.

(70) Li, L., Wartchow, C.A., Danthi, S.N., Shen, Z., Dechene, N., Pease, J., Choi, H.S., Doede, T., Chu, P., Ning, S., Lee, D.Y., Bednarski, M.D., Knox, S.J., 2004. A novel antiangiogenesis therapy using an integrin antagonist or antiFlk-1 antibody coated 90Y-labeled nanoparticles. Int J Radiat Oncol Biol Phys. 58: 1215-1227.

(71) London, Ch.A., 2013. Signal transduction and cancer, en: Withrow, S.J., Vail, D.M., Page, R.L. (Eds), Withrow and MacEwen's Small animal clinical oncology: 5th Edition. Elsevier, p. 221-229.

(72) Loukopoulos, P., Mungall, B.A., Straw, R.C., Thornton, J.R., Robinson, W.F., 2003a. Matrix metalloproteinase-2 and -9 involvement in canine tumors. Vet Pathol. 40: 382-394.

(73) Loukopoulos, P., O'Brien, T., Ghoddusi, M., Mungall, B.A., Robinson, W.F., 2004. Characterisation of three novel canine osteosarcoma cell lines producing high levels of matrix metalloproteinases. Res Vet Sci. 77: 131141.

(74) Loukopoulos, P., Robinson, W.F., 2007. Clinicopathological relevance of tumour grading in canine osteosarcoma. J Comp Pathol. 136: 65-73.

(75) Loukopoulos, P., Thornton, J.R., Robinson, W.F., 2003b. Clinical and pathologic relevance of p53 index in canine osseous tumors. Vet Pathol. 40: 237-248. 
(76) Ma, S., Yang, J., Li, J., Song, J., 2016. The clinical utility of the proliferating cell nuclear antigen expression in patients with hepatocellular carcinoma. Tumour Biol. 37: 7405-7412.

(77) Mac Gabhann, F., Qutub, A.A., Annex, B.H., Popel, A.S., 2010. Systems biology of pro-angiogenic therapies targeting the VEGF system. Wiley Interdiscip Rev Syst Biol Med. 2: 694-707.

(78) Mangham, D.C., Athanasou, N.A., 2011. Guidelines for histopathological specimen examination and diagnostic reporting of primary bone tumours. Clin Sarcoma Res. 1:6.

(79) Maniscalco, L., 2015. Canine Osteosarcoma: understanding its variability to improve treatment. Vet J. 203: 135-136.

(80) Martínez Ezquerro, J.D., Herrera, L., 2006. Angiogénesis: VEGF/VEGFRs como blancos terapéuticos en el tratamiento contra el cáncer. Cancerología. 1: 83-96.

(81) Masferrer, J.L., Leahy, K.M., Koki, A.T., Zweifel, B.S., Settle, S.L., Woerner, B.M., Edwards, D.A., Flickinger, A.G., Moore, R.J., Seibert, K., 2000. antiangiogenic and antitumor activities of cyclooxygenase-2 inhibitors. Cancer Res. 60: 1306-1311.

(82) McNeill, C.J., Overley, B., Shofer, F.S., Kent, M.S., Clifford, C.A., Samluk, M., Haney, S., Van Winkle, T.J., Sorenmo, K.U., 2007. Characterization of the biological behaviour of appendicular osteosarcoma in Rottweilers and a comparison with other breeds: a review of 258 dogs. Vet Comp Oncol. 5: 90-98.

(83) Mestrinho, L.A., Faísca, P., Peleteiro, M.C., Niza, M.M., 2017. PCNA and 
grade in 13 canine oral squamous cell carcinomas: association with prognosis. Vet Comp Oncol. 15: 18-24.

(84) Meyer, M., Clauss, M., Lepple Wienhues, A., Waltenberger, J., Augustin, H.G,, Ziche, M., Lanz, C., Büttner, M., Rziha, H.J., Dehio, C., 1999. A novel vascular endothelial growth factor encoded by orf virus, VEGF-E, mediates angiogenesis via signalling through VEGFR-2 (KDR) but not VEGFR-1 (Flt-1) receptor tyrosine kinases. EMBO J. 18: 363-374.

(85) Misdorp, W., Hart, A.A. 1979. Some Prognostic and epidemiological factors in canine osteosarcoma. J Natl Cancer Inst. 62: 537-545.

(86) Mitchell, D., Pobre, E.G., Mulivor, A.W., Grinberg, A.V., Castonguay, R., Monnell, T.E., Solban, N., Ucran, J.A., Scott Pearsall, R., Underwood, K.W., Seehra, J., Kumar, R., 2010. ALK1-Fc inhibits multiple mediators of angiogenesis and suppresses tumor growth. Mol Cancer Ther. 9: 379-388.

(87) Miyazono, K., Kamiya, Y., Morikawa, M., 2010. Bone morphogenetic protein receptors and signal transduction. J Biochem. 147: 35-51.

(88) Modiano, J.F., Henry, C.J., Macy, D.W., 2013. The etiology of cancer, en: Withrow, S.J., Vail, D.M., Page, R.L. (Eds), Withrow and MacEwen's Small Animal Clinical Oncology: 5th Edition. Elsevier, p. 1-29.

(89) Monteiro, B.P., de Lorimier, L.P., Moreau, M., Beauchamp, G., Blair, J., Lussier, B., Pelletier, J.P., Troncy, E., 2018. Pain characterization and response to palliative care in dogs with naturally-occurring appendicular osteosarcoma: an open label clinical trial. PLoS One. 13: 1-17.

(90) Mukaratirwa, S. 2005. Prognostic and predictive markers in canine tumours: rationale and relevance. A review. Vet Q. 27: 52-64. 
(91) Ng, Y.S., 2008. The biology of vascular endothelial cell growth factor isoforms, en: Ruhrberg, Ch. (Ed.), VEGF in development. Molecular Biology Intelligence Unit. Springer, p. 1-13.

(92) Nguyen, A., Scott, M.A., Dry, S.M., James, A.W., 2014. Roles of bone morphogenetic protein signaling in osteosarcoma. Int Orthop. 38: 23132322.

(93) Noël, A., Jost, M., Maquoi, E., 2008. Matrix metalloproteinases at cancer tumor-host interface. Semin Cell Dev Biol. 19: 52-60.

(94) Oh, S.P., Seki, T., Goss, K.A., Imamura, T., Yi, Y., Donahoe, P.K., Li, L., Miyazono, K., ten Dijke, P., Kim, S., Li, E., 2000. Activin receptor-like kinase 1 modulates transforming growth factor-B1 signaling in the regulation of angiogenesis. Proc Natl Acad Sci U S A. 97: 2626-2631.

(95) Ohta, G., Sakai, H., Kachi, S., Hirata, A., Yonemaru, K., Kitajima, A., Yanai, T., Masegi, T., 2004. Assessment of proliferative potentials of canine osteosarcomas and chondrosarcomas by MIB-1 immunohistochemistry and bromodeoxyuridine incorporation. J Comp Pathol. 131: 18-27.

(96) Okada, K., Hasegawa, T., Yokoyama, R., Beppu, Y., Itoi, E., 2003. Prognostic relevance of rosette-like features in osteosarcoma. J Clin Pathol. 56: 831-834.

(97) Otsuka, F., 2010. Multiple endocrine regulation by bone morphogenetic protein system. Endocr J. 57: 3-14.

(98) Patterson, B.C., Sang, Q.A., 1997. Angiostatin-converting enzyme activities of human matrilysin (MMP-7) and gelatinase B/Type IV collagenase (MMP-9). J Biol Chem. 272: 28823-28825. 
(99) Payne, R., 1997. Mechanisms and management of bone pain. Cancer. 80: 1608-1613.

(100) Peña, L., De Andrés, P.J., Clemente, M., Cuesta, P., Pérez Alenza, M.D., 2013. Prognostic value of histological grading in noninflammatory canine mammary carcinomas in a prospective study with two-year follow-up: relationship with clinical and histological characteristics. Vet Pathol. 50: 94105.

(101) Petersen, I., Wardelmann, E., 2016. Grading von Weichgewebe- und Knochensarkomen. Der Pathologe. 37: 320-327.

(102) Poblete, M.T., 2001. Marcadores de utilidad en cáncer mamario. Cuad. Cir. 15: 74-79.

(103) Poon, R.T., Fan, S.T., Wong, J., 2001. Clinical implications of circulating angiogenic factors in cancer patients. J Clin Oncol. 19: 1207-1225.

(104) Preziosi, R., Sarli, G., Benazzi, C., Marcato, P.S., 1995. Detection of proliferating cell nuclear antigen (PCNA) in canine and feline mammary tumours. J Comp Pathol. 113: 301-313.

(105) Rahimi, N., 2006. VEGFR-1 and VEGFR-2: Two non-identical twins with a unique physiognomy. Front Biosci. 11: 818-829.

(106) René, L., 2007. Angiogénesis and cáncer. Medwave. 7: e3546 doi: 10.5867/medwave.2007.03.3546

(107) Rhind, S.M., 2002. Veterinary oncological pathology current and future perspectives. Vet J. 163: 7-18.

(108) Rivera Valentin, R.K., Zhu, L., Hughes, D.P., 2015. Bone sarcomas in pediatrics: progress in our understanding of tumor biology and implications 
for therapy. Paediatr Drugs. 17: 257-271.

(109) Rosales Torres, A.M., Guzmán Sánchez, A., 2011. Importancia del factor de crecimiento del endotelio vascular (VEGF) y de sus receptores en el ciclo ovárico. Revisión. Rev Mex Cienc Pecu. 3: 89-111.

(110) Rubin, B.P., Antonescu, C.R., Gannon, F.H., Hunt, J.L., Inwards, C.Y., Klein, M.J., Kneisl, J.S., Montag, A.G., Peabody, T.D., Reith, J.D., Rosenberg, A.E., Krausz, T., 2010. Protocol for the examination of specimens from patients with tumors of bone. Arch Pathol Lab Med. 134:e1-7.

(111) Saam, D.E., Liptak, J.M., Stalker, M.J., Chun, R., 2011. Predictors of outcome in dogs treated with adjuvant carboplatin for appendicular osteosarcoma: 65 cases (1996-2006). J Am Vet Med Assoc. 238: 195-206.

(112) Saavedra Torres, J.S., Zuñiga Cerón, L.F., Freyre Bernal, S.I., Muñoz Ordoñez, G.W., Salguero, C. 2017. El rol de VEGF en la angiogénesis fisiológica y tumoral. Medicina. 39: 190-209.

(113) Sabattini, S., Scarpa, F., Berlato, D., Bettini, G., 2015. Histologic grading of canine mast cell tumor: is 2 better than 3?. Vet Pathol. 52: 70-73.

(114) Sabino, M.A., Ghilardi, J.R., Jongen, J.L., Keyser, C.P., Luger, N.M., Mach, D.B., Peters, C.M., Rogers, S.D., Schwei, M.J., de Felipe, C., Mantyh, P.W., 2002. Simultaneous reduction in cancer pain, bone destruction, and tumor growth by selective inhibition of cyclooxygenase-2. Cancer Res. 62: 73437349.

(115) Sanz Ressel, B.L., Massone, A.R., Barbeito, C.G., 2019. Immunohistochemical expression of selected phosphoproteins of the mTOR 
signalling pathway in canine cutaneous squamous cell carcinoma. Vet $\mathrm{J}$. 245: 41-48.

(116) Schmidt, A.F., Nielen, M., Klungel, O.H., Hoes, A.W., de Boer, A., Groenwold, R.H., Kirpensteijn, J., 2013. Prognostic factors of early metastasis and mortality in dogs with appendicular osteosarcoma after receiving surgery: an individual patient data meta-analysis. Prev Vet Med. 112: 414-422.

(117) Schott, C.R., Tatiersky, L.J., Foster, R.A., Wood, G.A., 2018. Histologic grade does not predict outcome in dogs with appendicular osteosarcoma receiving the standard of care. Vet Pathol. 55: 202-211.

(118) Selvarajah, G.T., Kirpensteijn, J., 2010. Prognostic and predictive biomarkers of canine osteosarcoma. Vet J. 185: 28-35.

(119) Selvarajah, G.T., Kirpensteijn, J., van Wolferen, M.E., Rao, N.A., Fieten, H., Mol, J.A., 2009. Gene expression profiling of canine osteosarcoma reveals genes associated with short and long survival times. Mol Cancer. 8: 72.

(120) Senra, A; Quintela, D., 1999. Los marcadores diagnósticos y pronósticos del cáncer de mama. Rev Senol Patol Mamar. 12: 121-132.

(121) Slayter, M.V., Boosinger, T.R., Pool, R.R., Dammrich, K., Misdorp, W., Larsen, S., 1994. Histological classification of bone and joint tumors of domestic animals. Armed Forces Institute of Pathology, American Registry of Pathology, and World Health Organization Collaborating Center for Comparative Oncology, Washington DC. Edited by American Registry of Pathology. Second Series. Volume 1. Washington, D.C. 
(122) Sokołowska, J., Urbańska, K., Giziński, S., Zabielska, K., Lechowski, R. 2015. Immunohistochemical detection of P-glycoprotein in various subtypes of canine lymphomas. Pol J Vet Sci. 18: 123-130.

(123) Sounni, N.E., Paye, A., Host, L., Noël, A., 2011. MT-MMPS as regulators of vessel stability associated with angiogenesis. Front Pharmacol. 2: 111.

(124) Spodnick, G.J., Berg, R.J., Rand, W.M., Schelling, S.H., Couto, G., Harvey, H.J., Henderson, R.A., MacEwen, G., Mauldin, N., McCaw, D.L., Moore, A.S., Morrison, W., Norris, A.M., O’Bradovich, J., O’Keefe, D.A., Page, R., Ruslander, D., Klausner, J., Straw, R., Thompson, J.P., Withrow, S.J., 1992. Prognosis for dogs with appendicular osteosarcoma treated by amputation alone: 162 cases (1978-1988). J Am Vet Med Assoc. 200: 995999.

(125) Suzuki, Y., Ohga, N., Morishita, Y., Hida, K., Miyazono, K., Watabe, T., 2010. BMP-9 induces proliferation of multiple types of endothelial cells in vitro and in vivo. J Cell Sci. 123: 1684-1692.

(126) Szewczyk, M., Lechowski, R., Zabielska, K., 2015. What do we know about canine osteosarcoma treatment? Review. Vet Res Commun. 39: 61-67.

(127) Thompson, K.G., Dittmer, K.E., 2017. Tumors of Bone, en: Meuten, D.J. (Ed.), Tumors in domestic animals: 5th edition. John Wiley \& Sons Inc, p. $356-424$.

(128) Torres Bernal, L.F., Díaz Rubio, J.L., Sánchez, P., Rodríguez Reyes, A., Valles Valles, D.R., Benitez Bribiesca, L., 2006. Análisis de expresión de PCNA, p53 y bcl-2 en la secuencia melanosis adquirida primaria-melanoma conjuntival. Rev Mex Oftalmol. 80: 234-240. 
(129) Urist, M.R., 1965. Bone: formation by autoinduction. Science. 150: 893899.

(130) Van Damme, J., Struyf, S., Opdenakker, G., 2004. Chemokine protease interactions in cancer. Semin Cancer Biol. 14: 201-208.

(131) Vecchia, L., Olivieri, C., Scotti, C., 2013. Activin receptor-like kinase 1: a novel anti-angiogenesis target from TGF- $\beta$ family. Mini Rev Med Chem. 13: 1398-1406.

(132) Vilches Moure, J.G., Ramos Vara, J.A., 2005. Comparison of rabbit monoclonal and mouse monoclonal antibodies in immunohistochemistry in canine tissues. J Vet Diagn Invest. 17: 346-350.

(133) Waltenberger, J., Claesson Welsh, L., Siegbahn, A., Shibuya, M., Heldin, C.H., 1994. Different signal transduction properties of KDR and Flt1, two receptors for vascular endothelial growth factor. J Biol Chem. 269: 2698826995.

(134) Wang, W., Luo, H., Wang, A., 2006. Expression of survivin and correlation with PCNA in osteosarcoma. J Surg Oncol. 93: 578-584.

(135) Wang, X., Wang, D., Yuan, N., Liu, F., Wang, F., Wang, B., Zhou, D., 2017. The prognostic value of PCNA expression in patients with osteosarcoma: A meta-analysis of 16 studies. Medicine (Baltimore). 96: e8254. https://doi: 10.1097/MD.0000000000008254.

(136) Wiley, D.M., Jin, S.W., 2011. Bone Morphogenetic protein functions as a context-dependent angiogenic cue in vertebrates. Semin Cell Dev Biol. 22: 1012-1018.

(137) Withrow, S.J., Vail, D.M., Page, R.L., 2013. Why worry about cancer in 
companion animals? en: Withrow and MacEwen's Small animal clinical oncology: 5th Edition. Elsevier, p. XV-XVi.

(138) Wolke, R.E., Nielsen, S.W., 1966. Site incidence of canine osteosarcoma. J Small Anim Pract. 7: 489-492.

(139) Xie, L., Ji, T., Guo, W., 2017. Anti-angiogenesis target therapy for advanced osteosarcoma. Oncol Rep. 38: 625-636.

(140) Xiong, B., Sun, T.J., Yuan, H.Y., Hu, M.B., Hu, W.D., Cheng, F.L., 2003. Cyclooxygenase-2 expression and angiogenesis in colorectal cancer. World J Gastroenterol. 9: 1237-1240.

(141) Xu, M., Xu, C.X., Bi, W.Z., Song, Z.G., Jia, J.P., Chai, W., Zhang, L.H., Wang, Y., 2013. Effects of endostar combined multidrug chemotherapy in osteosarcoma. Bone. 57: 111-115.

(142) Ye, L., Jiang, W.G., 2016. Bone morphogenetic proteins in tumour associated angiogenesis and implication in cancer therapies. Cancer Lett. 380: 586-597.

(143) Yoshikawa, H., Rettig, W.J., Takaoka, K., Alderman, E., Rup, B., Rosen, V., Wozney, J.M., Lane, J.M., Huvos, A.G., Garin Chesa, P., 1994. Expression of bone morphogenetic proteins in human osteosarcoma. Immunohistochemical detection with monoclonal antibody. Cancer. 73: 8591.

(144) Yoshikawa, H., Takanobu, N., Myoui, A., Ueda, T., 2004. Bone morphogenetic proteins in bone tumors. J Orthop Sci. 9: 334-340.

(145) Yoshikawa, H., Takaoka, K., Hamada, H., Ono, K., 1985. Clinical significance of bone morphogenetic activity in osteosarcoma. A study of 20 
cases. Cancer. 56: 1682-1687.

(146) Yoshikawa, H., Takaoka, K., Masuhara, K., Ono, K., Sakamoto, Y., 1988. Prognostic significance of bone morphogenetic activity in osteosarcoma tissue. Cancer. 61: 569-573. 


\section{Anexos}


Anexo I

Protocol for the Examination of Specimens From Patients With Tumors of Bone

Protocol applies to malignant bone tumors. Hematopoietic neoplasms are not included.

Based on AJCC/UICC TNM, $7^{\text {th }}$ edition

Protocol web posting date: October 2013

Procedures

- Biopsy

- Resection

Authors

Brian P, Rubin, MD, PhD, FCAP:

Departments of Anatomic Pathology and Molecular Genetics, Cleveland Clinic, Lemer Research Instifute and Taussig Cancer Center, Cleveland, Ohio

Cristina R. Antonescu, MD (Consultant)

Department of Pathology, Memorial Sloan-Kettering Cancer Center, New York, New York

Kumarasen Cooper, MBChB, DPhil, FRCPath

Department of Pathology. University of Vermont, Fletcher Allen Health Care, Burlington, Vermon

Francis $H$. Gannon, MD, FCAP

Department of Pathology, Baylor College of Medicine, Houston, Texas

Jennifer Leigh Hunt, MD. FCAP

Department of Anatomic Pathology, Cleveland Clinic, Cleveland, Ohio

Carrie Y. Inwards. MD

Department of Pathology, Mayo Clinic, Rochester, Minnesoto

Michael Jeffrey Klein, MD, FCAP

University of Alabama Birmingham Hospital Laboratories, Birmingham, Alabama

Jeffrey S. Kneisl, MD

Carolinas Medical Center, Department of Orthopedic Surgery, Charlotte, North Carolina

Alexander Lazar, MD, PhD, FCAP

Department of Pathology, Sarcoma Research Center. The University of Texas M D Anderson Cancer Center. Houston, Texas

Anthony G. Montag. MD

Department of Pathology. University of Chicago Medical Center, Chicago, Illinois

Terrance D. Peabody, MD

Department of Orthopedic Surgery, University of Chicago Medical Center, Chicago, Illinois

John D. Reith, MD, FCAP

Department of Pathology, Immunology, and Laboratory Medicine. University of Florida, Gainesville, Florida

Andrew E. Rosenberg, MD

Department of Pathology, Massachusetts General Hospital, Boston, Massachusetts

Thomas Krausz, MD, FRCPatht

Department of Pathology, University of Chicago Medical Center, Chicago, Illinois

For the Members of the Cancer Committee, College of American Pathologists

* Denotes primary author. † Denotes senior author. All other contributing authors are listed alphabetically. 
(0) 2013 College of American Pathologists (CAP). All rights reserved.

The College does not permit reproduction of any substantial portion of these protocols without its written authorization. The College hereby authorizes use of these protocols by physicians and other health care providers in reporting on surgical specimens, in teaching, and in carrying out medical research for nonprofit purposes. This authorization does not extend to reproduction or other use of any substantia portion of these protocols for commercial purposes without the written consent of the College.

The CAP also authorizes physicians and other health care practitioners to make modified versions of the Protocols solely for their individual use in reporting on surgical specimens for individual patients, teaching, and carrying out medical research for non-profit purposes.

The CAP further authorizes the following uses by physicians and other health care practitioners, in reporting on surgical specimens for individual patients, in teaching, and in carrying out medical research for non-profit purposes: (1) Dictation from the original or modified protocols for the purposes of creating a text-based patient record on paper, or in a word processing document; (2) Copying from the original or modified protocols into a text-based patient record on paper, or in a word processing document; (3) The use of a computerized system for items (1) and (2), provided that the protocol data is stored intact as a single text-based document, and is not stored as multiple discrete data fields.

Other than uses (1), (2), and (3) above, the CAP does not authorize any use of the Protocols in electronic medical records systems, pathology informatics systems, cancer registry computer systems, computerized databases, mappings between coding works, or any computerized system without a written license from the CAP.

Any public dissemination of the original or modified protocols is prohibited without a written license from the CAP.

The College of American Pathologists offers these protocols to assist pathologists in providing clinically useful and relevant information when reporting results of surgical specimen examinations of surgical specimens. The College regards the reporting elements in the "Surgical Pathology Cancer Case Summary" portion of the protocols as essential elements of the pathology report. However. the manner in which these elements are reported is at the discretion of each specific pathologist, taking into account clinician preferences, institutional policies, and individual practice.

The College developed these protocols as an educational tool to assist pathologists in the useful reporting of relevant information. It did not issue the protocols for use in litigation, reimbursement, or other contexts. Nevertheless, the College recognizes that the protocols might be used by hospitals, attorneys, payers, and others. Indeed, effective January 1, 2004, the Commission on Cancer of the A merican College of Surgeons mandated the use of the required data elements of the protocols as part of its Cancer Program Standards for Approved Cancer Programs. Therefore, it becomes even more important for pathologists to familiarize themselves with these documents. At the same time, the College cautions that use of the protocols other than for their intended educational purpose may involve additional considerations that are beyond the scope of this document.

The inclusion of a product name or service in a CAP publication should not be construed as an endorsement of such product or service, nor is failure to include the name of a product or service to be construed as disapproval. 


\section{CAP Bone Protocol Revision History}

\section{Version Code}

The definition of the version code can be found at www.cap.org/cancerprotocols.

Version: Bone 3.1.1.1

Summary of Changes

The following changes have been made since the June 2012 release.

\section{Explanatory Notes}

\section{A. Processing}

Molecular Studies: Table

Table 1 was updated.

\section{Classification of Bone Tumors}

The WHO classification was updated.

References to primitive neuroectodermal tumor (PNET) were deleted throughout the notes.

\section{Grading}

"Undifferentiated high-grade" was added in the definition of grade 3 in the second paragraph, as follows:

Grade 3 (high-grade) chondrosarcoma is hypercellular, pleomorphic, and contains prominent mitotic activity. Mesenchymal chondrosarcoma, fibrosarcoma, leiomyosarcoma, liposarcoma, undifferentiated high-grade pleomorphic sarcoma of bone and other "soft tissue-type" sarcomas that rarely occur in bone can be graded according to the French Federation of Cancer Centers Sarcoma Group (FNCLCC) grading system?

\section{Bone Tumor Grades (Summary)}

The list was updated.

References

References \#2,3, and 4 were updated, and a bibliography reference was added. 


\section{Surgical Pathology Cancer Case Summary}

Protocol web posting date: October 2013

BONE: Biopsy

Select a single response unless otherwise indicated.

Specimen (Note A)

Specify bone involved (if known):

_ Not specified

Procedure

_ Core needle biopsy

Curettage

Excisional biopsy

Other (specify):

Not specified

Tumor Site (select all that apply) (Note B)

Epiphysis or apophysis

- Metaphysis

Diaphysis

Cortex

Medullary cavity

_ Surface

- Tumor involves joint

- Tumor extension into soft tissue

- Cannot be determined

Tumor Size

Greatest dimension: __ $\mathrm{cm}$

+ Additional dimensions: $x$ cm

_Cannot be determined (see "Comment")

Histologic Type (World Health Organization [WHO] classification of bone tumors) (Note C) Specify:

_ Cannot be determined

+ Mitotic Rate (Note D)

+ Specify: 110 high-power fields (HPF)

( $1 \mathrm{HPF} \times 4 \overline{00}=0.1734 \mathrm{~mm}^{2} ; \times 40$ objective; most proliferative area)

Necrosis (Note D)

Not identified

_ Present

Extent: \%

_ Cannot be determined

+ Data elements preceded by this symbol are not required. However, these elements may be cinically important but are not yet validated or regularly used in patient management. 
Histologic Grade (Note D

Specify:

_ Cannot be determined

+ Lymph-Vascular Invasion (Note E)

+ Not identified

+ - Present

+ Indeterminate

+ Additional Pathologic Findings

+ Specify:

Ancillary Studies (required only if applicable)

Immunohistochemistry

Specify:

_ Not performed

Cytogenetics

Specify:

_ Not performed

Molecular Pathology

Specify:

_ Not performed

Radiographic Findings (it available) (Note F)

Specify:

_ Not available

+ Comment(s) 


\section{Surgical Pathology Cancer Case Summary}

Protocol web posting date: October 2013

BONE: Resection

Select a single response unless otherwise indicated.

Specimen (Note A)

Specify bone involved (if known):

_ Not specified

Procedure (Note G)

Intralesional resection

Marginal resection

Segmental/wide resection

Radical resection

Other (specify):

_ Not specified

Tumor Site (select all that apply) (Note B)

Epiphysis or apophysis

Metaphysis

_ Diaphysis

Cortical

Medullary cavity

Surface

_ Tumor involves joint

Tumor extension into soft tissue

Cannot be determined

Tumor Size

Greatest dimension:

_ cm

Additional dimensions: __ $\times$ _ cm

_ Cannot be determined

_ Multifocal tumor/discontinuous tumor af primary site (skip metastasis)

Histologic Type (World Health Organization [WHO] classification of bone tumors) (Note C, Note $\mathrm{H}$

Specify:

_ Cannot be determined

+ Mitotic Rate (Note D)

+ Specify: _ $/ 10$ high-power fields

( $1 \mathrm{HPF} \times 400=0.1734 \mathrm{~mm}^{2} ; \times 40$ objective; most proliferative area

Necrosis (macroscopic or microscopic) (Note D)

Not Identified

- Present

Extent: _ \%

+ Data elements preceded by this symbol are not required. However, these elements may be

clinically important but are not yet validated or regularly used in patient management. 
Histologic Grade (Note D)

Specify:

_ Not applicable

- Cannot be determined

Margins (Note I)

Cannot be assessed

- Margins uninvolved by sarcoma

Distance of sarcoma from closest margin: __ $\mathrm{cm}$ Specify margin (if known):

_ Margin (s) involved by sarcoma

Specify margin (s) (if known):

+ Lymph-Vascular Invasion (Note E)

$+\ldots$ Not identified

+ Present

+ Indeterminate

Pathologic Staging (PTNM) (Note J)

INM Descriptors (required only if applicable) (select all that apply) $\mathrm{m}$ (multiple)

- $r$ (recurrent)

_ y (postreatment)

Primary Tumor (pT)

_ PTX: Primary tumor cannot be assessed

- PTO: No evidence of primary tumor

PT1: Tumor $8 \mathrm{~cm}$ or less in greatest dimension

- PT2: Tumor more than $8 \mathrm{~cm}$ in greatest dimension

_ PT3: Discontinuous tumors in the primary bone site

Regional Lymph Nodes (pN) (Note K)

_ PNX: Regional lymph nodes cannot be assessed

- pNO: No regional lymph node metastasis

- pN1: Regional lymph node metastasis

_ No nodes submitted or found

Number of Lymph Nodes Examined

Specify:

_ Number cannot be determined (explain):

Number of Lymph Nodes involved

Specify:

_ Number cannot be determined (explain):

Distant Metastasis (PM)

Not applicable

pMla: Lung

_ PMIb: Metastasis involving distant sites other than lung + Specify site(s), if known:

+ Data elements preceded by this symbol are not required. However, these elements may be cinically important but are not yet validated or regularly used in patient management. 
+ Additional Pathologic Findings

+ Specify:

Ancillary Studies (required only if applicable)

Immunohistochemistry

Specify:

Not periormed

Cytogenetics

Specify:

Not performed

Molecular Pathology

Specify:

_ Not performed

Radiographic Findings (if available) (Note F) Specify:

Not available

Preresection Treatment (select all that apply)

No therapy

Chemotherapy performed

Radiation therapy performed

Therapy performed, type not specified

Unknown

Treatment Effect (select all that apply) (Note L)

Not identified

Present

+ Specify percentage of necrotic tumor (compared with pretreatment biopsy, if available):

Cannot be determined

+ Comment(s)

+ Data elements preceded by this symbol are not required. However, these elements may be clinically important but are not yet validated or regularly used in patient management. 


\section{Explanatory Notes}

These recommendations are used for all primary malignant tumors of bone except hematopoietic neoplasms, including lymphoma and plasma cell neoplasms.

\section{A. Processing}

\section{Fixation}

Tissue specimens from bone tumors optimally are received fresh/unfixed because of the importance of ancillary studies, such as cytogenetics, which require fresh tissue.

\section{Tissue Submission for Histologic Evaluation}

One section per centimeter of maximum dimension is usually recommended, although fewer sections are needed for very large tumors, especially if they are homogeneous. Tumors known to be high grade from a previous biopsy do not require as many sections as those that were previously diagnosed as low grade, as documentation of a high-grade component will change stage and prognosis in the latter case. Sections should be taken of grossly heterogeneous areas, and there is no need to submit more than 1 section of necrotic tumor (always with a transition to viable tumor). with the exception of chemotherapy effect on osteosarcomas and Ewing sarcoma.' Occasionally, gross pathology can be misleading, and areas that appear to be grossly necrotic may actually be myxoid or edematous. When this happens, additional sections of these areas should be submitted for histologic examination. When estimates of gross necrosis exceed those of histologic necrosis, the greater percentage of necrosis should be recorded on the surgical pathology report. In general, most tumors require 12 sections or fewer, excluding margins. Tumors with greater areas of heterogeneity may need to be sampled more thoroughly.

Fresh tissue for special studies should be submitted at the time the specimen is received. Note that classification of many subtypes of sarcoma is not dependent upon special studies, such as cytogenetics or molecular genetics, but frozen tissue may be needed to enter patients into treatment protocols. Discretion should be used in triaging tissue from sarcomas. Adequate tissue should be submitted for conventional light microscopy before tissue has been taken for cytogenetics, electron microscopy, or molecular analysis.

\section{Molecular Studies}

It is important to snap freeze a small portion of tissue whenever possible. This tissue can be used for a variety of molecular assays for tumor-specific molecular translocations (see Table 1) that help in classifying bone tumors. 2,3 In addition, treatment protocols increasingly require fresh tissue for correlative studies. Approximately $1 \mathrm{~cm}^{3}$ of fresh tissue (less is acceptable for small specimens, including core biopsies) should be cut into small, $0.2-\mathrm{cm}$ fragments, reserving sufficient tissue for histologic examination. This frozen tissue should ideally be stored at $-70^{\circ} \mathrm{C}$ and can be shipped on dry ice to facilities that perform molecular analysis. 
Table 1. Characteristic Cytogenetic and Molecular Events of Bone Tumors

\begin{tabular}{|c|c|c|}
\hline Histologic Type & Cytogenetic Events & Molecular Events \\
\hline Chondrosarcoma of bone & Complex & $I D H I$ and $I D H 2$ mutations \\
\hline \multirow[t]{8}{*}{ Ewing sarcoma } & $t(11 ; 22)(q 24 ; q 12)$ & EWSR I-FLII fusion \\
\hline & $t(21 ; 22)(q 12 ; q 12)$ & EWSRI-ERG fusion \\
\hline & $t(2 ; 22)(q 33 ; q 12)$ & EWSRI-FEV fusion \\
\hline & $t(7 ; 22)(p 22 ; q 12)$ & EWSRI-ETVI fusion \\
\hline & $t(17 ; 22)(q 12 ; q 12)$ & EWSRI-EIAF fusion \\
\hline & $\operatorname{inv}(22)(q 12 q 12)$ & EWSRI-ZSG \\
\hline & $t(16 ; 21)(p 11 ; q 22)$ & FUS-ERG \\
\hline & $\dagger(2 ; 16)(q 35 ; p 11)$ & FUS-FEV \\
\hline \multicolumn{3}{|l|}{ Ewing-like sarcomas" } \\
\hline & $\mathrm{t}(20 ; 22)(\mathrm{q} 13 ; \mathrm{q} 12)$ & EWSRI-NFATC2 \\
\hline & $\dagger(6 ; 22)(p 21 ; q 12)$ & EWSRI-POUSFI \\
\hline & $1(4 ; 22)(q 31 ; q 12)$ & EWSRI-SMARCAS \\
\hline & $\begin{array}{l}\text { Submicroscopic inv(22)in } \\
t(1 ; 22)(p 36.1 ; q 12)\end{array}$ & EWSRI-PATZ \\
\hline & $t(2 ; 22)(q 31 ; q 12)$ & EWSRI-SP3 \\
\hline & $t(4 ; 19)(q 35 ; q 13)$ & $C / C-D U \times 4$ \\
\hline \multicolumn{3}{|l|}{ Osteosarcoma } \\
\hline Low grade central & Simple & MDM2 amplification \\
\hline Parosteal & Ring chromosomes & 12q13-15 amplification \\
\hline High grade & Complex & \\
\hline
\end{tabular}

\# Ewing-like sarcomas are similar both clinically and histologically to Ewing sarcoma, but it is not known at the present time whether they represent true Ewing sarcomas. They are treated the same as true Ewing sarcomas

\section{B. Location of Neoplasms of Bone}

Relevant Radiologic Findings

Radiographic imaging plays an especially critical role in the diagnosis of bone fumors, Close collaboration with an experienced musculoskeletal radiologist and orthopedic surgeon is recommended.

The figure is a diagrammatic representation of the "anatomic" regions of a long bone. These locations are very important in classifying bone tumors. For instance, chondroblastomas almost always arise in the epiphysis. Epiphyses and apophyses are secondary ossification centers, and therefore are embryonic equivalents. The greater and lesser trochanters are apophyses, while the epiphyses are at the ends of long bones. 


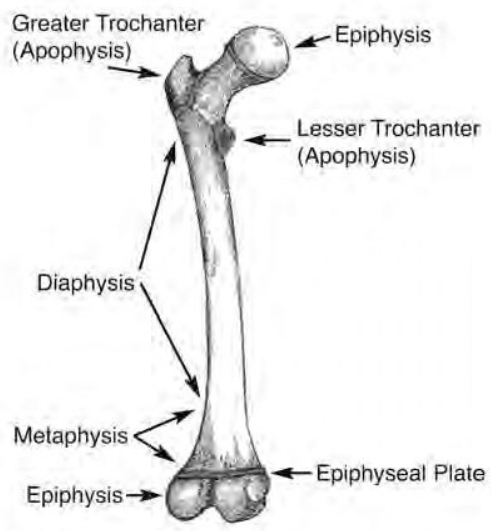

Important anatomic landmarks for tumor diagnosis in long bones. Adapted from Gray's Anatomy.15

C. Classification of Bone Tumors

\section{Intraoperative Consultation}

Histologic classification of bone tumors is sufficiently complex that, in many cases, it is unreasonable to expect a precise classification of these tumors based on an intraoperative consultation. A complete understanding of the surgeon's treatment algorithm is recommended before rendering a frozen section diagnosis, In the case of primary bone tumors, an intraoperative diagnosis of benign versus malignant will generally guide the immediate decision to curette, excise, or wait for permanent sections, and certain therapeutic options may be lost if the wrong path is pursued. Intraoperative consultation is usefu in assessing if "lesional" tissue is present and whether or not this tissue is necrotic, and in constructing a differential diagnosis that can direct the proper triage of tissue for flow cytometry (lymphoma), electron microscopy, and molecular studies/cytogenetics. Tissue triage optimally is performed at the time of frozen section. In many cases, it is important that a portion of tissue be submitted for ancillary studies, even from fine-needle aspiration (FNA) and core needle biopsy specimens, once sufficient tissue has been submitted for histologic evaluation.

\section{Tumor Classification from Biopsies}

It is not always possible to classify bone tumors precisely based on biopsy material, especially FNA and core needle biopsy specimens. Whereas pathologists should make every attempt to classify lesions in small biopsy specimens, on occasion stratification into very basic diagnostic categories, such as lymphoma, carcinoma, melanoma, and sarcoma, is all that is possible. In some cases, precise classification is only possible in open biopsies or resection specimens.

WHO Classification of Malignant Bone Tumors

Classification of tumors should be made according to the World Health Organization (WHO)

classification of bone tumors listed below. ${ }^{4}$ 
WHO Classification of Malignant Bone Tumors

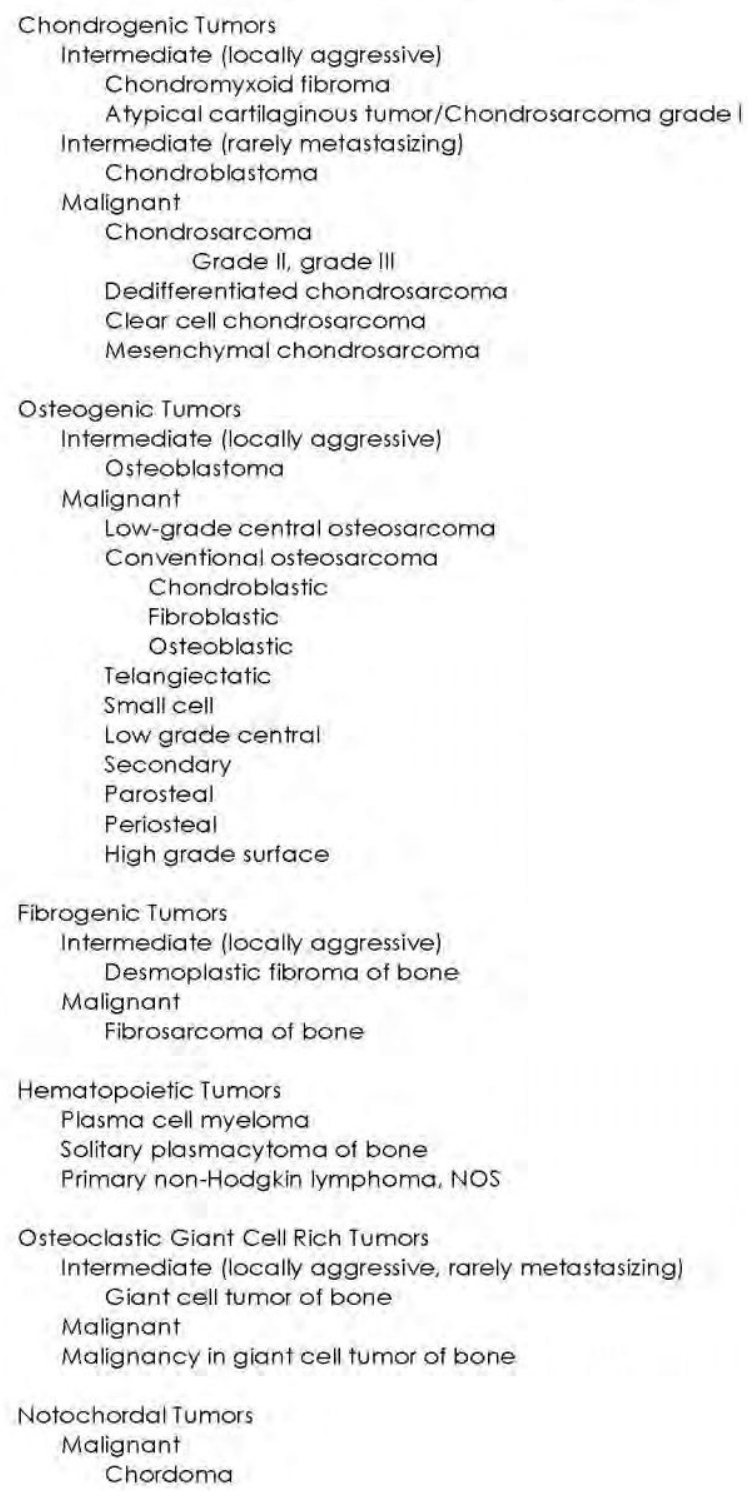




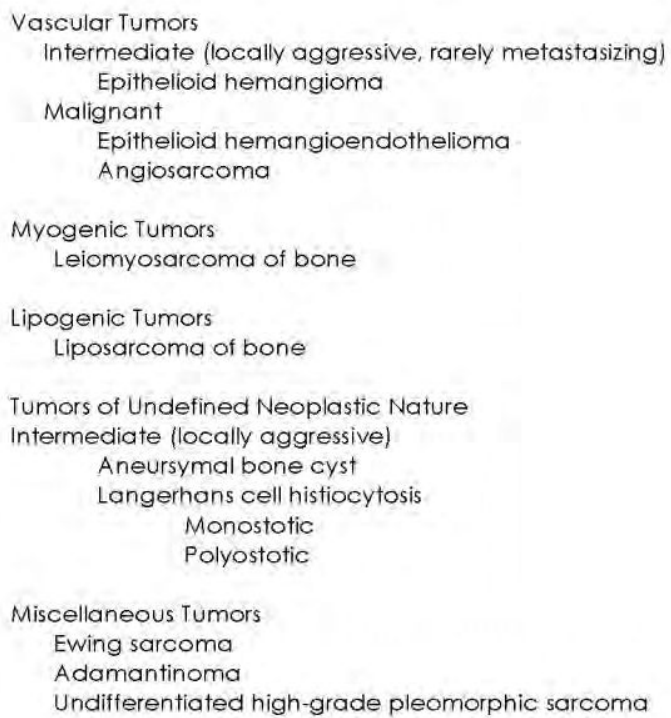

\section{Grading}

The grading of bone tumors is largely driven by the histologic diagnosis, and traditionally grading has been based on the system advocated by Broders, which assesses cellularity and nuclear

features/degree of anaplasia. ${ }^{5}$ The seventh edition of the AJCC Cancer Staging Manual recommends a 4-grade system. ${ }^{6} \mathrm{G} 1, \mathrm{G} 2$ are regarded as low grade and $\mathrm{G} 3$ and $\mathrm{G} 4$ as high grade. However, we advocate a more pragmatic approach to grading aggressive and malignant primary tumors of bone. Two bone fumors that are locally aggressive and metastasize infrequently, and thus are usually low grade, are low-grade central osteosarcoma and parosteal osteosarcoma. Periosteal osteosarcoma is generally regarded as a grade 2 osteosarcoma. Primary bone tumors that are generally high grade include malignant giant cell tumor, Ewing sarcoma, angiosarcoma, dedifferentiated chondrosarcoma, conventional osteosarcoma, telangiectactic osteosarcoma, small cell osteosarcoma, secondary osteosarcoma, and high-grade surface osteosarcoma.

Grading of conventional chondrosarcoma is based on cellularity, cytologic atypia, and mitotic figures. Grade 1 (low-grade) chondrosarcoma is hypocellular and similar histologically to enchondroma. Grade 2 (intermediate-grade) chondrosarcoma is more cellular than grade 1 chondrosarcoma; has more cytologic atypia, greater hyperchromasia and nuclear size; or has extensive myxoid stroma. Grade 3 (high-grade) chondrosarcoma is hypercellular, pleomorphic, and contains prominent mitotic activity. Mesenchymal chondrosarcoma, fibrosarcoma, leiomyosarcoma, liposarcoma, undifferentiated highgrade pleomorphic sarcoma of bone and other "soft tissue-type" sarcomas that rarely occur in bone can be graded according to the French Federation of Cancer Centers Sarcoma Group (FNCLCC) grading system? (see College of American Pathologists protocol for soft tissue tumors $s^{\circledR}$ ).

Chordomas are locally aggressive lesions with a propensity for metastasis late in their clinical course and are not graded. Adamantinomas tend to have a low-grade clinical course, but this is variable. 
Fortunately, they are very rare. According to the WHO classification of tumors of bone, adamantinomas are considered low grade.

Bone Tumor Grades (Summary)

Grade 1 (Low Grade)

Low-grade intramedullary (central) osteosarcoma

Parosteal osteosarcoma

Grade I chondrosarcoma

Clear cell chondrosarcoma

Grade 2

Periosteal osteosarcoma

Grade II chondrosarcoma

Classic adamantinoma

Chordoma

Grade 3 (High Grade)

Ewing sarcoma

Conventional osteosarcoma

Telangiectactic osteosarcoma

Mesenchymal chondrosarcoma

Small cell osteosarcoma

Secondary osteosarcoma

High-grade surface osteosarcoma

Dedifferentiated chondrosarcoma

Dedifferentiated chordoma

Malignancy in giant cell tumor

Grade III chondrosarcoma

Soft-tissue type sarcomas (eg, leiomyosarcoma)

Undifferentiated high-grade pleomorphic sarcoma

TNM Grading

The seventh edition of the American Joint Committee on Cancer (AJCC) and International Union Against Cancer (UICC) staging system for bone tumors includes a 4-grade system but effectively

collapses into high grade and low grade. ${ }^{6,9}$ Grading in the TNM grading system is based on differentiation only and does not generally apply to sarcomas.

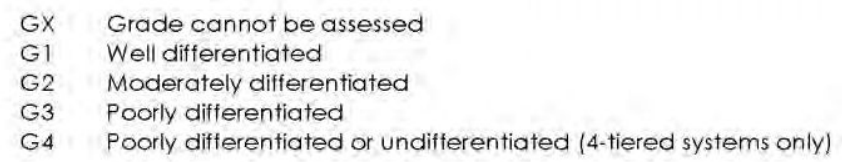

For purposes of using the AJCC staging system (see note K), 3-grade systems can be converted to a 2 grade (TNM) system as follows: grade 1 = low-grade; grade 2 and grade $3=$ high-grade. 
E. Lymph - Vascular Invasion

Lymph-vascular invasion (LVI) indicates whether microscopic lymph-vascular invasion is identified. LVI includes lymphatic invasion, vascular invasion, or lymph-vascular invasion. By AJCC/UICC convention. LVI does not affect the T category indicating local extent of tumor unless specifically included in the definition of a T category.

\section{F. Relevant Radiologic Findings}

Radiographic imaging plays an especially critical role in the diagnosis of bone tumors. Close collaboration with an experienced musculoskeletal radiologist and orthopedic surgeon is recommended.

\section{G. Definition of Procedures}

The following is a list of guidelines to be used in defining what type of procedure has been performed. This is based on the surgeon's intent and not based on the pathological assessment of the margins.

Intralesional Resection

Leaving gross tumor behind. Partial debulking or curettage are examples.

Marainal Resection

Removing the tumor and its pseudocapsule with a relatively small amount of adjacent tissue. There is no gross tumor at the margin; however, microscopic tumor may be present. Note that occasionally, a surgeon will perform an "excisional" biopsy, which effectively accomplishes the same thing as a marginal resection.

\section{Segmental/Wide Resection}

An intracompartmental resection. A single piece of bone is resected, including the lesion and a cuff of normal bone.

\section{Radical Resection}

The removal of an entire bone, or the excision of the adjacent muscle groups if the tumor is extracompartmental.

\section{H. Histological Classitication of Treated Lesions}

Due to extensive treatment effects, such as necrosis, fibrosis, and chemotherapy-induced and radiation-induced pleomorphism, it may not be possible to classify some lesions that were either never biopsied or where the biopsy was insufficient for a precise diagnosis.

\section{Margins}

It has been recommended that for all margins $<2 \mathrm{~cm}$, the distance of the fumor from the margin be reported in centimeters. ${ }^{10}$ However, there is a lack of agreement on this issue. We recommend specifying the location of all margins $<2 \mathrm{~cm}$. Margins from bone tumors should be taken as perpendicular margins, if possible. If the tumor is $>2 \mathrm{~cm}$ from the margin, the marrow can be scooped out and submitted as a margin.

\section{J. TNM and Stage Groupings}

The seventh edition TNM staging system for bone tumors of the A JCC and the UICC is recommended. 6,9

The classification is to be applied to all primary tumors of bone. Anatomic site is known to influence outcome; therefore, outcome data should be reported specifying site. Site groups for bone sarcoma are the following: extremity, pelvis, spine. Pathologic staging includes pathologic data obtained from examination of a resected specimen sufficient to evaluate the highest T category, histopathologic type and grade, regional lymph nodes as appropriate, or distant metastasis. Because regional lymph node 
involvement from bone tumors is rare, the pathologic stage grouping includes any of the following combinations: $\mathrm{PT}$ PG $\mathrm{pN}$ PM, or $\mathrm{PT}$ PG $\mathrm{CN} \mathrm{CM}$, or $\mathrm{CT} \mathrm{CN} \mathrm{PM}$

\section{TNM Descriptors}

For identification of special cases of TNM or pTNM classifications, the " $m$ " suffix and the " $y$ " and " $r$ " prefixes are used. Although they do not affect the stage grouping, they indicate cases needing separate analysis.

The " $\mathrm{m}$ " suffix indicates the presence of multiple primary tumors in a single site and is recorded in parentheses: PT (m)NM.

The " $y$ " prefix indicates those cases in which classification is performed during or following initial multimodality therapy (ie, neoadjuvant chemotherapy, radiation therapy, or both chemotherapy and radiation therapy). The cTNM or PTNM category is identified by a " $y$ " prefix. The ycTNM or ypTNM categorizes the extent of tumor actually present at the time of that examination. The " $y$ " categorization is not an estimate of tumor prior to multimodality therapy (ie, before initiation of neoadjuvant therapy).

The " $r$ " prefix indicates a recurrent tumor when staged after a documented disease-free interval, and is identified by the "r" prefix: rTNM.

N Category Considerations

Because of the rarity of lymph node involvement in sarcomas, the designation NX may not be appropriate and could be considered NO if no clinical involvement is evident.

\section{Stage Groupings}

\begin{tabular}{|c|c|c|c|c|c|}
\hline Stage IA & $T 1$ & NO & $\mathrm{MO}^{*}$ & G 1,2 & Low grade \\
\hline Stage $\mathrm{B}^{\# \#}$ & $\mathrm{~T} 2$ & NO & MO & G1,2 & Low grade \\
\hline Stage \|A & T1 & NO & MO & $G 3,4$ & High grade \\
\hline Stage \|B & $\mathrm{T} 2$ & NO & MO & G3,4 & High grade \\
\hline Stage III & T3 & NO & MO & G3,4 & High grade \\
\hline Stage IVA & Any $T$ & NO & Mla & Any $G$ & \\
\hline \multirow[t]{2}{*}{ Stage IVB } & Any $T$ & NI & Any $M$ & Any $G$ & \\
\hline & Any $T$ & Any $N$ & Mlb & Any $G$ & \\
\hline
\end{tabular}

"MO is defined as no distant metastasis.

मस $T 3$, NO, MO, G I, L Low grade should be considered stage IB.

\section{Additional Descriptors}

Residual Tumor (R)

Tumor remaining in a patient after therapy with curative intent (eg, surgical resection for cure) is categorized by a system known as $R$ classification, shown below.

RX Presence of residual tumor cannot be assessed

Ro No residual tumor

R1 Microscopic residual tumor

R2 Macroscopic residual tumor

For the surgeon, the R classification may be useful to indicate the known or assumed status of the completeness of a surgical excision. For the pathologist, the R classification is relevant to the status of 
the margins of a surgical resection specimen. That is, fumor involving the resection margin on pathologic examination may be assumed to correspond to residual tumor in the patient and may be classified as macroscopic or microscopic according to the findings at the specimen margin(s).

\section{K. Lymph Nodes}

Regional lymph node metastasis is extremely rare in adult bone sarcomas. Nodes are not sampled routinely, and it is not necessary to exhaustively search for nodes. When present, regional lymph node metastasis has prognostic importance and should be reported.

\section{Response to Chemotherapy/Radiation Therapy Effect}

It is essential to estimate neoadjuvant treatment effect in primary Ewing sarcoma and osteosarcoma of bone, as these have been shown to have prognostic significance. $1.11-14$ An entire representative slice of the tumor taken through the long axis should be mapped using a grid pattern diagram, photocopy, or radiologic film to indicate the site for each tumor block. In addition, a section of tumor perpendicular to the long axis should be sampled at the rate of 1 section per centimeter. Areas of soft tissue extension and the interface of tumor with normal tissue should also be sampled. Prognostically significant therapy response in osteosarcoma, according to most series, is defined at $90 \%$, with those tumors showing $90 \%$ therapy response associated with a favorable prognosis. 11,12 There are two protocols to assess response to therapy in Ewing sarcoma. Response can be assessed in the same manner as osteosarcoma or by the system of Picci which is expressed as grade I (macroscopic viable tumor), grade II (microscopic viable tumor), or grade III (no viable tumor). 13,14

\section{References}

1. Carpentieri DF, specimens from pediatric and adult patients with osseous and extraosseous Ewing sarcoma iamily oQualman SJ, Bowen J, Krausz T, Marchevsky A, Dickman PS. Protocol for the examination of $f$ tumors, including peripheral primitive neuroectodermal tumor and Ewing sarcoma. Arch Pathol Lab Med. 2005;129(7):866-871.

2. Taylor BS, Barretina J, Maki RG, Antonescu CR, Singer S, Ladanyi M. Advances in sarcoma genomics and new therapeutic targets. Nat Rev Cancer. 2011:11 (8):541-547. doi: 10.1038/nrc3087.

3. Rubin BP. Lazar JF, Oliveira AM. Molecular pathology of bone and soft tissue tumors. In: Tubbs. R. Stoler M. Cell and Tissue Based Molecular Pathology. Philadelphia, PA: Churchill Livingstone; 2009

4. Fletcher CDM, Bridge JA, Hogendoorn PCW, Mertens F, eds. WHO Classification of Tumors of Soft Tissue and Bone. $4^{\text {th }}$ ed. Geneva, Switzerland; WHO Press; 2013.

5. Inwards CY, Unni KK. Classification and grading of bone sarcomas. Hematol Oncol Clin North Am. 1995;9(3):545-569.

6. Edge SB, Byrd DR, Carducci MA, Compton CC, eds. AJCC Cancer Staging Manual. 7th ed. New York, NY: Springer; 2009.

7. Guillou L, Coindre JM, Bonichon F, et al. Comparative study of the National Cancer Institute and French Federation of Cancer Centers Sarcoma Group grading systems in a population of 410 adult patients with soft tissue sarcoma. J Clin Oncol. 1997:15(1):350-362.

8. Rubin BP, Cooper K. Fletcher CD, et al. Protocol for the examination of specimens from patients with tumors of soft tissue. Arch Pathol Lab Med. 2012;134(4):e31-39.

9. Sobin LH, Gospodarowicz M. Wittekind Ch, eds. UICC TNM Classification of Malignant Tumours. 7th ed. New York, NY: Wiley-Liss; 2009.

10. Abdul-Karim FW, Baver TW, Kilpatrick SE, et al. Recommendations for the reporting of bone tumors. Association of Directors of Anatomic and Surgical Pathology. Hum Pathol. 2004:35(10):1173-1178.

11. Picci P, Sangiorgi L, Rougraff BT, Neff JR, Casadei R, Campanacci M. Relationship of chemotherapy-induced necrosis and surgical margins to local recurrence in osteosarcoma. $J \mathrm{Clin}$ Oncol. 1994:12(12):2699-2705.

12. Raymond AK, Chawla SP, Carrasco CH, et al. Osteosarcoma chemotherapy effect: a prognostic factor. Semin Diagn Pathol. 1987;4(3):212-236. 
13. Bacci G, Ferrari S, Bertoni F, et al. Prognostic factors in nonmetastatic Ewing's sarcoma of bone treated with adjuvant chemotherapy: analysis of 359 patients at the Istituto Ortopedico Rizzoli. $J$ Clin Oncol. 2000;18(1):4-11.

14. Picci P, Bohling T, Bacci G, et al. Chemotherapy-induced tumor necrosis as a prognostic factor in localized Ewing's sarcoma of the extremities. J Clin Oncol. 1997;15(4):1553-1559.

15. Gray's Anatomy of the Human Body. Philadelphia, PA: Lea \& Febiger; 1918.

\section{Bibliography}

Rubin BP, Antonescu CR, Gannon FH, et al. Protocol for examination of specimens from patients with tumors of bone. Arch Pathol Lab Med. 2010;134:e1-e7. 
Anexo II

Descalcificación por quelación con ácido etilendiaminotetraacético (EDTA)

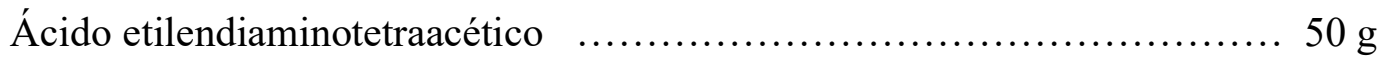

Disolver en $600 \mathrm{ml}$ de agua destilada y llevarlo a $1000 \mathrm{ml}$.

Fijar las piezas en formol al $10 \%$ o acetona.

Colocar las piezas en $50 \mathrm{ml}$ en esta solución, se deja 24 horas y se renueva el líquido. 


\section{Anexo III}

\section{Métodos de recuperación antigénica ("Antigen Retrieval")}

Método de irradiación con microondas (Gown y col., 1993; Leong y col., 1993).

- Los cortes de tejidos deben ser montados en portaobjetos tratados con poliL-lisina (Sigma Co., cat. N P 8920) o con silane (Sigma Co. cat. N M 6514) según instrucciones del fabricante.

- Desparafinar e hidratar.

- Lavar con PBS.

- Colocar en jarras de Coplin de plástico, sin tapar y llenas con buffer de citrato $10 \mathrm{mM}, \mathrm{pH} 6,0$.

- Colocar siempre el mismo número de jarras (generalmente 3) con un número fijo de preparados (4 o 5), agregar portaobjetos vacíos si es necesario.

- En lo posible utilizar un horno de microondas con plato giratorio. Las jarras se ponen cerca del centro.

- Irradiar durante 3 min a una potencia de $800 \mathrm{~W}$.

- Completar el volumen de líquido evaporado con buffer o con agua destilada.

- Irradiar durante 3 min a una potencia de $800 \mathrm{~W}$.

- Dejar enfriar 20 min en el buffer de citrato.

- Sumergir los preparados en PBS.

- Continuar con la técnica de IHQ de elección. 


\section{Anexo IV}

\section{Buffer de citrato pH 6,0 $10 \mathrm{mM}$}

- Ácido cítrico monohidrato $\left(\mathrm{H}_{3} \mathrm{C}_{6} \mathrm{H}_{5} \mathrm{O}_{7} \cdot \mathrm{H}_{2} \mathrm{O}\right)$ $2,1 \mathrm{~g}$

- Agua destilada. $1000 \mathrm{ml}$

- Ajustar el pH a 6,0 con $\mathrm{NaOH} 2 \mathrm{~N}$.

\section{Buffer salino de fosfato 0,01M (PBS), pH 7,2}

- Cloruro de sodio $(\mathrm{NaCl})$ $8,5 \mathrm{~g}$

- $\quad$ PB $0,1 \mathrm{M}$ $100 \mathrm{ml}$

- Agua destilada hasta. ... $.1000 \mathrm{ml}$ 


\section{Anexo V}

\section{Técnicas inmunohistoquímicas}

\section{A-Técnica del Polímero de dextrano ("EnVision ${ }^{\circledR}$ System").}

- Obtener y montar cortes de $5 \mu \mathrm{m}$ de espesor en portaobjetos con cargas positivas

- Colocar los cortes 10 min en la estufa a $60^{\circ} \mathrm{C}$

- Desparafinar mediante pasajes por xilol, de 10 min cada uno

- Hidratar mediante 2 pasajes por alcohol $100^{\circ}$, de 5 min cada uno

- Bloquear la actividad de la peroxidasa endógena mediante la incubación con solución de peróxido de hidrógeno $4 \mathrm{ml}$ en $200 \mathrm{ml}$ de metanol (3\%)

- Dos pasajes por alcohol $96^{\circ}$, de 5 min cada uno y 1 pasaje por alcohol $70^{\circ}$, de 5 min

- Lavar con PBS (solución de buffer fosfato), 2 pasajes de 5 min cada uno

- Proceder a la recuperación antigénica (ver método en el anexo III)

- Lavar con PBS (solución de buffer fosfato), 2 pasajes de 5 min cada uno

- Bloquear las uniones inespecíficas incubando con BSA (albúmina sérica bovina) al $1 \%$ durante $30 \mathrm{~min}$

- Escurrir y secar los vidrios

- Colocar el anticuerpo primario. Incubar en una cámara húmeda durante toda la noche a $4^{\circ} \mathrm{C}$

- Realizar 3 lavados con PBS, de 5 min cada uno

- Escurrir y secar los portaobjetos 
- Incubar con el anticuerpo secundario en una cámara húmeda, Kit "EnVision+ System-HRP Labelled Polymer Anti-mouse y Anti-Rabbit" (Dako, Carpinteria, CA, EE.UU.) para anticuerpos monoclonales y policlonales, durante $30 \mathrm{~min}$ a temperatura ambiente.

- Lavar con PBS, 2 pasajes de 5 min cada uno

- Escurrir y secar los vidrios

- Revelar con 3,3'-diaminobencidina (DAB peroxidase substrate Kit SK4100; Vector Laboratories, Burlingame, CA, EE.UU.) de 2 a 5 min, bajo control microscópico. La reacción se detiene en agua destilada

- Realizar la coloración de contraste (Hematoxilina de Gill)

- Deshidratar en concentraciones crecientes de alcohol etílico $\left(70^{\circ}-96^{\circ}-96^{\circ}\right.$ $100^{\circ}-100^{\circ}$ ) y 2 pasajes por xilol: 5 min cada una, finalmente montar.

B- Técnica de la streptavidina-biotina marcada (LSAB).

- Obtener y montar cortes de $5 \mu \mathrm{m}$ de espesor en portaobjetos con carga positiva

- Colocar los cortes 10 min en la estufa a $60{ }^{\circ} \mathrm{C}$

- Desparafinar mediante pasajes por xilol, de 15 min cada uno

- Hidratar mediante 2 pasajes por alcohol $100^{\circ}$, de 2 min cada uno, 1 pasaje por alcohol $96^{\circ}$, de $2 \min$ y 1 pasaje por alcohol $70^{\circ}$, de $2 \min$

- Lavar con PBS (solución de buffer fosfato) durante $5 \mathrm{~min}$

- Recuperación antigénica en microondas:

a) Colocar los portaobjetos en el buffer citrato 0,01 M pH 6.0, tapar (tapa perforada) y calentar 3 min con la potencia al $100 \%$ 
b) Calentar 6 min al $40 \%$ de potencia, detener el microondas, adicionar agua destilada caliente hasta completar el coplin y completar el calentamiento al $40 \%, 6$ min más.

c) Dejar enfriar $20 \mathrm{~min}$

- Lavar con PBS durante 5 min

- Bloquear la actividad de la peroxidasa endógena. Solución de $\mathrm{H}_{2} \mathrm{O}_{2}$ en metanol durante $20 \mathrm{~min}$

- Lavar con PBS, 2 pasajes de 5 min cada uno

- Secar los preparados y cubrirlos con solución de bloqueo (albúmina sérica caprina) durante $15 \mathrm{~min}$

- Escurrir el exceso de solución y sin lavar cubrir con el anticuerpo primario, de acuerdo con procedimiento correspondiente.

- Lavar con PBS, 2 pasajes de 5 min cada uno

- Secar los preparados y cubrirlos con anticuerpo secundario biotinilado (anticuerpo universal, Kit Cell Marque), en estufa a $25^{\circ}$ durante $30 \mathrm{~min}$

- Lavar con PBS, 2 pasajes de 5 min cada uno

- Secar los preparados y cubrirlos con estreptavidina-peroxidasa, en estufa a $25^{\circ}$ durante $30 \mathrm{~min}$

- Lavar con PBS, 3 pasajes de 5 min cada uno

- Bloquear las uniones inespecíficas incubando con BSA (albúmina sérica bovina) al $1 \%$ durante $30 \mathrm{~min}$

- Escurrir y secar los vidrios

- Colocar el anticuerpo primario e incubar en una cámara húmeda durante toda la noche a $4{ }^{\circ} \mathrm{C}$ 
- Realizar 3 lavados con PBS, de 5 min cada uno

- Secar y cubrir con la solución de cromógeno 3,3'-diaminobencidina (DAB)1 a $10 \mathrm{~min}$, de acuerdo con el anticuerpo primario utilizado, bajo control microscópico. La reacción se detuvo en agua destilada

- Agua destilada 2 lavados de 5 min cada uno

- Realizar la coloración de contraste con Hematoxilina BIOPUR ${ }^{\circledR}$ diluida 1:2 en agua destilada, 30 segundos a $1 \mathrm{~min}$

- Agua destilada 2 lavados rápidos

- Virar en agua corriente

- Agua destilada 1 lavados rápido

- Deshidratar en concentraciones crecientes de alcohol etílico $\left(70^{\circ}-96^{\circ}-100^{\circ}\right.$ $\left.100^{\circ}\right), 3$ min cada uno y 2 pasajes por xilol: 5 min cada una

- Montar 
Anexo VI

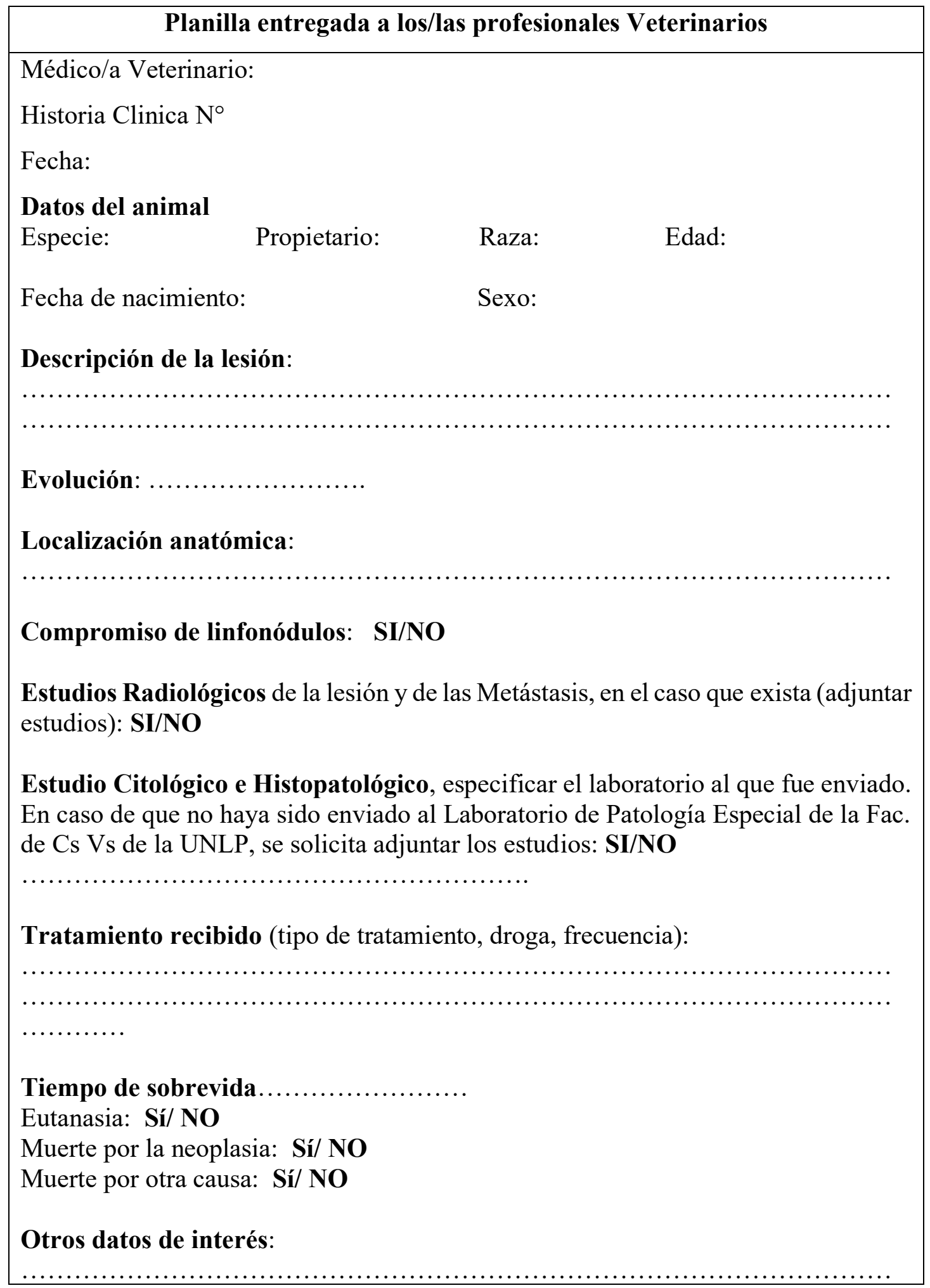

